\title{
BATTLES FOR BRANDING: POLITICAL MARKETING AND U.S. SENATE DEBATES
}

A Dissertation
presented to
the Faculty of the Graduate School
at the University of Missouri-Columbia
In Partial Fulfillment
of the Requirements for the Degree
Doctor of Philosophy
BOSH C. BRAMLETT
Br. Benjamin R. Warner, Dissertation Supervisor
May 2019


The undersigned, appointed by the dean of the Graduate School, have examined the dissertation entitled

\section{BATTLES FOR BRANDING: POLITICAL MARKETING AND U.S. SENATE}

\section{DEBATES}

presented by Josh C. Bramlett, a candidate for the degree of doctor of philosophy, and hereby certify that, in their opinion, it is worthy of acceptance.

\section{Professor Benjamin R. Warner}

Professor Mitchell S. McKinney

Professor J. Brian Houston

Professor Glen T. Cameron 


\section{ACKNOWLEDGEMENTS}

I would first like to thank my advisor, Dr. Benjamin Warner, for all of the time, feedback, dedication, and support he provided during my doctoral education and the dissertation process. Without his diligent guidance this dissertation would not have been completed in a timely manner. He also served as a mentor throughout my doctoral education, providing me opportunities to collaborate on research projects, network at conferences, and teach the upper-division course on persuasion. I will be forever grateful for his mentorship during my time at Mizzou and I will work throughout my career to live up to the standards he sets as an academic.

I would also like to thank the members of my dissertation committee. Dr. Mitchell McKinney has also been a mentor of mine during my doctoral education, and it is because of the research program he established at Mizzou that I am a political debates scholar. The opportunities provided to me by Dr. Warner and Dr. McKinney in the MU Political Communication Institute have been enriching, memorable, and rewarding. I will miss the PCI. I would also like to thank Dr. Brian Houston, whose advice during my doctoral education has made me a better writer and presenter, and Dr. Glen Cameron, whose advice on academic work and research has been immeasurably helpful.

I would not be the professional I am today without the support and advice of several other scholars and educators who have shaped my worldview and teaching philosophy. Dr. Mary Jackson-Pitts and Dr. Gilbert Fowler put me on the path to a doctoral education during my time at Arkansas State University. Dr. Joseph Howard and Dr. Gary Wekkin fostered my interest in the academic study of politics during my time at 
the University of Central Arkansas. Mr. Jim Owen, my high school history teacher, is the reason I am a teacher today.

I would also like to thank my family and friends for their support in life and during my doctoral program. I would like to thank my parents, Ron and Cheryl Bramlett, and my brother, Jeff Bramlett, for their love and support. I would like to thank Carly Voloto for being my rock. I would like to thank my graduate cohort, Joel Reed, Maria Butauski, Sarah Smith-Frigerio, Anna Valiavska, Alyssa Bish, Sopheak Hoeun, and Kristin Fitzsimmons for their camaraderie during our time at Mizzou. In particular, I would like to thank Joel Reed for constantly pushing me to be a better scholar and teacher and for all of the memories and good times. I would also like to thank Freddie Jennings, Molly Hardy, and Joseph Hoffswell for their mentorship and friendship. I would also like to thank my undergraduate research fellows Jarrod Blaylock, Caleb Seymour, and Drew States, without whom the content analytic portion of this dissertation would not have happened. I am grateful for the time and dedication that they provided in Spring 2019. I would also like to thank my colleagues who helped me with data collection as well as all of the students who participated in my study in Fall 2018.

Finally, I would like to thank the countless scholars whose prior work made mine possible. I would like to thank the ancient Romans for creating the archetype of a Senate. I would like to thank the framers of the Constitution of the United States for creating the U.S. Senate. I would like to thank the four candidates featured in this study for agreeing to participate in debates during the 2018 campaign season. I would also like to thank everyone who reads this dissertation. I hope you will find it interesting. 
TABLE OF CONTENTS

ACKNOWLEDGEMENTS

p. ii

LIST OF TABLES AND FIGURES

p. vi

ABSTRACT

p. viii

Chapter

I. INTRODUCTION, PURPOSE, AND PROJECT OVERVIEW p. 1

$\begin{array}{ll}\text { Purpose of the Study } & \text { p. } 3\end{array}$

$\begin{array}{ll}\text { Televised Debates } & \text { p. } 3\end{array}$

$\begin{array}{ll}\text { Political Marketing and Branding p. } 6 & \text { p }\end{array}$

$\begin{array}{ll}\text { Identity and Involvement } & \text { p. } 8\end{array}$

$\begin{array}{ll}\text { Project Overview p. } 10 & \text { p }\end{array}$

Dissertation Preview p. 11

$\begin{array}{ll}\text { II. LITERATURE REVIEW } & \text { p. } 12\end{array}$

$\begin{array}{ll}\text { Defining Televised Debates } & \text { p. } 12\end{array}$

$\begin{array}{ll}\text { Debate Effects } & \text { p. } 13\end{array}$

$\begin{array}{ll}\text { Senate Debates and Campaigns } & \text { p. } 17\end{array}$

$\begin{array}{ll}\text { Campaign Marketing p. } 22 & \text { p }\end{array}$

$\begin{array}{ll}\text { Branding p. } 24 & \text { p }\end{array}$

$\begin{array}{ll}\text { Debates as Political Marketing Events } & \text { p. } 29\end{array}$

$\begin{array}{ll}\text { Involvement and Persuasion } & \text { p. } 31\end{array}$

$\begin{array}{ll}\text { Identity and Persuasion } & \text { p. } 33\end{array}$

$\begin{array}{ll}\text { III. METHOD } & \text { p. } 39\end{array}$

$\begin{array}{ll}\text { Experimental Design } & \text { p. } 39\end{array}$

$\begin{array}{ll}\text { Experimental Prompts } & \text { p. } 41\end{array}$

$\begin{array}{ll}\text { Stimuli p. } 43 & \text { p }\end{array}$

$\begin{array}{ll}\text { Procedure } & \text { p. } 45\end{array}$

$\begin{array}{ll}\text { Demographics } & \text { p. } 48\end{array}$

$\begin{array}{ll}\text { Manipulation Checks } & \text { p. } 49\end{array}$ 
$\begin{array}{ll}\text { Branding } & \text { p. } 52\end{array}$

$\begin{array}{ll}\text { Content Analysis } & \text { p. } 53\end{array}$

$\begin{array}{ll}\text { Brand Measures } & \text { p. } 55\end{array}$

$\begin{array}{ll}\text { Survey Items } & \text { p. } 57\end{array}$

$\begin{array}{ll}\text { IV. RESULTS } & \text { p. } 62\end{array}$

$\begin{array}{ll}\text { Normative Effects of Senate Debates } & \text { p. } 62\end{array}$

$\begin{array}{ll}\text { Political Branding } & \text { p. } 67\end{array}$

$\begin{array}{ll}\text { Political Branding and Persuasion } & \text { p. } 69\end{array}$

$\begin{array}{ll}\text { Political Branding: Content Analysis Results } & \text { p. } 71\end{array}$

$\begin{array}{ll}\text { Involvement: Branding and Persuasion } & \text { p. } 80\end{array}$

$\begin{array}{ll}\text { V. DISCUSSION p. } 90 & \text { p }\end{array}$

$\begin{array}{lr}\text { Political Branding } & \text { p. } 91\end{array}$

$\begin{array}{lr}\text { Involvement } & \text { p. } 98\end{array}$

$\begin{array}{ll}\text { Normative Effects of Senate Debates } 103 & \text { p. } 103\end{array}$

$\begin{array}{ll}\text { Summary p. } 111 & \text { p }\end{array}$

$\begin{array}{lr}\text { Connecting Theory to Praxis } & \text { p. } 112\end{array}$

$\begin{array}{ll}\text { Limitations and Future Directions } & \text { p. } 115\end{array}$

$\begin{array}{ll}\text { Conclusion } & \text { p. } 118\end{array}$

$\begin{array}{lr}\text { REFERENCES } & \text { p. } 120\end{array}$

Appendix A: Candidate Brand Elements Code Book p. 141

Appendix B: Civics Knowledge Questions p. 144

Appendix C: Debate Knowledge Questions p. 145

$\begin{array}{ll}\text { Appendix D: Full Regression Tables } & \text { p. } 147\end{array}$

$\begin{array}{ll}\text { Vita } & \text { p. } 149\end{array}$ 


\section{LIST OF TABLES AND FIGURES}

TABLES

Table 2.1: Hypotheses and Research Questions p. 38

$\begin{array}{ll}\text { Table 4.1: Debate Learning } & \text { p. } 63\end{array}$

Table 4.2: In-Group and Out-Group Voting Likelihood p. 63

Table 4.3: Candidate Voting Preference Strength p. 64

Table 4.4: In-Group/Out-Group Changes in Candidate Evaluations p. 65

Table 4.5: Changes in Candidate Evaluations by Candidate and Party p. 65

Table 4.6: Brand Favorability and the Influence on Candidate Evaluations p. 71

Table 4.7: Political Brand Elements by Debate p. 71

Table 4.8: Political Brand Elements and Favorability p. 72

Table 4.9: Missouri Brand Association Frequencies p. 75

Table 4.10: North Dakota Brand Associations $\quad$ p. 77

Table 4.11: Example Response of Associations p. 80

Table 4.12: Candidate Brand Associations (total number of associations) p. 83

Table 4.13: Candidate Brand Favorability by Condition p. 84

Table 4.14: Candidate Brand Positivity and Negativity by Condition p. 85

Table 4.15: Involvement and Evaluative Associations p. 86

Table 4.16: Political Brand Elements by Condition $\quad$ p. 87

Table 4.17: Brand Association Means by Condition p. 88 


\section{FIGURES}

$\begin{array}{ll}\text { Figure 3.1: Personal Relevance by Condition } & \text { p. } 52\end{array}$

Figure 3.2: Nationalized Involvement by Condition p. 52

$\begin{array}{lr}\text { Figure 4.1: Brand Associations } & \text { p. } 69\end{array}$

$\begin{array}{ll}\text { Figure 4.2: Total Brand Strength } & \text { p. } 81\end{array}$

$\begin{array}{ll}\text { Figure 4.3: Candidate Brand Strength by Condition } & \text { p. } 83\end{array}$

Figure 4.4: Positive and Negative Associations by Condition p. 85

$\begin{array}{ll}\text { Figure 4.5: Brand Elements by Condition } & \text { p. } 88\end{array}$ 


\begin{abstract}
Televised political debates, as two-sided information flows, are dynamic political communication events that inform, persuade, and entertain voters. Political debates provide candidates the opportunity to brand themselves to voters, and political marketing provides a framework with which to analyze communication effects and how voters process and retain information in memory. Through an analysis of survey responses from participants who viewed a 2018 U.S. Senate debate, the current study incorporates a political marketing perspective to analyze how televised political debates influence voters' brand associations toward candidates.

My results led me to develop the concept of Debate Branding, where participating in a debate is more likely to generate positive brand associations with supporters than it is to generate negative brand associations with detractors. Each of the debating candidates in this study saw more positive in-group associations than negative out-group associations, highlighting the power of debates as branding opportunities. Moreover, brand favorability, i.e., how many positive or negative thoughts individuals had toward candidates, was a significant predictor of candidate evaluations. Additionally, respondents offered far more brand associations about the candidates as people than they did about the policy positions or party affiliation of the candidates. This finding contributes to the literature on candidate image and issues in political communication.

Debates, as persuasive events, can produce cognitive involvement in voters. Through an experimental design, my study explored how involvement influenced the brand associations of viewers. I found that personal relevance remains a core path to involvement, while also finding tentative, yet intriguing support for a new path to
\end{abstract}


involvement in political messages: nationalized partisan involvement. Cognitive involvement, in the form of brand associations, was highest when a debate was both personally relevant and nationalized. This has implications for the modern political media and electoral environment.

Televised political debates are largely studied at the presidential level and there is a corresponding paucity of literature on the effects of viewing Senate debates. I found that viewing a televised U.S. Senate debate promoted information acquisition, had substantive influences on attitudes such as political information efficacy, candidate evaluations, intention to vote for a candidate, and intention to vote in the midterm elections, and had marginal influences on political cynicism and interest. These findings have implications for educators, television programmers, political campaigns, and civic groups across the country. Presidential debates are not the only debates that have positive democratic outcomes. 


\section{Chapter I: Introduction, Purpose, and Project Overview}

The political communication media environment is constantly evolving (Bennett \& Iyengar, 2008; Bennett \& Pfetsch, 2018; Chadwick, 2013). Each election cycle seems to feature a new mechanism that changes campaigning, from online fundraising in 2004 (Kreiss, 2016) to the use of YouTube in 2008 (Kenski, Hardy, \& Jamieson, 2010) to advanced uses of Facebook and digital media in 2012 (Kreiss, 2016) to the personalized use of Twitter by a presidential candidate in 2016 (Scacco \& Coe, 2017). Despite these changes from one election cycle to the next, certain campaign communication processes, such as political advertising or holding rallies, are constants. Perhaps the most enduring constant is the presence of televised campaign debates.

The 2018 election cycle was a compelling electoral environment because it was the first mid-term election of Donald Trump's presidency. Political scientists forecast that Democrats would take back the House of Representatives and that Republicans would likely maintain their 51-49 majority in the U.S. Senate or gain a seat or two (Campbell, 2018). Midterms are typically difficult for an incumbent president's party (Campbell, 2018) and the 2018 midterms were no different. Democrats won the House of Representatives, gaining a 235-199 majority, while Republicans increased their majority in the Senate to 53-47 (Briz, Fisher, Jin, McClure, \& Mihalik, 2019). Republicans increased their majority by winning several key states that had incumbent Democratic senators such as Missouri, North Dakota, Indiana, and Florida (Sabato \& Kondik, 2018). These Senate races were high stakes and high-spending, two factors that foster competitive Senate campaign communication environments that influence voters (Kahn 
\& Kenney, 1999). For instance, in Florida over $\$ 116$ million was spent, in Missouri, over \$51 million, and in Indiana, over \$43 million ("Most Expensive Races,” 2019).

Televised debates were a major part of these competitive communication environments and played a role in the electoral process in the battle for the Senate. CSPAN's archive of 2018 U.S. Senate general election debates features 46 total debates (C-SPAN, 2019). These debates were critical opportunities for incumbent senators and challenger candidates to make their cases to voters. Much is known about the effects of presidential debates, which are one of the most influential and anticipated sources of communicated information during presidential elections (Pfau, Houston, \& Semmler, 2007) as they inform and persuade voters (Abramowitz, 1978; Benoit \& Hansen, 2004; Benoit, Hansen, \& Verser, 2003; Holbrook, 1996; 1999; Jamieson \& Adasiewicz, 2000; McKinney \& Warner, 2013). However, our knowledge of down-ballot debates is lacking as they are comparably understudied (McKinney \& Carlin, 2004, p. 226). I was therefore interested in examining televised debates in the context of the 2018 midterm elections.

Debates are a focal point of campaign messaging (Carlin, 1992), making them central moments for political marketing. Political marketing is a voter-centered perspective that views voters as consumers who must be sold on the service of a representative (Newman, 1994). Political marketing is a process where candidates strategically portray themselves to key segments of voters (Newman, 1994), seeking to strengthen support of current supporters and win over critical undecided voters. Candidates do this by promoting "the campaign platform they put forward and the image they create for themselves" (Newman, 1994, p. 88). Televised debates are an important moment for candidates to promote their campaign agenda (Fenno, 1996; Jackson-Beeck 
\& Meadow, 1979; McKinney, 2005). Therefore, political marketing provides a lens in which to analyze how candidates market themselves in debates and how voters process this information. Moreover, debates are important moments of clash between candidates from opposing parties (Carlin, 1992) where partisans root for the candidate of their party (Munro, Ditto, Lockhart, Fagerlin, Gready, \& Peterson, 2002). Voters' involvement in cheering on parties is increasingly driven by partisan social identities (Mason, 2018) that are increasingly nationalized (Hopkins, 2018).

\section{Purpose of the Study}

The primary focus of this dissertation is in adopting a voter-centric political marketing perspective to assess how debates influence voter memory and attitudes in the context of a nationalized political landscape. I pursued this question in three primary areas. First, by adopting a voter-centered political marketing and branding perspective (Newman, 1994), I examined how viewers processed debate content, engaged with debate content, and were influenced by debate content. Second, I examined the roles of personal relevance and nationalized partisan involvement to answer questions related to involvement in persuasive messages (Cho \& Boster, 2005; Johnson \& Eagly, 1989; 1990; Petty \& Cacioppo, 1979; 1986). Third, I examined understudied downballot debates (McKinney \& Carlin, 2004) to determine their effects on normative and persuasive outcomes relative to prior findings related to presidential debates. The following sections will expand upon each of these three core areas.

\section{Televised Debates}

Debates are significant moments in elections for a variety of reasons (McKinney \& Carlin, 2004). Presidential debates are normatively important because they educate 
voters on candidate stances (Benoit \& Hanson, 2004; Jamieson \& Adasiewicz, 2000), alter candidate evaluations (McKinney \& Warner, 2013), influence voter cynicism and efficacy (McKinney \& Warner, 2013), and exist in the national zeitgeist as a ritual that occurs every four years (Greenberg, 2009; Schroeder, 2008). In fact, Pfau et al. (2007) found that of 17 different sources of campaign information available for voters in the 2004 election, debates were one of the most important for normative outcomes. Although general election debates often happen at a point in the election when most voters have made up their minds (Schroeder, 2008), they can influence undecided voters (Geer, 1988; McKinney \& Warner, 2013), and reinforce prior candidate preferences (Holbert, 2005). With non-presidential debates, at the level of "subpresidential campaigns" (Kahn \& Kenney, 1999, p. 166), however, research on debate effects is limited. One study by Robertson (2005) found that the general election debates between John Thune and Tom Daschle in the 2004 South Dakota U.S. race influenced vote choice for viewers. The research on normative outcomes for Senate debates is limited if not non-existent. More studies of Senate debates are needed, not only to analyze their influence on voter decisions, but for their effect on normative outcomes such as political efficacy, interest, cynicism, and knowledge. Senate debates also deserve attention as candidates in Senate races are not as salient to voters as general election presidential candidates (Fridkin \& Kenney, 2011), which provides potential for greater debate effects.

Televised debates are "media events" (McKinney \& Carlin, 2004, p. 214) that generate extensive press coverage. Debates as televised events provide a blend of entertainment and information (Schroeder, 2008). Debates as televised spectacles offer candidates the opportunity to influence public perception of the candidate as a person, as 
exemplified most famously by John F. Kennedy's appearance in the first general-election televised presidential debate of 1960, but also by other television performers such as Ronald Reagan or Bill Clinton (Schroeder, 2008). Debates offer high rewards but they also have high risks, and each campaign is aware of this. The risks of debates are most notable in historical presidential debate examples, such as Gerald Ford's Eastern Europe comment in 1976, Michael Dukakis' answer to Bernard Shaw in 1988, George H.W. Bush's watch-checking in 1992, or Al Gore's sighs in 2000 (Schroeder, 2008) but the risk is also evident for Senate candidates. In recent election cycles, some notable down-ballot debate examples include Indiana candidate Richard Mourdock, who made a controversial abortion statement in 2012 (Associated Press, 2012), and then-Illinois Senator Mark Kirk, who made an inflammatory remark about his opponent Tammy Duckworth's family in 2016 (Berenson, 2016).

Voters are paying attention to how the candidates behave and appear on stage, and this can lead to changes in evaluations of candidates based on nonverbal behavior (Seiter et al., 2009), candidate personality traits (e.g., Warner et al., 2011), and candidate traits central to job performance such as competence (Benoit et al., 2003). Debates are also opportunities for voters to learn about candidate stances on issues. Issue and image can be dichotomized, but the two are related and both contribute to how voters form perceptions of and evaluate candidates (Hacker, 2004a; 2004b; Hacker, Zakahi, Giles, \& McQuitty, 2000). Adopting a political marketing lens can fit image and issue under a larger umbrella of candidate branding (Cwalina, Falkowski, \& Newman, 2011; Nielsen, 2016; 2017; Scammell, 2014). A political marketing perspective offers an intriguing way 
to examine how debates as televised events influence viewers' thoughts about candidate image and issue stances.

\section{Political Marketing and Branding}

Most campaign communication falls within the scope of political marketing (Cwalina et al., 2011; Newman, 1994). The field of "political marketing science" (Cwalina et al., 2011, p. 7) overlaps with and is rooted in research from political communication at large. Television advertising, campaign events, participating in debates, and engaging in constituent outreach are all elements of political marketing. The effects of campaign communication on citizens are also effects of political marketing. Vote choice, trust in government, and image evaluations are all elements of political marketing effects (Cwalina et al., 2011). A political marketing and branding perspective can allow for a nuanced way of looking at how voters view politicians and how campaigns activate attributes in voters' minds. For instance, Cwalina et al. (2011) examined verbal associations voters make when prompted to think about candidates. This allows for voters to volunteer their associations, which can be issue-based and imagebased depending on what is most salient in their minds.

Verbal branding associations are rooted in consumer branding research (Anderson, 1983; Keller, 1993). In this perspective, the brand (or politician) is the central node in memory, and consumers (or voters) then associate attributes from there. In verbal brand associations, the number of associations, the valence of associations, and the content of associations contribute to brand equity (Keller, 1993) and in the political context, political brand value (Nielsen \& Larsen, 2014). Brand associations are similar to thought-listing, which has been used in persuasion research to examine elaboration (Petty 
\& Cacioppo, 1986). It is also similar to political communication work on priming and second-level agenda setting (Iyengar \& Kinder, 1987; Kiousis \& Shields, 2008). When consuming political information, voters store candidate information in their "web of associations" (Lodge \& Taber, 2013, p. 228) about candidates, and when encountering new information, different associations can be activated.

Political debates in particular provide compelling arenas for priming and memorybased activations and associations. Debates offer clash (Carlin, 1992), and are unique compared to other campaign information sources as they are two-sided information environments (Holbert \& Benoit, 2009). Therefore, they serve as "battles for branding" that offer individuals the opportunity to hear pro-attitudinal and counter-attitudinal information. A branding perspective based on memory associations allows for the effects of pro- and counter-attitudinal information to be assessed in an interesting way. Counterattitudinal information may not ultimately persuade a voter to change their mind, but it may promote counter-arguing from highly motivated individuals (Lord, Ross, \& Lepper, 1979), which would be evident in the valence, or favorability, of partisan brand associations. Pro-attitudinal information, conversely, can elicit numerous positive associations from debate viewers excited about their preferred candidate who shares their partisan identity and policy outcome goals.

Jackson-Beeck and Meadow (1979) famously argued that candidates do not pursue the public's agenda or the press' agenda in debates - they pursue their own agendas. Debates thus offer campaigns and candidates the opportunity to brand themselves in voters' minds through strategic focus on their preferred issues to promote their candidate's identity and to differentiate from the opposition. In branding, identity 
and differentiation are centerpieces (Aaker, 1996; Nielsen, 2016; 2017). Moreover, ensuring that consumers make the associations with your brand that you want them to make is a fundamental goal of marketing (Keller, 1993; Romaniuk \& Nenycz-Thielf, 2013). Televised political debates provide candidates the opportunity to prime and activate the preferred associations they want voters to make when considering their candidate. Focusing on their preferred issue agenda (Jackson-Beeck \& Meadow, 1979) can allow candidates to influence what topics are salient to voters, and a branding perspective can assess how successful the candidates are at doing so. If the policy messages and self-presentation elements focused on by candidates in the debate are made salient to voters, then the political marketing on the part of the campaign was successful. If not, then this may highlight the unpredictability and volatility of televised debates, the resistance to new information from partisans, or also a lack of motivation and involvement from viewers. Hence, this dissertation will take a voter-centered perspective to explore the branding opportunities presented by debates.

\section{Identity and Involvement}

Social identity theory (e.g., Tajfel, 1982) has influenced recent thinking in both political and consumer research (Bhattacharya \& Sen, 2003; Greene, 1999, 2002, 2004; He, Li, \& Harris, 2012; Mason, 2018; Reed, 2002). In commercial marketing, the strongest bonds between consumers and companies occur when consumers socially identify with that company (Bhattacharya \& Sen, 2003). Social identification with brands occurs when "self-definitional needs" (Bhattacharya \& Sen, 2003, p. 77) are fulfilled by a company for a consumer. A famous example is with Harley-Davidson, where the brand becomes part of motorcycle owners' identity through owning memorabilia and 
socializing with other bikers (Aaker, 1996). Importantly, individuals who identify with a company can become "champions of the companies with whom they identify" (Bhattacharya and Sen, 2003, p. 77) but will also be "likely to develop negative biased attitude toward the focal brand's competing brands" (He, Li, \& Harris, 2012, p. 654). These dynamics - being an advocate for your side and an opponent of the other - are centerpieces of the group competition that arises from social identity and are evident in politics as well (Mason, 2018; Tajfel, 1982). Mason (2018) argues that social identity has become more salient in politics as the parties have become more demographically sorted. Issue positions can matter less than a voter's identity, and party identification can be more important than policy preferences. For voters with strong identification with their party, winning elections can be more important than legislation and policy outcomes.

If winning for winning's sake is more important than policy outcomes, as Mason (2018) argues, then this brings to question the nature of motivation and involvement for voters who follow politics. In persuasion literature, motivation to elaborate about a topic is often based on three types of involvement: outcome-relevant, impression-relevant, and value-relevant (Cho \& Boster, 2005; Johnson \& Eagly, 1989; 1990; Park, Levine, Westerman, Orfgen, \& Foregger, 2007). Value-relevant involvement occurs when a topic causes an "activation of attitudes that are linked to important values" (Johnson \& Eagly, 1989, p. 290). Impression-relevant involvement occurs when a topic makes "salient to subjects the self-presentational consequences of their postmessage positions" (Johnson \& Eagly, 1989, p. 292). Outcome-relevant involvement occurs when a topic makes "salient to message recipients the relevance of an issue to their currently important goals or outcomes" (Johnson \& Eagly, 1989, p. 292). 
In a political environment dominated by social identity, values- and outcomerelevant involvement are linked, but also do not fully capture what motivates voters to pay attention to campaigns. Today's electoral environment is increasingly nationalized (Hopkins, 2018). Today, as Hopkins (2018) argues, we have "elections dominated by national partisan identities" (p. 21). This means that voters may care about election outcomes for myriad reasons such as personal relevance, values, or their sense of partisan identity as members of the Democratic or Republican social group. The classic drivers of involvement in persuasive messages may not completely explain why individuals engage in political messages. I therefore wanted to explore the extent to which nationalized partisan involvement can motivate viewers of Senate debates as compared to a more traditional personal relevance motivation.

\section{Project Overview}

The current study explored questions related to brand associative memory, persuasion and involvement, and the normative and persuasive outcomes of televised debate viewing. This was done through a $2 \times 4$ experiment featuring a pre- and post-debate survey and four experimental conditions. I emulated classic persuasion experiments (Petty \& Cacioppo, 1986) to manipulate personal relevance, and then, building upon a social identity perspective rooted in the nationalization of politics (Hopkins, 2018; Mason, 2018), I primed the national partisan stakes of a debate for viewers to test if a nationalized partisan context could produce more cognitive involvement from debate viewers. I attempted to manipulate personal relevance by having participants watch either

a Missouri U.S. Senate debate or a North Dakota U.S. Senate debate. I attempted to prime nationalized involvement through reading an experimental prompt emphasizing the 
nationalized partisan stakes to half of the participants and an informational prompt to the other half. This created four conditions: Missouri National, Missouri Informational, North Dakota National, and North Dakota Informational.

Second, I used a pre-test/post-test design to assess the influence that viewing a U.S. Senate debate had on self-reported attitudes on several normative democratic attitudes such as political information efficacy, political cynicism, and political interest and persuasive outcomes such as candidate evaluations and voting intentions. Finally, in the post-debate survey, viewers participated in a brand association task where they listed what came to mind when they thought of each candidate from the debate. The brand association task, based upon methods in marketing psychology and persuasion (Cwalina \& Falkowski, 2015; Keller, 1993; Nielsen, 2016; Petty \& Cacioppo, 1986), allowed me to explore the number of total thoughts offered by participants after viewing a debate, the valence of each thought, as well as the content of each thought - whether it focused on the policy, party, or person (Speed, Butler, \& Collins, 2015).

\section{Dissertation Preview}

The next chapter, Chapter II, provides a review of the literature in which I discuss debates, marketing, political marketing, persuasion, involvement, and social identity. Each of these discussions of literature lead to research questions and/or hypotheses. I then discuss my method, experimental design, and sample in Chapter III. Chapter IV features results of my surveys, content analysis, and experiment. Chapter V includes a discussion of the major findings from the three primary fields of my study: branding, persuasion, and political communication, as well as implications for practice, limitations and future directions, and a conclusion. 


\section{Chapter II: Literature Review}

Televised debates, Senate campaigns, political marketing, and involvement and identity are the areas covered in this literature review. First, much is known about presidential debate effects as well as Senate campaign effects, but there is much to learn about Senate debate effects. Second, political campaigns engage in marketing to brand themselves to different segments of voters and a political marketing perspective focuses on campaign brand strategy as well as voter memory to assess how campaigns market themselves and how voters process this information. Third, classic paths to involvement may not fully capture why individuals attune to political messages in a nationalized political environment driven by political social identities. After each of these sections, several hypotheses or research questions are posed.

\section{Defining Televised Debates}

Ever since Auer (1962) famously said the first televised debates between John F. Kennedy and Richard Nixon were "faux debates" scholars have grappled with the assertion. Though some have characterized them as joint press conferences (Auer, 1981; Lanoue \& Schrott, 1991) others have demonstrated them to exhibit substantial clash between candidates and argued they should be recognized "as a unique form of debate" (Carlin, 1989, p. 213). Televised debates may not be pure debates one would find in a $19^{\text {th }}$ century Ivy League debate hall, but they create a similar environment for the participants who have to think on their feet (Jamieson \& Birdsell, 1988). These events remain important in the democratic process because they are "the only campaign event which allows voters to see candidates side-by-side" (Carlin, 1989, p. 210). As Jamieson and Birdsell (1988) note, “debates provide a level of contact with candidates unmatched in spot ads and news segments. The debates offer the longest, most intense view of the 
candidates available to the electorate" (p. 126). Schroeder (2008) believes debates should primarily be thought of as television spectacles that are "governed not by the rules of rhetoric or politics but by the demands of their host medium. The values of debates are the values of television: celebrity, visuals, conflict, and hype" (p. 9).

Debates matter because the American public expects them (Pfau et al. 1999; Schroeder, 2008) as part of the ritual of the campaign season (Greenberg, 2009) and because they are the biggest media event of the election cycle (Kaid, McKinney, \& Tedesco, 2000). Poor performances that violate expectations can hurt candidates (Pfau, 1987) and great performances can elevate them (Schrott \& Lanoue, 2013). Even though presidential debates are expected by the public and institutionalized with the Commission on Presidential Debates (Schroeder, 2008), candidates still want to participant in debates to promote their message. Televised debates give candidates a tremendous platform to deliver their agenda to the public (Jackson-Beeck \& Meadow, 1979; McKinney, 2005). In fact, televised presidential debates generally receive the highest ratings of any television program outside of the Super Bowl, with ratings similar to those received by series finales of shows such as Seinfeld and MASH (Schroeder, 2008). The high number of viewers are one reason presidential debates matter (McKinney \& Carlin, 2004), along with the normative benefits provided to viewers.

\section{Debate Effects}

The vast majority of studies regarding the effects of viewing televised debates examines presidential debates, and as such, presidential debate literature will be a large focus of this section. In a campaign communication environment with a wide variety of sources and choices, debates are but one source of information (Pfau, 2002), yet they 
stand out as one of the most important due to their influence on the voters and press coverage (Pfau et al., 2007). Debates increase campaign interest (Drew \& Weaver, 2006; Pfau, 1987), influence candidate preferences and voting decisions (Carlin \& McKinney, 1994; McKinney \& Warner, 2013), educate voters about the candidates and their stances on issues (Benoit \& Hanson, 2004; Benoit et al., 2003), reduce cynicism (Chaffee, 1978; McKinney \& Warner, 2013), and increase voter political information efficacy (McKinney \& Chattopadhyay, 2007; McKinney, Rill, \& Gully, 2011; McKinney \& Warner, 2013). Of these, educating voters may be the most important function of debates (Jamieson, 2015; Jamieson \& Birdsell, 1988). The educational function of debates is well-established in the literature (Benoit \& Hansen, 2004; Holbrook, 1996; 1999; Winneg \& Jamieson, 2017). Candidates and context can matter, as voters can learn more from debates with lesser known candidates (Holbrook, 1999) compared to debates with wellknown incumbents in non-competitive races (Drew \& Weaver, 1999). Delli-Carpini and Keeter (1996) praise debates, particularly the town hall format, noting that it led to significant increases in political knowledge (citing Delli-Carpini, Keeter, \& Webb, 1993). By learning from debates, viewers may then go on to consider more issues when evaluating candidates at the ballot (Benoit et al., 2003). Learning could be based on motivation and ability, and viewers who possess prior political knowledge and enjoy thinking can be more likely to learn from debates (Jennings, Warner, McKinney, Kearney, Funk, \& Bramlett, 2018).

In addition to educating voters about issues, debates can inform voters about the personal qualities, or image, of candidates (McKinney, Dudash, \& Hodgkinson, 2003; Warner, Carlin, Winfrey, Schnoebelen, \& Trosanovski, 2011; Yawn, Ellsworth, Beatty, 
\& Kahn, 1998; Zakahi, 2004; Zhu, Milavsky, \& Biswas, 1994). The extent to which voters may learn more about candidate image than about issues is debated (Zhu et al., 1994; McKinney et al., 2003), but the literature does establish that debates influence image perceptions (e.g., Benoit et al., 2003). Research on the role of candidate image in debates dates back to the studies of the first televised debates in 1960 and 1976 (e.g., Dennis, Chaffee, \& Choe, 1979; Simons \& Leibowtiz, 1979; Kraus \& Smith, 1962; Tannenbaum, Greenberg, \& Silverman, 1962), and naturally so, as the contrasting appearances of John F. Kennedy and Richard Nixon in 1960 are now mythological and the 1976 participation of Gerald Ford marked the first time a sitting president performed on a debate stage. Candidate image can mean many things. Performing on a debate stage can reveal candidate personality (Benoit et al., 2003). Debates, particularly primary debates, can also reveal one's electability to voters (Yawn et al., 1998). How one acts on stage can even influence perceptions of traits such as aggressiveness (McKinney, Rill, \& Watson, 2011; Warner et al., 2011) and sense of humor (Stewart, 2011). Nonverbal behavior can also influence evaluations (Seiter, Weger, Kinzer, \& Jensen, 2009). In addition to educating voters about issues and offering insights into image, debates can influence which candidate voters support (Benoit et al., 2003; McKinney \& Carlin, 2004). In fact, debates may be the most important single moment in the election cycle in deciding whom to vote for (Carlin \& McKinney, 1994), although they occur at a point in the cycle when most voters have made up their mind (Schroeder, 2008), and only a relatively small percentage of undecided voters are up for grabs (McKinney \& Carlin, 2004). In some elections, however, a small percentage of voters can separate winners from losers. One reason that vote choice is often not changed for many debate viewers is 
that voters' prior opinions and biases can influence the effectiveness of persuasive appeals and evaluations of candidate arguments about issues (Jarman, 2016; Munro et al., 2002). The candidate that a voter supports before the debate will often be the candidate the voter thinks won the debate (Munro et al., 2002; Schrott \& Lanoue, 2013), which leads to post-debate "who won?" polls being heavily influenced by partisanship. Truly exceptional performances by candidates can manage to overcome partisanship, as shown in Schrott and Lanoue's (2013) analysis of data related to every presidential debate from 1960 to 2008. In addition to vote preference and debate performance, candidate evaluations are influenced by viewing debates (McKinney \& Warner, 2013). Debates can serve to reinforce attitudes toward candidates, most often leading to viewers liking their preferred candidate more after viewing a debate (Mullinix, 2015; Warner, McKinney, Bramlett, Jennings \& Funk, 2018). With opposing candidates, viewers can develop more negative feelings but to a smaller extent compared to the increase in positive feelings toward their preferred candidate (Mullinix, 2015; Warner et al., 2018). An analysis of multiple decades worth of survey data related to debates in the U.S. and Canada found that, for the most part, evaluations of candidates improve after debates, and that incumbents do not have a disadvantage although challengers do gain more favorability overall (Blais \& Perrella, 2008). Debates, therefore, are "one good way for candidates to improve their images, even if they come under attack and even if they are forced to make denials" (Blais \& Perrella, 2008, p. 460).

Debates also have value for broader normative reasons (Pfau, 2002). Reducing cynicism and increasing internal efficacy and interest are important functions of debate viewing as this can improve the overall democratic quality of the electorate. The efficacy 
of voters has long been a measure of healthy citizenship for political scientists (Almond \& Verba, 1963; Campbell, Converse, Miller, \& Stokes, 1960; Campbell, Gurin, \& Miller, 1954; Craig, 1989). Political information efficacy (PIE), which is one's confidence in their own political knowledge and ability to talk about it (Kaid, McKinney, \& Tedesco, 2007) is one form of efficacy and viewing political debates often increases PIE (McKinney \& Warner, 2013). Additionally, viewing political debates can decrease cynicism (McKinney \& Warner, 2013; Jamieson, 2015; Stroud, Stephens, \& Pye, 2011) and increase political interest (Pfau, 1987), both of which are viewed as normative goals of active citizenship (Verba, \& Schlozman, \& Brady, 1995). The multi-cycle study by McKinney and Warner (2013) observed cynicism usually reduces after debate viewing, but one study in the literature (Wald \& Lupfer, 1978) found that debate viewing increased cynicism. The increase in cynicism from Wald and Lupfer's (1978) study may be an artifact of the specific debate and the time in which it took place. Wald and Lupfer (1978) posit that cynicism may have increased after viewing the first debate between Gerald Ford and Jimmy Carter because of the wider political context of the time and because of the pessimistic rhetoric of both candidates (p. 351). Still, in general, it can be expected that cynicism will decrease after debate viewing.

\section{Senate Debates and Campaigns}

All of the above findings come from research on presidential debates, and the influence of Senate debates on normative attitudes has not been adequately explored. Debates are most influential when certain conditions are met (Chaffee, 1978). These are: a large number of undecided voters, a close race, an unknown candidate, and high interest in the race. These conditions are likely to occur with Senate races for a number of 
reasons. Close Senate races are likely to have a sizable amount of undecided voters and challengers who are far less well-known than incumbent U.S. senators (Kahn \& Kenney, 1999). Close Senate races also feature far more press attention than less competitive races, which will lead to more interest in the candidates not only by the press but by the public as well (Kahn \& Kenney, 1999). In short, it is likely that Senate debates could produce the contexts noted by Chaffee (1978).

Subpresidential debates are severely understudied compared to presidential debates (McKinney \& Carlin, 2004; Louden, 2005). McKinney and Carlin (2004) wrote that while "state and local televised debates may differ from their presidential counterparts...we are unable to make any conclusive claims due to the scarcity of research in this area" (p. 226). Subpresidential debates are understudied, and as such, there are few studies of Senate debates and Senate debate effects in particular. Robertson (2005) found that the electoral fortune of candidates can be influenced by participating in Senate debates. The 2004 South Dakota debate between John Thune and incumbent senator Tom Daschle significantly influenced vote choice in a debate that 56 percent of viewers thought that Thune won. Moreover, the debate increased image evaluations of more traits for Thune than it did for Daschle, and later, Thune won the election. However, this study did not include an analysis of partisanship, which is an important factor in evaluation of debate candidates (Munro et al., 2002; Schrott \& Lanoue, 2013). It also highlights that image evaluations are more susceptible to change for lesser known challengers (Zhu et al., 1994). Richard Fenno (1996) conducted in-depth, multi-cycle interviews with U.S. Senators running for election and re-election, and although he did not do a systematic analysis of debates, he pointed to the need for candidates to 
incorporate their debate strategy into their broader strategy: "a campaign theme must be carried into the debate; it cannot be created during the debate" (Fenno, 1996, p. 213).

There have also been content analyses of Senate debates. Like presidential debates, Senate debates are likely to feature more policy than character discussion (Airne \& Benoit, 2005). Unlike gubernatorial debates, Senate debates will likely discuss national in addition to state and local issues (Henson \& Benoit, 2009). While Senate debates are unpredictable, they do still allow for "candidate controlled discourse" (Henson \& Benoit, 2009, p. 703), which is in line with Jackson-Beeck and Meadow's (1979) contention that candidates pursue their own agenda during debates.

While the amount of studies related directly to Senate debates is limited, that is not the case with broader Senate campaigning (e.g., Abramowitz \& Segal, 1992; Fenno, 1996; Kahn \& Kenney, 1999; Krasno, 1994). Myriad factors are important in how Senate campaigns are decided. The popularity of a president matters, as senators can ride the coattails of one up for re-election, particularly if the president vocally endorses the senator (Campbell \& Sumners, 1990). Further, presidential approval ratings matter for their electoral fate in mid-term cycles (Koch, 2000). Swing voters matter (Hill, 2017), and competitive Senate races are likely to have more undecided voters (Kahn \& Kenney, 1999). The economy matters, particularly for evaluations of incumbents in the president's party (Hibbing \& Alford, 1981). Votes by incumbents on legislation such as the Affordable Care Act matters (Konisky \& Richardson, 2012). The size of the state matters, as incumbents in large states are more vulnerable than those of small states (Hibbing \& Brandes, 1983). The variance from race to race matters and is actually what makes Senate campaigns more dynamic than congressional campaigns, which are usually less 
competitive across the board (Kahn \& Kenney, 1999). Results of prior elections matter, as incumbents who survived a close race the prior cycle are more likely to face strong challengers (Stewart, 1989). The quality of challengers is an important factor as well (Duquette, Mixon, \& Cebula, 2017). Moreover, prior elections can influence the campaign strategy of incumbents, sometimes leading to overconfidence (Fenno, 1996). A campaign theme, and focused strategy, is important for incumbents (Fenno, 1996). Finally, the complex interplay between the campaigns, voters, and the press matters (Kahn \& Kenney, 1999).

Local media coverage of policy influences voter knowledge of issues in Senate campaigns (Kahn \& Kenney, 1999), and coverage of candidates makes candidate traits weigh more heavily in voters' evaluations of candidates (Fridkin \& Kenney, 2011), highlighting both agenda setting and priming. Senate campaigns and their press coverage are more likely to focus on issues, particularly when races are close (Kahn \& Kenney, 1999). When Senate candidates do focus on issues, legislation from the prior Congress or party-owned issues will often be emphasized (Brasher, 2003). Voters in Senate elections are likely to consider issues when evaluating candidates (Miller, 1990), and can do this based on the issues covered by the campaigns (Druckman, 2004) but also possibly from the issues that exist in the larger information environment (Dalager, 1996). Voters may ultimately decide how to vote based on the candidates themselves and criteria such as the incumbent's record or the challenger's resume (Abramowtiz, 1988) or the competence of the candidates (Miller, 1990). Challengers and incumbents feed off each other, as the level of fundraising done by opponents leads to reactionary fundraising by the other campaign (Stewart, 1989). With high amounts of fundraising, then, it is no surprise than 
Senate challengers are more well-known than House challengers (Jacobson \& Wolfinger, 1989). Fundraising and polling in the early fall determine how competitive Senate races will be (Kahn \& Kenney, 1999). Importantly, the closer a Senate race is, the more that voter party identification matters (Kahn \& Kenney, 1999, p. 219).

However, to date there is not as much focus on Senate debates in particular. Perhaps this is because studies of Senate and congressional elections focus on the macro level, i.e. a broad view of all the races happening in a given year. Whatever the case, Senate debates happen with frequency across the country, with 46 general election debates from the 2018 midterm cycle available on C-SPAN (C-SPAN, 2019). Therefore, it is important to direct academic attention toward them and to understand how debate viewing influences voters. Senate debates do not receive the millions of viewers that presidential campaigns do but they still contribute to the overall political information cycle (Chadwick, 2013) in a number of ways. Most Senate debates are broadcast on local networks, C-SPAN, and available online. Senate debates can generate online conversation on social media and can serve as opportunities for campaigns to solicit donations and volunteer sign-ups. Debates in high-profile races will often receive coverage on national cable networks, and it is likely that debates will drive coverage in local state media as well. If local voters tune into Senate debates, it is likely that persuasive, educational, and normative influences will occur. Senate campaigns often have more undecided voters than presidential campaigns (Kahn \& Kenney, 1999), and televised debates are likely, based on our understanding of general election and primary election presidential debates, to influence normative and persuasive outcomes. However, the effects cannot be known without being tested, and there is value in replicating 
analyses of communicative processes in different contexts (DeAndrea \& Holbert, 2017).

Therefore, several hypotheses are proposed:

H1: Senate debates will promote political information acquisition.

Hla: Motivation and ability will promote debate information acquisition.

$H 2$ : Senate debates will increase voting intentions.

H3: Senate debates will influence candidate evaluations.

H4: Senate debates will increase political information efficacy.

H5: Senate debates will decrease political cynicism.

H6: Senate debates will increase political interest.

\section{Campaign Marketing}

Marketing and branding provide an interesting language with which to study political campaigns. This terminology is increasingly used by academics as well as the political press, with the past few election cycles featuring more news stories mentioning branding in relation to campaigns and politicians (Milewicz \& Milewicz, 2014). However, political marketing has always been a mainstay of American politics. For instance, "Tippecanoe and Tyler Too" is one of the most famous slogans in American electoral history (Van Meter, 2008), and slogans are a central component of fostering brand identity (Aaker, 1996). The history of $20^{\text {th }}$ century presidential communication shows the centrality of "spin" and image building (Greenberg, 2016). Greenberg (2016) defines spin as "the systematic use, through a range of tools and techniques, of public image and message craft" (p. 8). This is similar to Bloom's (1973) definition of public relations in politics: working to shape candidate "image, actual and potential, and the public's reaction to it" (p. 254). Spin, image, and public relations are components of 
political marketing (Kotler \& Keller, 1976). The study of candidate image has existed for some time in political communication (e.g., Nimmo \& Savage, 1976), and to some scholars, candidate image is the central component of how campaigning is similar to marketing (Newman, 1994; Nimmo, 1975).

The role of candidate image in televised debates was cemented forever after the first debate between John F. Kennedy and Richard Nixon in 1960. Public memory holds that Kennedy won this debate in part due to his good looks and demeanor in contrast to Nixon (McKinney \& Carlin, 2004), which has been supported by some empirical testing (Druckman, 2003). However, it may be the case that Kennedy simply won the debate outright (Katz \& Feldman, 1962; Schroeder, 2008). Candidate image was also important in that it altered Richard Nixon's subsequent strategy in 1968. Joe McGinnis' (1969) The Selling of the President detailed how Richard Nixon hired Madison Avenue consumer advertising consultants to manage his political advertising during his successful campaign in 1968. The 1968 election and the work by McGinnis led to a number of new perspectives on the role of candidate image and professional consulting in politics. Bloom (1973) took a pessimistic view of campaign marketing and public relations, deriding the 1960s campaigns and the rise of political advertising. Several others (Kotler, 1975; Nimmo, 1975; Shama, 1976) saw the trends in campaigning and laid the theoretical groundwork for linking political campaigning to consumer marketing.

To Nimmo (1975), the promotion of candidate image made campaigning similar to marketing. Kotler (1975) saw that candidates had different market segments to manage, from different segments of voters to different segments of elites to engage for fundraising. Kotler (1975) compared challenger candidates to an "unknown product" (p. 
768) who needed to build name recognition with consumers/voters. Shama (1976) also found campaigning similar to commercial marketing because candidates are sold to the public in a similar fashion as goods and services. Later theorizing, however, disputes the idea of political marketing selling a candidate as a product.

Newman (1994) argued that selling a candidate is not like selling a bar of soap, rather, it is more comparable to marketing done by lawyers or dentists. A candidate is offering their services as someone who will represent voters' interests once elected. To Newman (1994), the political marketing process required candidates "to segment their markets, position themselves, and choose appropriate strategies to win office" (Newman, 1994, p. 150). These perspectives laid the groundwork for what is now a field of "political marketing science" (Cwalina et al., 2011, p. 7). This more mature field has answers for the ethical concerns of Bloom (1973), who wrote about the role of political image in the aftermath of Nixon's campaigns. Newman (1994) views political marketing as a process that "centers on the consumer, in this case the voter, as the primary focus of the campaign" (p. 33), and Scammell (2014) argues that ethical political marketing "takes us seriously as adult citizen-consumers" (p. 185).

\section{Branding}

Political and consumer marketing are both concerned with branding. A brand is the combination of associations people make when thinking about a product or service (Keller, 1993). Brand associations are a cognitive process, and much of the literature stems from Anderson's (1983) theory of associative memory, although there are different branding memory models (see Van Osselaer and Janiszewski, 2001 for a review). Associations come from memory and are activated based on the stimuli presented to 
consumers such as advertisements or other messages. As Keller (1993) notes, "marketing activity for a brand potentially can create value for the brand by improving consumers' ability to recall or recognize the brand" (p. 14). Stimuli can make the brand more salient. In associative memory, there is a central "node" which is the starting point from which all other associations come. With political branding, a politician's name is the central node (Cwalina \& Falkowski, 2015, p. 169). In commercial branding, the product is the central node, but in political branding, the human brand, or candidate, matters (Speed, Butler \& Collins, 2015). Therefore, a candidate brand could be defined as the cumulative collection of retrievable associations in memory that voters have about a candidate.

The goal for marketers is to create "favorable, strong, and unique brand associations" (Keller, 1993, p. 2) in the minds of consumers. The composition of favorability, strength, and uniqueness comprise brand equity. Essentially, it is the balance of the number of negative or positive associations with a brand as well as the content of the attributes stated by consumers. In political branding, brand equity is called "political brand value" (Nielsen, 2016). Strength is "the number of associations the voter attaches to the political brand" (p. 84), uniqueness is "the diversity of the associations" (Nielsen, 2016, p. 84), and favorability is "the valence that respondents themselves attach to their associations" (p. 85). Importantly, partisanship can predict high political brand value (Nielsen \& Larsen, 2014).

Political brand value can be influenced by exposure to political stimuli, which can activate prior associations from voters' minds (Nielsen, 2016, p. 75) or make new information the basis for evaluation of candidates (Lodge \& Taber, 2013, p. 51). This is done through the process of spreading activation through priming (Cacciatore, Schuefele, 
\& Iyengar, 2016; Collins \& Loftus, 1975; Iyengar \& Kinder, 1987; Lodge \& Taber, 2013). In this process, information obtained from political media influences the associations that come to mind when voters are asked to think about a candidate (Cacciatore et al., 2016; Lodge \& Taber, 2013). The associations that come to mind then activate more associations that are linked to the first association and subsequent associations (Collins \& Loftus, 1975; Lodge \& Taber, 2013). This can be measured through a verbal association task (Cwalina, Falkowski, \& Newman, 2011) where participants write down as many words as they can when thinking about a politician. These associations can be positive, negative, or neutral, and are linked to other associations based on how frequently certain attributes are directly linked to each other. Importantly, positive candidate brand associations are related to support for candidates (Cwalina \& Falkowski, 2015) and parties (Nielsen, 2016).

Strong brand value and identity will also differentiate one brand from other brands (Aaker, 1996). In politics, differentiation can occur based on policies as well as with candidate personalities and life stories (Scammell, 2014). If a candidate or party are successful at branding, then a voter will think of them when they think of a certain issue or trait. Just as hearing "Big Mac" would make one more likely to think of McDonald's than Burger King (Aaker, 1996, p. 203), hearing "immigration" could make one more likely to think of a Republican than a Democrat. In this way, political brand differentiation is not dissimilar to issue ownership (Petrocik, 1996). Associations are also important in branding when viewed as "benefits" (Van Osselaer \& Janiszewski, 2001). If attributes that are closely linked to a candidate's name, as the central node, are positive and are things that benefit voters, then this will be positive for the candidate. For 
instance, if a dominant association made with "Donald Trump" was "Supreme Court" that could be viewed as a benefit for a conservative voter.

Importantly, then, the political party of a candidate is part of their brand identity. The first association a voter may make when thinking about a politician is their party, and in this way brand associations are similar to heuristic-based decision making (Guzmán, Paswan, \& Van Steenburg, 2015). However, while Guzmán et al. (2015) note that voters have always used shortcuts, citing the foundational works by Downs (1957) and Campbell et al. (1960), they argue that brand associations are a more nuanced way of measuring and assessing these cognitive shortcuts.

Using the candidate's party as the main brand association is a simple heuristic, and associations can be viewed as a non-complex random assortment of recall (Nielsen \& Larson, 2014). However, voters can make complex associations as well. A political brand can also consist of an amalgamation of associations based on the party, leader, and policies (French \& Smith, 2010) or defined slightly differently, the policies, party, and person (Speed, Butler, \& Collins, 2015). When considering non-presidential candidates, "person" is more applicable, although the leader of a party is sure to influence considerations of other politicians in that party.

Since political stimuli make attributes more salient and activate memories in voters, it can be expected that debate viewers will generate associations from memory after viewing a debate, which is Brand Strength. Since political consumers can be expected to be biased towards a candidate from their party, it can be expected that there will be more positive associations made toward in-party candidates than out-party candidates for higher brand favorability. Additionally, it can be expected that a debate, as 
a two-sided information flow and battle between candidates, will produce both positive and negative thoughts: more positive thoughts for one's preferred candidate, and more negative thoughts for the opposition candidate, but that, based on prior research, in-group positivity will outweigh out-group negativity (Warner et al., 2018).

Based on this discussion, several hypotheses are posited:

H7: Brand Strength will be higher for in-party candidates than for out-party candidates.

H8: Brand Favorability will be higher for in-party candidates than out-party candidates.

H9: There will be more positive brand favorability for in-group candidates than negative brand favorability for out-group candidates.

Additionally, the favorability of associations can be expected to influence candidate evaluations (Cwalina \& Falkowski, 2015). Cwalina and Falkowski (2015) found that more positive associations led to more candidate support, and more negative associations led to less support. Therefore, the following hypothesis is formulated:

H10: Brand favorability will be associated with candidate evaluations such that positive brand favorability will increase evaluations and negative brand favorability will decrease evaluations.

Finally, as televised debates feature policy discussions, showcase the candidates as people, and are battles between representatives of two major parties, it can be expected that brand elements related to policy, person, and party (Speed, Butler, \& Collins, 2015) would be salient in viewers' minds after the debate. Candidates in debates do focus more on policy discussions than on character discussions (Benoit, 2014), and this has been 
shown to be the case in a Senate debate as well (Benoit \& Hansen, 2005). However, the extent to which policy, person, and party become salient for debate viewers and how these attributes are perceived has not been explored.

Therefore, the following research questions are proposed:

$R Q 1$ : Was policy, party, or person more prevalent in brand associations after viewing a debate?

$R Q 2$ : Which brand elements were the most favorably perceived by debate viewers?

\section{Debates as Political Marketing Events}

Debates serve as exceptional examples of political marketing because, as television spectacles (Schroeder, 2008) they are fundamentally marketing and public relations events intended to influence brand image and value. The purpose of political public relations is to "establish and communicate the salience of political priorities in media coverage, public opinion, and policymaking" (Kiousis, Kim, Carnifax, \& Kochhar, 2015, p. 615), and communicating your campaign's agenda in a debate can accomplish those objectives. Campaigns also have multiple segments to consider, such as undecided voters, low turnout voters, or strong partisans who could donate or volunteer after a strong performance. When handling different constituencies, a candidate can be constrained in what they say. Having to balance one's rhetoric to appeal to both undecided voters and partisan supporters can be likened to accommodation strategies pursued in business, where a business can find it difficult "to accommodate either party to any degree - at least not without flip-flopping on the issue" (Cameron, Cropp, \& Reber, 2001, p. 251). 
Koll and von Wallpach (2014) note that an important element of branding is "that brand managers need to (a) specify a set of associations to link with the brand and (b) to align activities for consumers to learn these associations" (p. 1502). This is brandmatching: a process where the attributes marketed by a brand appear in consumers' brand associations (Koll \& von Wallpach, 2014; Romaniuk \& Nenycz-Thielf, 2013). Televised debates could be opportunities for brand matching, as they are events that allow for “candidate-controlled discourse" (Henson \& Benoit, 2009, p. 703) where candidates pursue their agenda over that of the press and public opinion polls (Jackson-Beeck \& Meadow, 1979). In a consumer context, Romaniuk and Nenycz-Thielf (2013) found that new customers' associations matched the brand marketing more than frequent customers. In the debate context, this could mean that brand match in associations would be high when viewers are not familiar with the candidates, which is something that could be expected with Senate candidates (Kahn \& Kenney, 1999). Therefore, it is worth exploring the extent to which debate content matched brand associations. To explore this, frequency analyses of brand associations will be conducted to qualitatively explore the dominant attributes discussed by debate viewers and how this is related to debate content. The following research questions are therefore posited:

RQ3: What were the dominant attributes of candidates listed by respondents? $R Q 4$ : Was brand-matching evident in viewer brand associations?

\section{Involvement and Persuasion}

The extent to which debate viewers pay attention, process information, become persuaded, or counter-argue messages can depend upon their involvement, which is "the motivational state induced by an association between an activated attitude and some 
aspect of the self-concept" (Johnson \& Eagly, 1989, p. 293). Involvement is often measured by the relevance of a persuasive message to an individual (Johnson \& Eagly, 1989; Petty \& Cacioppo, 1979; 1986; Petty, Cacioppo, \& Goldman, 1981). Early work established personal relevance as an important driver of involvement (Petty \& Cacioppo, 1979 ; 1986) but there has been much debate about what types of relevance there are in persuasion, and how they affect people (Johnson \& Eagly, 1989; 1990; Park et al., 2007; Petty \& Cacioppo, 1990). Cho and Boster (2005) showed through a confirmatory factor analysis that the three most common types of involvement - outcome-, value-, and impression-relevant - were three separate facets. The full definitions of each type of involvement from Johnson and Eagly (1989) are provided in Chapter I of this document, but briefly they are: impression-relevant concerns one's public perception, value-relevant concerns personal values, and outcome-relevant concerns tangible outcomes. Relevance along each of the three dimensions can lead to elaboration and persuasion, although value-relevant involvement has been shown to lead to less attitude change than outcomerelevant involvement (Johnson \& Eagly, 1989). However, a reason that outcome-relevant involvement often leads to more attitude change is that experimental manipulations for outcome-relevance tend to emphasize topics with which individuals are not familiar. The classic example is a policy change at one's university compared to the same policy change occurring at a different university at a distant location (Petty \& Cacioppo, 1986). A policy change at one's own university would be more personally relevant, and activate more involvement, but it may be a topic the person did not know about earlier, as these policy changes are often made up for the purpose of the experiment. Thus, the attitude change being measured is often actually attitude formation, as people did not have prior 
opinions on the topic (Johnson \& Eagly, 1989; Park et al., 2007). The fact that attitude formation is an outcome is by no means a weakness, however, as attitude formation along with attitude reinforcement and attitude change are the three key types of persuasion (Miller, 2002; Holbert, Garrett, \& Gleason, 2010). In the realm of televised political debates, there can be attitude formation for viewers who had not paid prior attention to the race, attitude reinforcement for viewers who identify with a party, and attitude change for undecided voters (Warner et al., 2018).

Even if individuals are not necessarily familiar with a topic, being told that it is important can increase outcome-relevant involvement. Cho and Boster (2005) write that "When involvement is elicited by the perception that important future consequences are at stake, people are likely to pay attention to messages and to process them in-depth and extensively" (p. 239). In other words, being told that an outcome is important can make the outcome important to an individual, who will then elaborate more on the message.

This form of outcome involvement and personal relevance does not fully speak to the ways in which voters attend to political messages. A student will care about policy changes at their own university compared to another university because their personal life would not be influenced by what is happening at another school. Similarly, a voter is likely to naturally care more about the outcome of a campaign for Senate in their home state compared to another state. However, in today's national political environment, people may also care about the outcomes of campaigns for reasons beyond the traditional forms of involvement from persuasion literature. Involvement in political messages can be driven by partisanship, social identities, and nationalized politics. 


\section{Identity and Persuasion}

Partisan identification can be viewed as a component of social identity for voters (Greene, 1999; 2002; 2004; Mason, 2018). Greene (1999) argues that "social identification with a political party is an important additional element of partisanship" (p. 393). Identifying with a party is one element of an individual's support for the party, much like identification with a consumer brand can be based on that brand fulfilling “self-definitional needs" for consumers (Bhattacharya \& Sen, 2003, p. 77). Mason (2018) argues that "partisanship can now be thought of as a mega-identity, with all the psychological and behavioral magnifications that implies" (p. 14). This social identitybased partisanship causes individuals to not only have stronger positive feelings toward their own party, but more negative feelings toward the other party (Iyengar, Sood, \& Lelkes, 2015; Mason, 2018), a feature of identity involvement that is evident in consumer branding and social identity as well (He, Li, \& Harris, 2012). Additionally, partisan social identities are increasingly nationalized (Hopkins, 2018) and today's campaign environment features "elections dominated by national partisan identities" (Hopkins, 2018, p. 21) where, linking branding to nationalized politics, "like McDonald's, today's major parties are thoroughly nationalized brands" (Hopkins, 2018, p. 143).

Partisanship as social identity is similar to the "value proposition" (Aaker, 1996, p. 95) of consumer brands, which "is a statement of the functional, emotional, and selfexpressive benefit delivered by the brand that provide value to the customer" (p. 95). Aaker defines a functional benefit as "a benefit based on a product attribute that provides functional utility to the customer" (p. 95). An emotional benefit is "when a purchase or use of a particular brand gives the customer a positive feeling" (p. 97). Finally, "a brand 
can thus provide a self-expressive benefit by providing a way for a person to communicate his or her self-image" (p. 99). In a Downsian view, partisanship would purely be based on the functional benefits (Downs, 1957). A person would vote for a party expecting the party to pass policies that the voter supports. With a social identity view, partisanship is more about emotional and self-expressive benefits. A person could support a political party for the emotional benefits of feeling good due to the sense of belonging that comes with group membership. A person could also support a party for the self-expressive benefits that come with using bumper stickers or putting up yard signs. In fact, Mason (2018) observed that the use of these self-expressive forms of participation, using bumper stickers and posting yard signs, are higher post-2000 than they were in the prior decades. This speaks to an increase in self-expressive identity-based partisanship.

Mason (2018) additionally argues that "partisanship trumps policy positions in determining our feelings toward the two parties" (p. 52). Rooting for one's party is now more important for many voters than actual policy outcomes. Voters root for their party against the other party because voters' "individual sense of esteem is tied to the group's status, and therefore any reduction in that status would be painful to experience" (Mason, 2018, p. 23). Partisans will actively root for a candidate from their own party in the same way that they will root for their favorite sports team, as Mason pointed out in the podcast New Books in Political Science (iTunes, 2018).

Rooting for a political party or candidate from that political party in the same way that one would root for a sports team brings to mind the dichotomy of outcome-relevant and value-relevant involvement. To measure outcome-relevant involvement, Park et al. (2007) employed a scale with items saying a topic would "affect me personally, have a 
big impact on my life, would not have important consequences for me, would have little effect on me personally" (p. 102). To measure values-relevant involvement, their scale included items saying a topic "is an important issue to me, is an issue I care about, is a trivial issue," or "I really don't care about the issue" (p. 102).

Midterm elections could induce involvement along both outcome-relevant and value-relevant paths, although these traditional models may not fully capture what motivates individuals to pay attention to political campaigns. Outcome relevance could occur both locally and nationally, but the national importance may require context for voters whereas local personal relevance may be more obvious. For example, voters should naturally care who their personal senator is, but they may not think that an election in a different state from theirs would affect their lives personally. However, if they are cognizant of the stakes of the election, such as a Senate majority deciding which party is in power, then a Senate election in a different state could promote involvement from debate viewers. Being aware of the national stakes could also lead to a greater sense of intergroup competition due to the "partisan team-based mindset" (Mason, 2018, p. 43) prevalent in politics today. An issue such as control of the Senate majority could capture much of the values-relevant involvement measured by Park et al. (2007), but it may more precisely capture partisan competition (i.e., wanting your team to win and the other team to lose). For instance, values-relevant involvement assumes that an issue is important to individuals and their beliefs, so being aware that control of the Senate majority could have implications for national issues such as the Supreme Court or healthcare would induce values-relevant involvement for individuals with strong beliefs about certain issues. However, as Mason (2018) argues, partisans may care about elections not so much 
because of policy beliefs but simply because they want their team to win. Therefore, twosided political communication environments, such as political debates, could induce a form of involvement not fully captured by outcome- or value-relevant involvement: nationalized partisan involvement.

Therefore, I will explore the possibilities of multiple types of involvement modified to fit partisan politics. The first is based on outcome-relevant involvement and personal relevance (e.g., Cho \& Boster, 2005; Petty \& Cacioppo, 1979; 1986). Midterm Senate elections can invite personal relevance for elections in one's home state. The second type of involvement that will be explored is nationalized partisan involvement. Being informed of the national political stakes of a campaign, even one that is not your own state, could activate partisan social identities as a result of the increasingly nationalized political environment (Hopkins, 2018; Mason, 2018).

Based on this discussion, several differences can be expected. First, as shown in elaboration literature (Petty \& Cacioppo, 1979; 1986), greater involvement can lead to greater elaboration as measured in the number of thoughts. In the current study, the number of thoughts is a measure of brand strength. More involvement should lead to higher brand strength for candidates. Therefore, the following hypotheses are proposed:

H11: Greater involvement, whether through Personal Relevance or Nationalized Partisan Involvement, will lead to higher brand strength relative to viewers with lower involvement.

H11a: The presence of both Personal Relevance and Nationalized Partisan Involvement will lead to the highest brand strength. 
Social identification with a party (Iyengar et al., 2015) or a brand (He et al., 2012) can lead to individuals developing more positive thoughts toward their preferred candidate/brand and more negative thoughts toward the competing candidate/brand. More partisan involvement, therefore, could produce more positive or negative thoughts as an outcome of persuasion. The following hypotheses will explore this:

H12: Debate viewers with higher involvement, whether through Personal Relevance or Nationalized Partisan Involvement, will have higher in-group candidate brand favorability and lower out-group candidate brand favorability relative to debate viewers with lower involvement.

H12a: The presence of both Personal Relevance and Nationalized Partisan Involvement will lead to the highest in-group candidate brand favorability and the lowest out-group candidate brand favorability.

It may also be the case that the type of involvement influences the type of associations, and the brand elements that are salient. To do this, respondent associations will be analyzed for party, policy, and person (Speed et al, 2015). High levels of involvement could lead to the most issue-relevant thoughts (Petty \& Cacioppo, 1986), which in a debate would be policy brand elements. Nationalized involvement could induce more party-brand elements as partisanship was activated and can serve as a heuristic (Guzmán et al., 2015). The following research question is thus stated: RQ5: Will different types of involvement make different brand element associations more salient? 
Table 2.1 features all of the hypotheses and research questions for this study.

Table 2.1: Hypotheses and Research Questions

H1: Senate debates will promote political information acquisition.

H1a: Motivation and ability will promote debate information acquisition.

$\mathrm{H} 2$ : Senate debates will increase voting intentions.

H3: Senate debates will influence candidate evaluations.

H4: Senate debates will increase political information efficacy.

H5: Senate debates will decrease political cynicism.

H6: Senate debates will increase political interest.

H7: Brand Strength will be higher for in-party candidates than for out-party candidates.

H8: Brand Favorability will be higher for in-party candidates than out-party candidates.

H9: There will be more positive brand favorability for in-group candidates than negative brand favorability for out-group candidates.

H10: Brand favorability will be associated with candidate evaluations such that positive brand favorability will increase evaluations and negative brand favorability will decrease evaluations.

RQ1: Was policy, party, or person more prevalent in brand associations after viewing a debate?

RQ2: Which brand elements were the most favorably perceived by debate viewers?

RQ3: What were the dominant attributes of candidates listed by respondents?

RQ4: Was brand-matching evident in viewer brand associations?

H11: Greater involvement, whether through Personal Relevance or Nationalized

Partisan Involvement, will lead to higher brand strength relative to debate viewers with lower involvement.

H11a: The presence of both Personal Relevance and Nationalized Partisan Involvement will lead to the highest brand strength.

H12: Debate viewers with higher involvement, whether through Personal Relevance or Nationalized Involvement, will have higher in-group candidate brand favorability and lower out-group candidate brand favorability relative to debate viewers with lower involvement.

H12a: The presence of both Personal Relevance and Nationalized Partisan Involvement will lead to the highest in-group candidate brand favorability and the lowest out-group candidate brand favorability.

RQ5: Will different types of involvement make different brand element associations more salient? 


\section{Chapter III}

This chapter provides an overview of the study's design and process. First, I will discuss the experimental design intended to manipulate personal relevance and nationalized involvement. Second, I will discuss the stimuli: two U.S. Senate debates from October 2018. Third, I will discuss study procedure, sampling, and participant demographics. Then, I will discuss the manipulation checks conducted. This will be followed by a discussion of the branding measures used along with the content analysis

process. Finally, I will discuss the debate effects measures used in the survey instrument. This study received IRB approval on September 26, 2018.

\section{Experimental Design}

Prior to viewing a U.S. Senate debate, participants were read either a nationalized experimental prompt or an informational prompt ahead of viewing either an in-state or out-of-state U.S. Senate debate. This created a 2x4 experimental design: pre-debate/postdebate (within-subjects) by experimental condition (between-subjects). The full breakdown of experimental conditions was: in-state nationalized condition (Condition 1), in-state informational condition (Condition 2), out-of-state nationalized condition (Condition 3), and out-of-state informational condition (Condition 4). The in-state debate featured candidates in the Senate race in Missouri, the state in which the study was conducted. The out-of-state debate featured candidates in the North Dakota U.S. Senate race. Featuring debates from two different states allowed me to explore involvement in persuasive messages in a manner that emulated the classic involvement experimental designs (Petty \& Cacioppo, 1979; 1986). There were thus two manipulations of involvement. Personal relevance was manipulated by having participants watch either a 
debate from one's own state or one from another state. Nationalized partisan involvement was primed through the experimental prompt that discussed the national political implications of the Senate election.

The low personal relevance debate was selected in an effort to closely match other key characteristics of the high personal relevance debate. Thus, in the summer and fall of 2018, close attention was paid to Senate campaigns throughout the country to determine which out-of-state campaign would be appropriate to feature in relation to the Missouri Senate campaign. Several campaigns, primarily the races in North Dakota, Nevada, Florida, Arizona, and Indiana were closely monitored for announcements of debates as these were all races that were listed as "toss-ups" throughout the summer by Larry Sabato's Crystal Ball (Sabato, 2018). Each race featured competitive polling and highlevels of fundraising and spending, which are the criteria for when campaign communication in Senate races is most influential (Kahn \& Kenney, 1999). Among these, the North Dakota campaign was the priority campaign to monitor as it was regionally distinct from Missouri, thus adhering to classic designs (Petty \& Cacioppo, 1979; 1986), and also featured an incumbent female Democratic senator competing against a GOP male challenger, thus matching Missouri on the interaction of gender balance, incumbency, and partisanship.

An October 2018 North Dakota U.S. Senate debate was used as the out-of-state debate. At the time of this project's defense as a prospectus in August 2018, the most recent RealClearPolitics polling from June 2018 had a 0.5 percent lead for Kevin Cramer (“North Dakota Senate," n.d.). In Missouri, a July 8, 2018 polling average on RCP featured a 1-point lead for Claire McCaskill (“Missouri Senate," n.d.). On October 1, the 
RCP average for North Dakota was +6 Cramer and on the date of the actual debate (October 18) it was +8.7 Cramer. On October 1 , the RCP average for Missouri was +0.3 for Hawley and on the date of the actual debate it was +0.5 Hawley.

\section{Experimental Prompts}

The experimental prompts are listed below. The first was designed to make nationalized partisan competition more salient with a message emphasizing that every Senate race had the potential to deliver a majority to either party given that the partisan composition of the Senate was 51-49 at the time. Election forecasters were projecting that the Senate majority would hinge on several key races and Missouri and North Dakota were both on the list of races to watch (e.g., Sabato, 2018). Each prompt was read immediately before viewing the debate. Prompts were read by graduate students or faculty familiar with the purpose of the study. The prompt reader first instructed participants to "please place your phones, laptops, or tablets away. Please do not look at them during the debate." Then, the prompt was read. The nationalized prompt was:

You are about to watch a U.S. Senate debate between the Democratic and Republican candidates for Senate in [Missouri/North Dakota]. The Democratic candidate is [Claire McCaskill/Heidi Heitkamp] and the Republican candidate is [Josh Hawley/Kevin Cramer]. The Senate's balance of power is currently up for grabs in this year's midterms as the Republican Party has a 51-49 majority of one vote. The [McCaskill-Hawley/Heitkamp-Cramer] race has been identified as one of the main races that could decide who controls the Senate. The party that controls the Senate gets to decide very important things such as whether to replace a vacant seat on the Supreme Court, whether to vote on important 
legislation, and may even decide whether to remove President Trump from office if he is impeached by the House of Representatives. The winner of this debate could go on to win the election, and the winner of this election could very well decide whether the Democrats take the Senate or if the Republicans keep the Senate. As you watch this debate, please think about which party you want to win the election and to control the Senate.

The informational prompt was designed to be a control condition that also offered a predebate script of similar length but did not influence nationalized involvement. Here, a simple description of the debate was offered. This prompt read:

You are about to watch a U.S. Senate debate between two candidates for Senate in Missouri. The candidates are [Claire McCaskill/Heidi Heitkamp] and [Josh Hawley/Kevin Cramer]. There are 100 U.S. Senators and every state has an equal number of two Senators. The candidates in this debate will be on the ballot in November. This debate is to see who will represent the state of [Missouri/North Dakota] in the U.S. Senate in the next Congress. Debates are important moments in the U.S. election system, dating back to the Lincoln-Douglas debates of 1858 and the Kennedy-Nixon debates of 1960. Debates allow voters to hear candidates talk about their views and answer questions from moderators. Debates allow candidates the opportunity to speak directly to voters, and for voters to hear the candidates who wish to represent them. As you watch the debate, please pay attention and listen to what the candidates have to say. 


\section{Stimuli}

The stimuli for this study were two U.S. Senate debates held on Thursday, October 18, 2018. The in-state debate was held on October 18, 2018, a Missouri U.S. Senate debate between Republican candidate Josh Hawley and incumbent Democratic senator Claire McCaskill. This debate was held in St. Louis, Missouri and was cosponsored by local PBS, NPR, and NBC affiliates (Hendry, 2018). Some participants viewed the debate in real time via the live feed from the local PBS affiliate's website. Others viewed the recorded debate on later nights using the YouTube video from PBS. The North Dakota U.S. Senate debate was held on October, 18, 2018 in Bismarck, North Dakota and was sponsored by the North Dakota Newspaper Association (Hageman, 2018). Participants were shown C-SPAN's recording of the debate. Both debates were shown in their entirety and were approximately one hour in length.

The Missouri debate had elements of a town-hall debate, with questions from panelists as well as citizens in the audience. The debate opened with a discussion about the federal debt, which led to discussions of tax cuts, Medicare, Social Security, and the Affordable Care Act. Pre-existing conditions, insurance companies, and the Medicare donut hole were also discussed in this section of the debate. Then, foreign policy was discussed with an emphasis on Saudi Arabia, as the murder of journalist Jamal Khashoggi had recently happened. This led to mentions of human rights, the Iran deal, Israel, and military spending cuts. A question about mass shootings followed, with points made about national background checks, the NRA, the $2^{\text {nd }}$ amendment, and bump stocks. This was followed by a separate question about arming school teachers. Next, tariffs and farming were discussed, with mentions of NAFTA renegotiations, financial assistance for 
farmers, and China. After this, healthcare was again discussed, primarily in relation to the lawsuit regarding pre-existing conditions protections. Issues surrounding policing and racial tensions were the next topic, followed by climate change. These were followed by discussions of the right-to-work vote by Missouri voters as well as minimum wage, the border wall, border security, and immigration. After this, the candidates gave their closing remarks where McCaskill mentioned her independence and Hawley talked about the need for constitutional judges.

The North Dakota debate covered many of the same issues although it was a panelist-format debate featuring four journalist panelists who asked all of the questions. Heidi Heitkamp opened with an apology for a campaign newspaper advertisement her campaign had sent out that violated the privacy of sexual violence survivors. Kevin Cramer thanked the press for being there and thanked everyone for watching the debate. The first question was about pre-existing health conditions, which was followed by a discussion of tariffs, farmers, and trade. Next, school safety in relation to mass shootings was asked about by the high-school journalist panelist. This was followed by a question about the Mueller investigation and election interference, followed by a question about freedom of the press, where Heitkamp mentioned Jamal Khashoggi. After this, a question about voting your conscience or as a representative of your state's voters was asked in relation to Heitkamp's vote against Brett Kavanaugh. This was followed by a question about which advertisement from each campaign the other thought was most dishonest. Military spending cuts were then discussed followed by questions about privatizing the post office and a recent Supreme Course case on voter I.D. After this, climate change was discussed followed by a question about how to improve reporting on sexual assault. Next, 
a question about civility in political debate was asked followed by a question on the border wall and immigration. Then, a question about the Kavanaugh confirmation process was asked. The panelists then allowed the candidates to ask each other a question, where Cramer asked about the Heitkamp advertisement alleging he had voted for his own pay raise and Heitkamp asked Cramer about his commitment to not cutting Medicaid and Social Security. After this, the candidates gave their closing remarks where Cramer thanked everyone, mentioned his time campaigning around the state, and invoked Chuck Schumer. Heitkamp similarly discussed her travels around the state and closed by saying she would work across the aisle.

\section{Procedure}

Participants enrolled in undergraduate communication courses were invited to participate in the study which occurred over several nights in October 2018. Participants received extra credit for completing the study. Participants were told to come to the department of communication building, where they were then randomly assigned to conditions. This was done by drawing a room number from a bucket, which had an even distribution of 2-to-4 room numbers depending on the night. The first night of the study, October 18, 2018, featured a live viewing of the in-state Missouri U.S. Senate debate. Though both debates were held on October 18, a decision was made to only show the Missouri debate live due to the higher likelihood that students could watch the Missouri debate on their own. However, for the taped showings, only three total students indicated in the post-test that they had watched the debate before the study, and two actually claimed to have viewed the North Dakota debate. Several core tests were ran with these 
individuals removed, but results did not differ to an extent that justified removing them from the sample.

I also wanted to assess if the participants who watched the Missouri debate live differed from those who viewed the taped debate. To test this, values for political information efficacy, political interest, political cynicism, vote choice, debate knowledge, brand strength, and brand favorability were compared using 2x6 RM-ANOVAs with pre/post-debate as the within-subjects factor and the experimental conditions as the between-subjects factor. Results varied on these comparisons but there were no consistent differences between those who viewed the Missouri debate live relative to those who viewed it taped. There was a significant difference in Missouri Live National and Missouri Taped National in levels of cynicism, where MO Live National had a pre-debate mean of 5.0 and a post-debate mean of 4.88 while MO Taped National had a pre-debate mean of 4.84 and a post-debate mean of 4.73. The differences in PIE for the MO Live Inform viewers and taped MO Inform viewers approached significance. However, political interest, voting intentions, and information gained from the debate were not significantly different when comparing intra-condition taped to live Missouri viewers.

On Thursday, October 18, participants were randomly assigned to one of two conditions: Missouri National ( $n=37$ ) or Missouri Informational ( $n=32)$. Upon being assigned to a condition, participants went to the debate-viewing room and completed the pre-debate survey. Participants were handed sheets of paper with a link to the Qualtrics survey. These links were shortened with the "bit.ly" website's tools to provide easy links to enter into a browser. About one minute before showing the debate, after participants had completed the pre-test, either the primary researcher or a research assistant entered 
the room and read the prompt. After the debate, the research assistant who supervised the room handed out sheets with a link to the post-debate survey and provided instructions on completing the survey. This process was repeated for each night of data collection.

On Monday, October 22, participants were randomly assigned to one of two conditions: North Dakota National $(n=50)$ or North Dakota Informational $(n=57)$. On Tuesday, October 23, participants were randomly assigned to one of two conditions: Missouri National $(n=11)$ or Missouri Informational $(n=6)$. After these three nights of data collection, there was an imbalance in overall participants between the in-state and out-of-state debates. The total sample was also not large enough. Therefore, on the final night of data collection, the first 30 participants were randomly assigned to one of the two Missouri conditions. After the first 30 participants were randomly assigned to a Missouri condition, the rest of the participants were randomly assigned to one of the four total conditions. The breakdown for participants on the final night of data collection was: North Dakota Informational $(n=11)$, North Dakota National $(n=9)$, Missouri Informational $(n=30)$, and Missouri National $(n=26)$.

In total, 269 participants completed both the pre- and post-debate survey and were included in this study. The breakdown by condition is: Missouri National $(n=74,37$ live and 37 taped), Missouri Informational ( $n=68,32$ live and 36 taped), North Dakota National $(n=59)$, and North Dakota Informational $(n=68)$. Overall, there were 136 participants in the informational conditions and 133 participants in the nationalized conditions. There were 142 total participants in Missouri conditions and 127 total participants in North Dakota conditions. 


\section{Demographics}

In the pre-debate survey, participants self-reported demographic information. For gender, 62.1 percent of participants self-identified as female $(n=167), 37.2 \%$ as male $(n$ $=100$ ), and $0.7 \%$ preferred not to report or answered a fill-in-the-blank for self-reporting $(n=2)$. One percent of participants reported an age older than 23 , with no participant being older than 27 . A plurality $(29 \%, n=78)$ were 19 years old, followed by 20 -yearolds $(21.5 \%, n=58), 21$-year-olds $(19.3 \%, n=52), 18$-year-olds $(14.5 \%, n=39), 22$ year-olds $(10 \%, n=27)$, and 23-year-olds $(4.1 \%, n=11)$. For classification, $25.7 \%$ were seniors $(n=69), 20.8 \%$ were juniors $(n=56), 28.3 \%$ were sophomores $(n=76)$, and $25.3 \%$ were freshmen $(n=68)$.

A large majority of participants, $82.1 \%$, self-identified as White/Caucasian $(n=$ $221)$, followed by $5.6 \%$ identifying as African-American $(n=15), 5.6 \%$ as Asian $(n=$ 15), 3.3\% Hispanic $(n=9), 0.7$ as Pacific Islander $(n=2)$, and $2.6 \%$ as Other $(n=7)$. Political ideology was measured in the pre-test on a 1-7 scale ranging from extremely liberal to extremely conservative $(M=4.08, S D=1.54)$. For political party affiliation, $4.8 \%$ identified as a strong Democrat $(n=13), 13.4 \%$ as Democrat $(n=36), 18.2 \%$ as Lean Democrat $(n=49), 18.6 \%$ as no preference $(n=50), 23 \%$ as Lean Republican $(n=$ 62), $17.8 \%$ as Republican $(n=48)$, and $4.1 \%$ as a strong Republican $(n=11)$. Among those with no preference, a follow-up question asked to choose which party they identified with the most. Among these 50 individuals, 27 chose Republican and 23 chose Democrat. Therefore, for analyses featuring a dichotomous party identification variable, the breakdown is $45 \%$ Democratic $(n=121)$ and 55\% Republican $(n=148)$. The variable Partisan Strength was also computed, where no preference was coded as " 0 " $(n=50)$, 
lean Democrat or lean Republican was coded as "1" $(n=111)$, Democrat or Republican as " 2 ” $(n=84)$, and strong Democrat or strong Republican as “ 3 ” $(n=24)$.

\section{Manipulation checks}

Several scales and items were created to serve as manipulation checks. First, Ability was measured in the pre-test through a scale of two items, "How much have you heard about the Senate race in [Missouri/North Dakota]?" and "How much do you know about the Senate race in [Missouri/North Dakota]?" that were measured on a $1=A n$ Extremely Small Amount to $7=$ An Extremely Large Amount scale $(r=.766, M=1.91$, $S D=1.18$ ). An independent samples t-test with the two states as groups indicated that participants in the Missouri conditions had heard significantly more about their respective race $(M=2.89, S D=1.43)$ than participants in the North Dakota conditions $(M=1.26$, $S D=.68), t(206.5)=12.15, p<.001$ and also knew significantly more about their respective race $(M=2.2, S D=1.3)$ than participants in the North Dakota conditions $(M=$ $1.12, S D=.37), t(166.97)=9.62, p<.001$.

In the post-test, two scales were measured on a $1=$ To an Extremely Small Extent to $7=$ To an Extremely Large Extent scale. Personal Relevance $(r=.754, M=3.5, S D=$ 1.53) was measured with two items, "How relevant is the U.S. Senate race in [Missouri/North Dakota] to you personally?" and "How important is it to you who wins the U.S. Senate race in [Missouri/North Dakota]?" Finally, Nationalized Involvement $(\alpha=$ $.78, M=4.53, S D=1.22$ ) was measured with three items, "How important do you think the U.S. Senate race in [Missouri/North Dakota] is to the country as a whole?", "How likely is the U.S. Senate race in [Missouri/North Dakota] in deciding which party controls 
the majority in the U.S. Senate?" and "How important is it to you which party controls the majority in the U.S. Senate?"

For each, an ANOVA by condition was assessed. The first, Personal Relevance, had significant differences by condition, $F(3,268)=17.74, p<.001, \eta^{2}=.17$, Power $=$ 1.0. Post-hoc analyses reveal several key findings related to the prompts. First, personal relevance was significantly lower for North Dakota Informational viewers $(M=2.51, S D$ $=1.12)$ compared to the other three conditions of North Dakota National $(M=3.37, S D=$ 1.44), Missouri Informational $(M=3.96, S D=1.58)$, and Missouri National $(M=4.06$, $S D=1.43)$. There were no significant differences between Missouri National and Informational, indicating that viewing the Missouri debate was personally relevant for Missouri viewers regardless of their prompt. Both Missouri conditions were also significantly higher than North Dakota National, although it too was substantively higher than North Dakota Informational with a mean difference of 0.86 . This indicates that the nationalizing prompt also made the North Dakota debate seem more personally relevant to viewers. Even so, the Missouri debate was inherently more personally relevant to debate viewers, as the informational condition had a 0.59 mean difference compared to ND National.

A similar ANOVA was analyzed for the three-item Nationalized Involvement scale. This ANOVA also had significant main effects, $F(3,268)=10.15, p<.001, \eta^{2}=$ .10, Power $=.99$, and also had significant differences between North Dakota Informational $(M=3.88, S D=1.17)$ compared to the other three conditions of North Dakota National $(M=4.79, S D=1.18)$, Missouri Informational $(M=4.60, S D=1.17)$, and Missouri National $(M=4.86, S D=1.15)$. However, there were not significant 
differences in the pairwise comparisons between North Dakota National, Missouri Informational, and Missouri National. The mean difference between North Dakota Informational and National was 0.91 , almost a full point. This points to the experimental prompt working. It is also important to note that these items were asked in the postdebate survey, approximately 70 minutes after participants listened to a researcher read the experimental prompt. It is interesting that Missouri Informational had a relatively high mean, although it was smaller than ND National (-.19) and MO National (-.26). This could be due to several factors, such as the campaign information environment that debate viewers were operating in. Viewers could have heard about the importance of the campaign from local news, friends and family, or inferred it due to the prevalence of ads. It also could have simply been because the debate itself featured content that invoked the national importance of the campaign, as at the beginning of the debate, the moderator Judy Woodruff stated, "Welcome to this debate, one of the most important Senate races this year" ("Missouri Senate Debate", 2018). Of course, this also served as a double prime for the condition which had just heard the experimental prompt. The differences for both manipulation check scales are illustrated in Figures 3.1 and 3.2. 
Figure 3.1: Personal Relevance by Condition

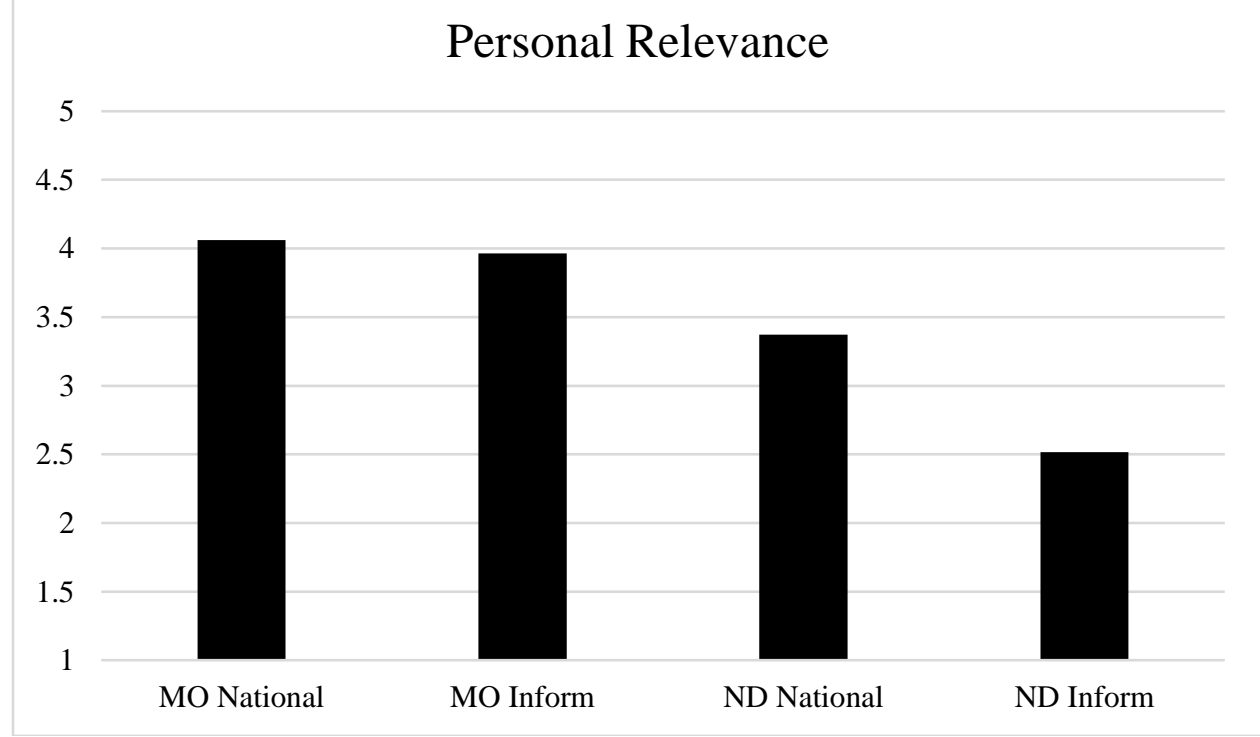

Figure 3.2: Nationalized Involvement by Condition

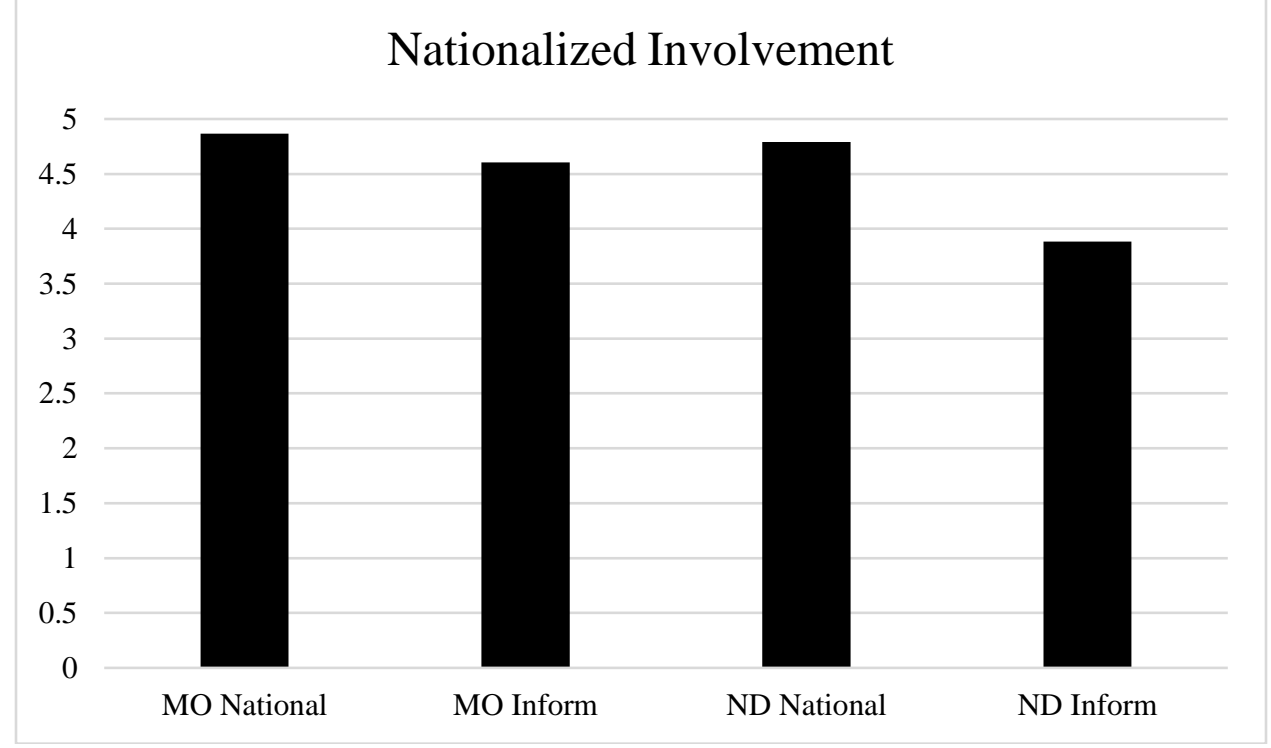

\section{Branding}

Brand association task. After viewing the debate, participants were asked to complete a verbal association task (Cwalina \& Falkowski, 2015). The present study emulated Cwalina and Falkowski (2015) while modifying the fully open-ended response method to facilitate efficient and reliable unitization. After viewing the debate 
participants were prompted to answer two questions, one for each of the candidates participating in the debate they viewed, "What comes to mind when you think of [Claire McCaskill/Josh Hawley/Heidi Heitkamp/Kevin Cramer]? (Mühlbacher, Raies, Grohs, \& Koll, 2016). Under this prompt, there were up to 20 open-ended answer slots. Participants were told they have 2.5 minutes to enter their responses (Cacioppo, von Himmel, \& Ernst, 1997). The order of these questions, i.e. Democratic vs. Republican candidate, was randomized in Qualtrics. After participants filled as many slots as they wished, follow-up questions using Qualtrics' embedded text feature asked participants to rate each of their responses on as either $1=$ Positive, $2=$ Negative, or $3=$ Neutral . The embedded text was entered into the prompt: "You said that Kevin Cramer [e.g., voted for Obamacare repeal]. How would you rate that statement?"

\section{Content Analysis}

A content analysis was conducted with the brand association responses. The content analysis aimed to analyze the political brand elements of party, policy, and person (Speed, Butler, \& Collins, 2015). The unit of analysis in the content analysis was an individual brand association. In February 2019, several training meetings were conducted with three undergraduate research fellows enrolled in a research course where their participation in this research project was a component of their earning course credit. Training meetings occurred twice a week for approximately three weeks. For each meeting, the coders coded practice samples and sent them to me beforehand. I would then run inter-coder reliability analyses using Hayes' K-Alpha macro in SPSS, which was the reliability test I used in the final sample as well (Hayes \& Krippendorff, 2007). After assessing reliability, I would find example coding units where the coders had differed, 
and I would take notes for discussion. In the meetings we would discuss differences and interpretations of units and through this process the code book was refined multiple times before it was finalized for the final sample.

There were three practice samples for the coder training. In the first few meetings, similar units of analysis from presidential debate data were used. A prior study from the 2016 U.S. presidential elections featured open-ended responses to the question "What should voters know about Hillary Clinton/Donald Trump?" After using this data as practice, I then conducted two final rounds of practice coding with responses collected in a follow-up survey after the 2018 elections. About three weeks after the election, I sent an email to participants who had indicated in the post-debate survey that they would be interested in taking a survey after the election. A total of 26 people filled out this survey which included the brand association task. Due to the low amount of responses, I did not use this data for an analysis of debate effect decay in this study, but I was able to use the brand association responses for content analysis training. I used these responses for two final rounds of training: one for North Dakota $(\alpha=.82)$, which was first, and one for Missouri $(\alpha=.89)$, which was the last sample for training. After seeing that reliability was exceptional, I sent the final sample to the coders. The full sample consisted of 5,154 brand associations: 2,894 in the Missouri debate and 2,260 in the North Dakota debate. Each debate was treated as its own sample. I divided the sample into thirds as evenly as possible, and divided it based on participant responses. For example, a coder's sample did not cut off in the middle of one individual's brand associations. Due to differing levels of responses from individual participants, i.e., some participants offered 7 responses while others offered 17, the sample could not be perfectly divided, but the final breakdown was 
2,049 responses for coder 1, 2,066 responses for coder 2, and 2,087 responses for coder 3. A 10 percent overlap in each debate was utilized for inter-coder reliability. Each coder completed their coding within one month. Exceptional reliability was reached: Missouri $(\alpha=.92)$ and North Dakota $(\alpha=.91)$.

From the content analysis, several variables were created. These were created by combining the associations of both candidates. This created the variables of Party Associations ( $n=612,11.9 \%)$, Policy Associations $(n=579,11.2 \%)$, Personal Associations $(n=3903,75.7 \%)$, Other Associations $(n=41, .008 \%)$, and Incomplete Associations $(n=19, .004 \%)$. The complete code book is listed in Appendix A with full descriptions for variables. For party, the top-line description was "An association should be coded as a party-brand element if it discusses the party which the candidate is a member of or the ideology of the candidate and/or candidate's party." For policy, the topline description was "An association should be coded as a policy-brand element if it discusses policies such as taxes, the economy, healthcare, crime, immigration, foreign policy, etc." For person, the top-line description was "An association should be coded as a person-brand element if it discusses the candidate as a person or is related to them as a person." "Other Associations" were those that did not pertain to any of the brand elements, such as "Spaghetti" or "Yeet." "Incomplete Associations" were responses that cut-off in mid-sentence, which were likely a product of the timer advancing the screen while someone was finishing a response. Some examples are "More roo" and "I think o."

\section{Brand Measures}

The variable Brand Strength was created by adding the total number of message-

relevant brand associations an individual made (Petty \& Cacioppo, 1986). This was done 
by creating new variables for each response and re-coding any Party, Policy, or Person response as "1" and all other or incomplete responses as " 0. " The responses were summed to create a total number of message-relevant brand associations. This was first done for the Republican and Democratic candidates. Then, in-group/out-group variables were created by multiplying Republican Brand Strength by the dummy-coded Republican identification variable, Democratic Brand Strength by the dummy-coded Democratic identification variable, then adding the two, and then doing the opposite to create outgroup brand strength (Democratic ID x Republican Candidate Brand Strength, Republican ID x Democratic Candidate Brand Strength). This created In-Group Candidate Brand Strength $(M=9.75, S D=4.03)$ and Out-Group Candidate Brand Strength $(M=9.19, S D=3.79)$ as well as Total Brand Strength, which was the combined amount for in-group and out-group candidate associations $(M=18.94, S D=7.29)$.

The variable Brand Favorability was created by subtracting the sum of total negative associations from the sum of total positive associations respondents had for a candidate. Similar in-group/out-group candidate variables were created as with Brand Strength. These were: In-Group Candidate Brand Favorability $(M=5.15, S D=5.10)$ and Out-Group Candidate Brand Favorability $(M=-1.1, S D=5.53)$. Additionally, variables for positive and negative favorability were created. These were: In-Group Positive Favorability $(M=6.59, S D=4.16)$, In-Group Negative Favorability $(M=1.44, S D=$ 1.84), Out-Group Positive Favorability $(M=3.22, S D=3.12)$, and Out-Group Negative Favorability $(M=4.31, S D=3.43)$. 


\section{Survey Items}

Voting. In the pre-test, participants were first asked if they were registered to vote in the 2018 midterms. Among participants, 75.5 percent $(n=203)$ indicated they were registered to vote. When participants indicated they were registered to vote, a follow-up question asked if they were registered to vote in Missouri/North Dakota $(1=Y e s, 2=N o$, $3=$ Don't Know). In the Missouri conditions, 94 of 107 self-identified registered voters were registered in Missouri (87.9\%) while 11 were not and 2 were unsure. In the North Dakota conditions, none were registered in North Dakota, although 4 were unsure.

Participants were also asked "How likely are you to vote in the 2018 midterms?" on a 1-7 Very Unlikely to Very Likely scale in the pre-test $(M=4.73, S D=1.98)$ and post-test $(M$ $=5.03, S D=1.79)$. This item will heretofore be referred to as Midterm Voting Intentions.

Participants were then asked, "If you were to vote in the U.S. Senate race in Missouri/North Dakota, which candidate would you likely vote for?" on a $1=$ Definitely Voting Hawley/Cramer to $7=$ Definitely Voting McCaskill/Heitkamp scale in the pre-test $(\mathrm{M}=4.04, \mathrm{SD}=1.23)$ and post-test $(\mathrm{M}=4.03, \mathrm{SD}=2.01)$. For my analysis, $\mathrm{I}$ created a new vote choice variable as I was interested in whether debates make people stronger or weaker in their overall voting preferences. Therefore, I computed a variable where $1=$ Undecided/Neither, 2 = Leaning toward a candidate, $3=$ Probably voting for a candidate, and $4=$ Definitely voting for a candidate, where the leaning, probably, and definitely options for both candidates, i.e., "Probably Voting McCaskill/Probably Voting Hawley" were combined. This created the Voting Preference Strength variable: pre-test $(M=1.62, S D=1.06)$ and post-test $(M=2.75, S D=.98)$. Participants were also asked, "If you were to vote in the U.S. Senate race in Missouri/North Dakota, how likely would 
you be to vote for the following candidates?" for each candidate on a $1=$ Very Unlikely to $7=$ Very Likely scale. Similar to other variables, these items were re-coded to InGroup Voting Likelihood (pre $M=4.48, S D=1.35$, post $M=5.40, S D=1.46$ ) and OutGroup Voting Likelihood (pre $M=3.33, S D=1.36$, post $M=2.75, S D=1.59$ ).

Knowledge and Learning. In the pre-test, participants were asked a variation of the civics knowledge questions utilized in the American National Election Study survey with open-ended response questions to gauge recall memory features (Kim \& Garrett, 2012). These were: "What political office does Jeff Sessions now hold?," "What political office does Mike Pence now hold?," "What political office does John Roberts now hold?", "What political office does Paul Ryan now hold?," "Do you know how many times a person can be elected President of the United States under current laws?," "For how many years is a United States Senator elected? That is, how many years are there in one full term of office for a U.S. Senator?," and "On which of the following does the U.S. Federal Government currently spend the least (foreign aid, Medicare, national defense, or Social Security)?" Correct answers were coded as 1 and added to create a composite Civics Knowledge variable $(M=2.9, S D=1.65)$. The percent correct for each question is available in Appendix B.

In the post-test, knowledge was measured through a quiz of debate material. For Missouri, this quiz was created by me along with a team of research assistants while the live debate occurred on October 18. For North Dakota, the quiz was created by me during a pre-screening of the debate the weekend before the taped showings of it. In each debate, the quiz consisted of eight questions: 2 open-ended questions and 6 multiple choice questions. Among the multiple choice, 2 answers were the Democratic candidate, 2 
answers were the Republican candidate, 1 answer was neither, and 1 answer was both. Correct answers were then coded as 1 and added for summative knowledge variables: Missouri Debate Learning $(M=4.40, S D=1.88)$, North Dakota Debate Learning $(M=$ 4.75, $S D=1.87)$, and Overall Debate Learning $(M=4.57, S D=1.88)$. The full quizzes for each debate are available in Appendix C.

Debate elaboration. In the post-debate survey participants were asked about their attentiveness to the arguments based on a scale from Reynolds (2007): "During the debate were you: Attempting to analyze the issues in the message, Not very attentive to the ideas*, Deep in thought about the message, Unconcerned with the ideas*, Extending a good deal of cognitive effort, Distracted by other thoughts not related to the message*, Not really exerting your mind*, Doing your best to think about what was said, Reflecting on the implications of the arguments, Resting your mind*, Searching your mind in response to the ideas, Taking it easy*" on a $1=$ Strongly Disagree to $7=$ Strongly Agree scale. After the items marked with asterisks were reverse coded, these 12 items were used to create a Debate Elaboration scale $(\alpha=.912, M=5.05, S D=.93)$.

Political cynicism. Before and after viewing the debate, respondents were asked about their political cynicism based on the eight-item ANES-adapted scale used in prior research (e.g., McKinney \& Warner, 2013; Warner, McGowen, \& Hawthorne, 2012) on a $1=$ Strongly Disagree to $7=$ Strongly Agree basis. These items are: "Politicians cannot be trusted," "Politicians are corrupt," "Politicians are dishonest," "Politicians are more interested in power than what people think," "Politicians make promises that are never kept," "Politicians are too greedy," "Politicians always tell the public what they want to hear instead of what they actually plant to do," and "Politicians are more concerned about 
power than advocating for citizens." This scale was measured in the pre $(\alpha=.914, M=$ 4.59, $S D=1.02)$ and post-test $(\alpha=.936, M=4.69, S D=1.01)$.

Political information efficacy. Respondents were asked about their Political Information Efficacy (Kaid, McKinney, \& Tedesco, 2007) with an adapted version of Kaid et al.'s (2007) four items on a $1=$ Strongly Disagree to $7=$ Strongly Agree scale: "I consider myself well qualified to participate in politics," "I feel that I have a pretty good understanding of the important political issues facing our country," "I think that I am better informed about politics and government than most people," and "If a friend asked me about the midterm elections, I feel I would have enough information to help my friend figure out who to vote for." This scale was measured in the pre $(\alpha=.88, M=3.23, S D=$ 1.61) and post-test $(\alpha=.90, M=3.97, S D=1.39)$.

Political interest. Respondents were asked about their political interest on a 1-7 Likert-type 3-item scale ranging from $1=$ Strongly Disagree to $7=$ Strongly Agree for three questions often used in political research (e.g., McKinney \& Warner, 2013): "I am interested in politics," "I follow politics closely," and "Politics are important to me personally." This scale was measured in the pre $(\alpha=.899, M=3.74, S D=1.64)$ and posttest $(\alpha=.87, M=3.84, S D=1.58)$.

For both PIE and political interest, there was an error in the Qualtrics survey, where the orders of "Agree" and "Somewhat Agree" as well as "Disagree" and "Somewhat Disagree" were flipped. This likely led to the slightly higher standard deviations than was present in the post-test scales. I recoded these two pre-test scales so that it was in the correct order of "Strongly Disagree, Disagree, Somewhat Disagree, Neither Agree nor Disagree, Somewhat Agree, Agree, and Strongly Agree.” In the pre- 
test, the presentation was "Strongly Disagree, Somewhat Disagree, Disagree, Neither Agree nor Disagree, Agree, Somewhat Agree, and Strongly Agree.”

Feeling thermometer evaluations. To examine candidate evaluations, several "feeling thermometer" questions were asked before and after the debate where respondents are asked to rate a candidate on a scale of 0 (very cold) to 100 (very warmly). Viewers of both debates were asked to evaluate the candidates in not only their debate but the other debate as a baseline. In Missouri, these were: McCaskill (pre $M=$ 44.73, $S D=21.05$, post $M=54.11, S D=25.08)$, Hawley (pre $M=48.04, S D=19.57$, post $M=55.55, S D=25.89$ ), Heitkamp (pre $M=48.62, S D=9.39$, post $M=46.82, S D=$ 12.46), and Cramer (pre $M=49.38, S D=9.52$, post $M=47.6, S D=12.56$ ). In North Dakota, these were: Heitkamp (pre $M=48.72, S D=12.39$, post $M=52.3, S D=23.5$ ), Cramer (pre $M=48.02, S D=13.87$, post $M=50.79, S D=24.71$ ), McCaskill (pre $M=$ 41.69, $S D=25.19$, post $M=42.37, S D=24.3$ ), and Hawley (pre $M=45.18, S D=21.88$, post $M=46.23, S D=22.33)$.

For analytic purposes, candidate evaluation variables were created for the ingroup and out-group candidates of the relevant debate. For example, the in-group candidate evaluation was a variable featuring Missouri Democratic identifying viewers' feelings toward McCaskill, Missouri Republican feelings toward Hawley, North Dakota Missouri Democratic feelings toward Heitkamp, and North Dakota Republican feelings toward Cramer. These were: in-group candidate evaluations (pre $M=52.61, S D=16.05$, post $M=67.69, S D=17.97$ ) and out-group candidate evaluations (pre $M=42.04, S D=$ 16.96 , post $M=39.03, S D=22.46$ ). 


\section{Chapter IV}

This chapter will discuss the results of my analyses related to the three primary areas of this study. First, to better understand debate effects in the context of U.S. Senate debates, I will outline my findings related to their normative and persuasive outcomes. Second, through a utilization of the branding methodology, I will discuss key findings related to brand strength, brand favorability, and political brand elements to better understand how debate viewers processed information about candidates. Finally, I will discuss key findings related to involvement and brand associations.

\section{Normative Effects of Senate Debates}

The first hypothesis, $H 1$, "Senate debates will promote political information acquisition," was explored through a one sample t-test with post-debate knowledge as the test variable. Results were significant, $t(269)=39.77, p<.001$, showing that the average responses were greater than zero $(M=4.57, S D=1.88)$. To further assess knowledge effects, and to answer Hla, "Motivation and ability will promote debate information acquisition,” I conducted a stepwise linear regression with gender, party affiliation, debate, debate elaboration, and pre-debate civics knowledge as independent variables and post-debate knowledge as the dependent variable. Pre-debate civics knowledge represented ability and debate elaboration represented motivation. Gender, party affiliation, and debate were dummy-coded (Female; Democrat; Missouri $=1$ ). Results of the linear regression were significant, $F(5,262)=18.15, p<.001, \mathrm{r}^{2}=.26$, indicating the overall model predicted information gained in the debate. Additionally, the $\mathrm{r}^{2}$ change was significant in the stepwise linear regression model when adding Civics Knowledge $\left(\Delta \mathrm{r}^{2}=\right.$

$.11)$ and Debate Elaboration $\left(\Delta r^{2}=.09\right)$, highlighting that both motivation and ability 
increased learning. Results of the model with standardized regression coefficients are presented in Table 4.1.

Table 4.1: Debate Learning

\begin{tabular}{ll}
\hline & Post-Debate Knowledge \\
\hline Being Female & -.09 \\
Being Democrat & .09 \\
Viewing Missouri Debate & $-.14 * *$ \\
Pre-Debate Civics Knowledge & $.29 * * *$ \\
Debate Elaboration & $.30^{* * *}$ \\
\hline Note: $*=p<.05, * *=p<.01, * * *=p<.001$
\end{tabular}

To answer $H 2$, "Senate debates will increase vote intentions," multiple paired samples t-tests were conducted. The first was for Midterm Voting Intentions, which significantly increased from pre-debate $(M=4.73, S D=1.98)$ to post-debate $(M=5.03$, $S D=1.8), t(269)=-5.1, p<.001, d_{z}=.31$. Second, in-group candidate voting likelihood significantly increased from pre-debate $(M=4.48, S D=1.35)$ to after the debate $(M=$ $5.40, S D=1.46), t(268)=-9.04, p<.001, d_{z}=.55$ for a mean shift of in-group candidate preference of .92 points. Out-group candidate voting likelihood also significantly shifted, from pre-debate $(M=3.33, S D=1.36)$ to post $(M=2.75, S D=1.59), t(264)=5.39, p<$ $.001, d_{z}=-.33$. On a 1-7 scale, viewing a debate made participants about a half-point (.56) less likely to vote for the out-party candidate. Table 4.2 shows the means and standard deviations of changes in in-group and out-group candidate voting likelihood.

Table 4.2: In-Group and Out-Group Voting Likelihood

\begin{tabular}{lll}
\hline \multicolumn{1}{c}{ Pre-Debate M (SD) } & Post-Debate M(SD) \\
\cline { 1 - 1 } \multicolumn{1}{c}{ In-Group } & & \\
Missouri & $4.78(1.46)$ & $5.49(1.48)$ \\
North Dakota & $4.14(1.14)$ & $5.30(1.43)$ \\
\multicolumn{1}{c}{ Out-Group } & & \\
Missouri & $3.04(1.54)$ & $2.74(1.62)$ \\
North Dakota & $3.65(1.04)$ & $2.80(1.57)$ \\
\hline
\end{tabular}


I then analyzed Voting Preference Strength, which saw a significant shift from before the debate $(M=1.62, S D=1.06)$ to after the debate $(M=2.76, S D=.98), t(267)=$ $-15.62, p<.001, d_{z}=.95$. There was a shift in voting preference of over a full point on a 1-4 scale, indicating the average respondent went from being between undecided or leaning toward a candidate to being between leaning and probably voting for a candidate, providing support for $\mathrm{H} 2$. The largest plurality $(31 \%, n=85)$ chose Leaning, followed by Probably $(30.1 \%, n=81)$ and Definitely voting for a candidate $(27.8 \%, n=75)$.

It is important to note how many respondents selected that they were undecided or were not likely to vote for either candidate in the pre-debate questionnaire. In the North Dakota debate, 93.7 percent $(n=119)$ of participants chose undecided/neither in the predebate, highlighting that viewers did not know anything about these candidates. In Missouri, 49.6 percent $(n=70)$ were undecided before the debate. After the debate, only 14 percent $(n=20)$ of Missouri debate viewers were undecided and only 6.3 percent of viewers $(n=8)$ of North Dakota debate viewers still chose undecided/neither. A total of 10.4 percent $(n=28)$ of debate viewers were undecided after the debate in the combined sample. Thus, although there were a significant number of undecided voters in both debates before debate viewing, and an especially high number for North Dakota, after the debate this amount shrank considerably, pointing to the power of debates to influence voting intentions. Table 4.3 illustrates changes in candidate preference.

Table 4.3: Candidate Voting Preference Strength

\begin{tabular}{lll}
\hline & Pre-Debate M (SD) & Post-Debate M(SD) \\
\hline Missouri & $2.02(1.19)$ & $2.73(1.05)$ \\
North Dakota & $1.17(.66)$ & $2.75(.98)$ \\
\hline
\end{tabular}


To answer $H 3$, "Senate debates will influence candidate evaluations," paired samples t-tests were conducted on in-group and out-group candidate feeling thermometers. Tests revealed that candidate evaluations did shift during the debate. Postdebate in-group feelings were significantly higher than pre-debate scores, $t(266)=-12.31$, $p<.001, d_{z}=.75$. Post-debate out-group feelings were significantly lower than predebate scores, $t(267)=2.27, p=.024, d_{z}=-.14$. The differences in effect sizes highlights that in-group candidate evaluations had more changes than out-group candidate feelings. Descriptive statistics of the means and standard deviations are shown in Table 4.4 for the overall sample. Table 4.5 breaks it down by party and candidate.

Table 4.4: In/Group/Out-Group Changes in Candidate Evaluations

\begin{tabular}{lll}
\hline & Pre-Debate M (SD) & Post-Debate M(SD) \\
\hline In-Group & $52.77(15.93)$ & $67.5(17.97)$ \\
Out-Group & $42.01(16.98)$ & $38.97(22.49)$ \\
\hline
\end{tabular}

Table 4.5: Changes in Candidate Evaluations by Party and Candidate

\begin{tabular}{lll}
\hline & Pre-Debate M(SD) & Post-Debate M(SD) \\
\hline McCaskill: Democrats & $53.69(19.34)$ & $67.96(16.0)$ \\
McCaskill: Republicans & $36.44(19.33)$ & $41.42(25.44)$ \\
Hawley: Republicans & $55.11(16.67)$ & $71.67(17.33)$ \\
Hawley: Democrats & $40.3(19.83)$ & $37.57(21.61)$ \\
Heitkamp: Democrats & $51.28(13.5)$ & $66.7(19.3)$ \\
Heitkamp: Republicans & $46.84(11.34)$ & $41.19(19.74)$ \\
Cramer: Republicans & $50.66(13.02)$ & $63.59(18.75)$ \\
Cramer: Democrats & $45.04(13.78)$ & $33.17(20.84)$ \\
\hline
\end{tabular}

To answer $H 4$, "Senate debates will increase PIE," a similar paired samples t-test was conducted with the 4-item PIE scale. The paired samples t-test showed a significant change from pre-debate PIE $(M=3.23, S D=1.6)$ to post-debate $(M=3.97, S D=1.39)$, $t(268)=-11.36, p<.001, d_{z}=.69$, providing support for $\mathrm{H} 4$ in the largest shift among the normative political attitudes examined as evident from the large effect size. The change 
in PIE was almost 3/4ths of a point, although the movement was from the 3-point on the scale, "Somewhat Disagree" toward the 4-point "Neither Agree nor Disagree." Still, this large shift speaks to the power of televised debates to make people more confident in their ability to talk about politics, which is the essence of what PIE measures.

Additionally, this study featured an adapted version of PIE, with the $4^{\text {th }}$ item stating, "If a friend asked me about the midterm elections, I feel I would have enough information to help my friend figure out who to vote for." This item featured the largest shift from predebate to post-debate for the PIE items, from an average of $2.67(S D=1.76)$ before viewing a debate to an average of $3.85(S D=1.61)$ after viewing a debate.

To answer $H 5$, "Senate debates will decrease cynicism," a paired-samples t-test was conducted based on an 8-item computed term for political cynicism. Results revealed that post-debate cynicism $(M=4.59, S D=1.02)$ was lower than pre-debate cynicism $(M$ $=4.69, S D=1.01)$ in the overall sample, $t(268)=2.37, p=.02, d_{z}=-.14$, providing support for H3. In the overall sample, political cynicism decreased by .099 points. While this is not a large number, it speaks to the power of political debates and campaign information to involve viewers in the political process and make them feel better about political institutions, although the average viewer remained near the 4-point on the scale, which was "neither agree nor disagree."

To answer H6, "Senate debates will increase political interest," similar tests were conducted using the 3-item political interest scale. Results of the paired-samples t-test revealed that political interest increased from pre-debate $(M=3.74, S D=1.64)$ to postdebate, $(M=3.84, S D=1.58), \mathrm{t}(268)=-1.93, p=.055, d_{z}=.12$, although the increase was only approaching conventional levels of statistical significance. Therefore, support 
for $\mathrm{H6}$ is tentative. However, it is worth pointing out the high starting point for interest $(M=3.74)$ compared to PIE $(M=3.23)$, indicating that political interest may itself be a more stable variable that PIE. That is, viewing a single debate may not make someone more interested in politics, but it could make someone more confident in their ability to discuss politics. Additionally, individual paired samples t-tests for the three political interest items shows that the item "I follow politics closely" had a significant $(p<.001)$ shift from pre-debate $(M=3.06, S D=1.81)$ to post-debate $(M=3.3, S D=1.65)$ while the other two items ("I am interested in politics; Politics are important to me personally") did not feature significant shifts.

Results from these tests indicate that viewing televised U.S. Senate debates can persuade voters and influence normative democratic attitudes. Viewing a televised U.S. Senate debate promoted learning about issues discussed in the debate and substantively increased the confidence in one's ability to discuss politics (PIE). Intention to vote in the midterm elections and vote intentions for candidates significantly increased. Candidate evaluations also changed with a more sizable effect of increased positive feelings toward in-group candidates than increased negative feelings toward out-party candidates. Finally, political interest marginally increased and political cynicism marginally decreased.

\section{Political Branding}

In this section I will provide an overview of the findings related to candidate branding effects from the two U.S. Senate debates featured in this study. I will first assess brand strength and brand favorability. Then I will assess the influence of brand favorability on attitudes toward candidates. I'll then discuss content analysis findings related to brand elements and brand matching. 
To answer $H 7$, "Brand Strength will be higher for in-party candidates than for out-party candidates," I conducted a paired samples t-test for in-group candidate brand strength and out-group candidate brand strength where brand strength was the number of message-relevant (i.e., party, policy, or person) brand associations offered by viewers. Results were significant, $t(268)=3.22, p<.001, d_{z}=.20$, showing that in-group candidate brand strength $(M=9.75, S D=4.03)$ was significantly higher than out-group candidate brand strength $(M=9.19, S D=3.8)$.

To answer $H 8$, "Brand Favorability will be higher for in-party candidates than out-party candidates," a paired samples t-test was conducted comparing in-group candidate brand positive favorability to out-group candidate brand positive favorability where positive favorability was the number of message-relevant positive brand associations offered by viewers. Results were significant, $t(268)=10.86, p<.001, d_{z}=$ .66 , indicating that in-group candidate brand favorability $(M=6.59, S D=4.16)$ was significantly higher than out-group candidate brand favorability $(M=3.22, S D=3.12)$.

To answer $H 9$, "There will be more positive brand favorability for in-group candidates than negative brand favorability for out-group candidates," another paired samples t-test was conducted comparing in-group candidate brand positive favorability to out-group candidate brand negative favorability where positive favorability was the number of message-relevant positive associations toward the in-group candidate and negative favorability was the number of message relevant negative associations made toward the out-group candidate. Results were significant, $t(268)=10.01, p<.001, d_{z}=$ .61 , indicating that in-group candidate positive favorability $(M=6.59, S D=4.16)$ was significantly higher than out-group candidate negative favorability $(M=4.31, S D=3.43)$. 
Figure 4.1 visualizes brand association results with the means of each of the following variables: in-group brand strength, out-group brand strength, in-group positive associations, out-group negative associations, out-group positive associations, and ingroup negative associations.

Figure 4.1: Brand Associations

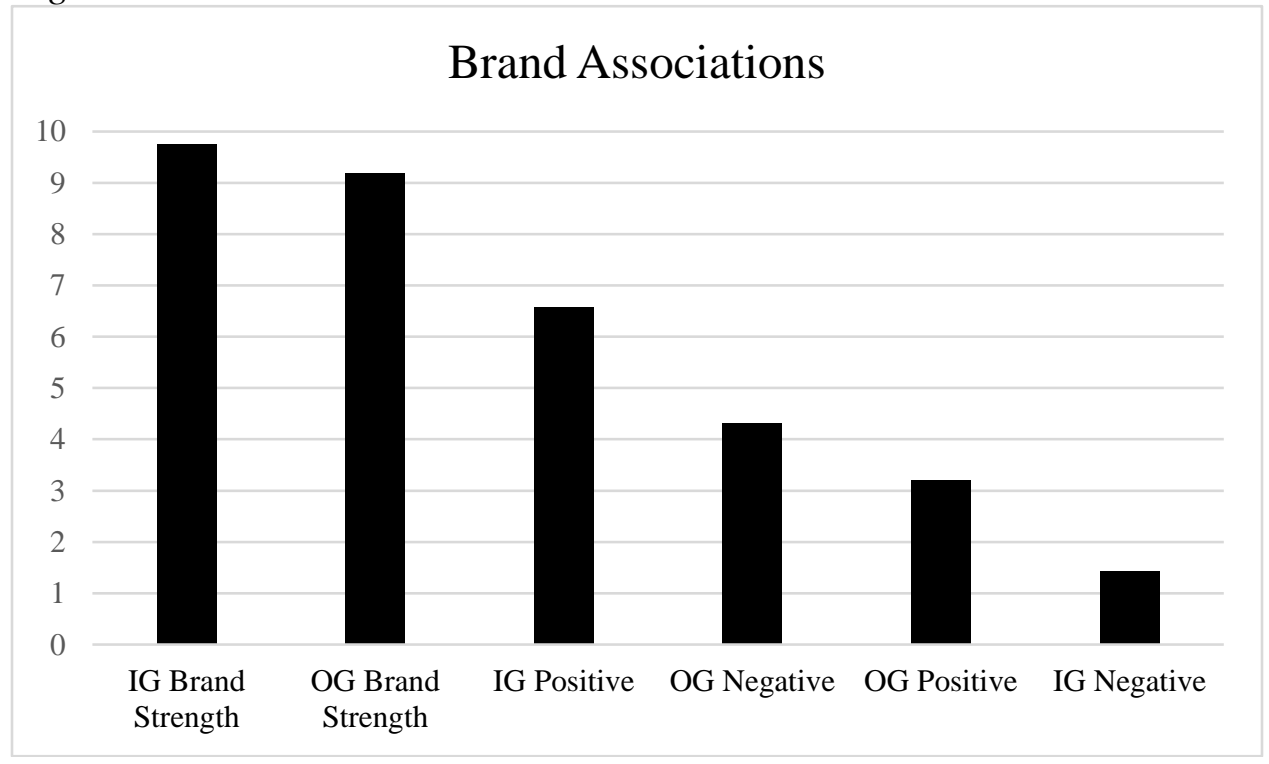

\section{Political Branding and Persuasion}

Next, to assess the influence of brand associative memory on attitudes, I conducted two linear regressions with different types of brand favorability as the primary independent variables and post-debate feeling thermometers as the dependent variable. This was done to assess $H 10$, "Brand favorability will be associated with candidate evaluations such that positive brand favorability will increase evaluations and negative brand favorability will decrease evaluations." In each regression, I first accounted for predebate feeling thermometers, gender, strength of partisanship, debate watched, and total message-relevant in-group or out-group candidate associations. To assess the influence of in-group brand associations on in-group candidate evaluations, regressions were 
conducted with in-group positive or negative associations as the primary independent variable and in-group post-debate feeling thermometers as the dependent variable. When assessing in-group positive associations' influence on in-group candidate evaluations, the regression was significant, $F(6,259)=43.54, p<.001, r^{2}=.50, \Delta r^{2}=.23$, indicating that in-group positive associations were a significant predictor of higher in-group candidate evaluations. Regression results were also significant for the influence of in-group negative thoughts on in-group candidate evaluations, $F(6,259)=32.81, p<.001, r^{2}=.43$, $\Delta r^{2}=.16$, indicating that in-group negative associations were a significant predictor of lower in-group candidate evaluations.

To assess the influence of out-group associations on out-group evaluations, similar regressions were conducted with out-group positive or negative associations as the primary independent variable and out-group post-debate feeling thermometers as the dependent variable. Regression results were significant, $F(6,260)=36.62, p<.001, r^{2}=$ $.46, \Delta r^{2}=.16$, indicating that out-group positive thoughts were a significant predictor of higher out-group candidate evaluations. Regression results were also significant, $F(6,260)$ $=40.47, p<.001, r^{2}=.48, \Delta r^{2}=.19$, indicating that out-group negative associations were a significant predictor of lower out-group candidate evaluations. The standardized coefficients for each of these test results are available in Table 4.6 below. Full regression tables for each of the four tests are available in Appendix D. In table 4.6, the top row is post-debate candidate evaluations. The first two variables in the independent variable list are pre-debate in-group evaluations and pre-debate out-group evaluations. As can be seen, each type of brand favorability corresponded with the appropriate changes in candidate evaluations. More positive associations toward a candidate, be that the in-group 
or out-group candidate, predicted more positive feelings toward the candidate, and more negative associations toward a candidate, be that the in-group or out-group candidate, predicted more negative feelings toward the candidate.

Table 4.6: Brand Favorability and the Influence on Candidate Evaluations

\begin{tabular}{lllll}
\hline & $\begin{array}{l}\text { In-Group } \\
\text { Evaluation }\end{array}$ & $\begin{array}{l}\text { In-Group } \\
\text { Evaluation }\end{array}$ & $\begin{array}{l}\text { Out-Group } \\
\text { Evaluation }\end{array}$ & $\begin{array}{l}\text { Out-Group } \\
\text { Evaluation }\end{array}$ \\
\hline Pre-Debate IG FT & $.25^{* * *}$ & $.24 * * *$ & & \\
Pre-Debate OG FT & & & $.32^{* * *}$ & $.30^{* * *}$ \\
Being Female & .01 & .04 & .05 & .05 \\
Partisan Strength & $.12^{*}$ & $.15^{* *}$ & $-.26^{* * *}$ & $-.25^{* * *}$ \\
Viewing MO & .08 & .08 & $.13^{* *}$ & $.12^{*}$ \\
IG Strength & $-.41^{* * *}$ & $.29^{* * *}$ & & \\
OG Strength & & & $-.21^{* * *}$ & $.27^{* * *}$ \\
IG Positive Associations & $.83^{* * *}$ & & & \\
IG Negative Associations & & $-.42^{* * *}$ & & \\
OG Positive Associations & & & $.47 * * *$ & \\
OG Negative Associations & & & & $-.52^{* * * *}$ \\
\hline Note: $*=p<.05, * *=p<.01, * * *=p<.001$ & &
\end{tabular}

\section{Political Branding: Content Analysis Results}

To explore $R Q 1$, "Was policy, party, or person more prevalent in brand associations after viewing a debate?" descriptive statistics were assessed for party brand associations, personal brand associations, and policy brand associations as well as a chisquare difference test. Table 4.7 highlights the prevalence of brand associations overall as well as by debate. Total numbers and percentage per column are shown. The number of non-message relevant associations is also shown (other or incomplete). Those 60 nonrelevant associations were excluded from analyses.

Table 4.7: Political Brand Elements by Debate

\begin{tabular}{llll}
\hline & Total & Missouri & North Dakota \\
\hline Party & $612(11.9 \%)$ & $292(10.1 \%)$ & $320(14.2 \%)$ \\
Policy & $579(11.2 \%)$ & $381(13.2 \%)$ & $198(8.8 \%)$ \\
Person & $3,903(75.7 \%)$ & $2,181(75.4 \%)$ & $1,722(76.2 \%)$ \\
Other & $41(0.8 \%)$ & $31(1.1 \%)$ & $10(0.45 \%)$ \\
Incomplete & $19(0.4 \%)$ & $9(0.3 \%)$ & $10(0.45 \%)$ \\
\hline
\end{tabular}


A $2 \times 3$ chi-square test, state by brand element, showed significant results, $\chi^{2}(2)=$ $39.67, p<.001, \mathrm{~V}=.09$, highlighting a few differences by debate. Missouri viewers were more likely to recall policy brand associations than North Dakota viewers, while North Dakota viewers were more likely to recall party brand associations than Missouri viewers. However, it is important to point out the similarly high focus on personal brand elements in both debates along with the vast difference in the amount of person-brand element associations compared to policy and party.

To explore $R Q 2$, "Which brand elements were the most favorably perceived by debate viewers?" brand elements were assessed for their valence. Results of a $3 \times 3$ chisquare test were significant, $\chi^{2}(4)=128.48, p<.001, \mathrm{~V}=.11$, indicating several differences which are highlighted in Table 4.8. Percentages are for columns, and again, non-message relevant associations are shown here but were excluded from analysis.

Table 4.8: Political Brand Elements and Favorability

\begin{tabular}{llllll}
\hline & Party & Policy & Person & Other & Incomplete \\
\hline Positive & $238(38.9 \%)$ & $281(48.6 \%)$ & $2,118(54.3 \%)$ & $13(31.7 \%)$ & $2(10.5 \%)$ \\
Negative & $170(27.8 \%)$ & $180(31.1 \%)$ & $1,198(30.7 \%)$ & $7(17.1 \%)$ & $4(21.1 \%)$ \\
Neutral & $204(33.3 \%)$ & $117(20.2 \%)$ & $587(15 \%)$ & $21(51.2 \%)$ & $13(68.4 \%)$ \\
\hline
\end{tabular}

As seen in Table 4.8, brand associations were far more likely to be positive, and person-based elements were the most likely to be positive. This highlights the power of televised debates to serve as opportunities for candidates to positively promote their image with voters. For party, policy, and person brand elements alike, a plurality or majority of brand associations were positive. Additionally, a third of party-based associations were neutral, showing that party-based associations were not necessarily evaluative, but a heuristic that was easy to recall. 
To better understand how debate viewers assessed party, policy, and person, some qualitative examples from participants who offered all three types of brand associations are presented. Responses are presented as written by participants. Regarding Heidi Heitkamp, one person responded: "Democrat, Security, Education, Medicine, North Dakota, Loyal, Hardworking, Honest, Brave, Intelligent, Outspoken, Thoughtful, Sincere, and Respectful" where the first association was party-based, the second through fourth were policy-based, and the rest were person-based. Regarding Kevin Cramer, this same person responded: “Argumentative, Direct, North Dakota, Republican, Border walls, Security, Rash, Government, Opinions, Power, Authoratative (sp), Intelligent, Helpful, To the point, and Attention getting" where Republican was party-based, border walls and security were policy-based, and the rest were person-based. Responses where viewers simply stated the candidate's states, i.e. "North Dakota" or "Missouri" were coded as person-based in the study.

Regarding Heitkamp, another person responded: "Woman, democrat, sweet, intense, aggressive, supports Obamacare, experienced, well put together, senator, against trump tariffs, "for the people of north dakota", screwed up some campaign ad, apologetic, and somber" where "supports Obamacare and against Trump tariffs" were policy associations and "Democrat" was a party association while the rest were personal. Regarding Cramer, the same person responded: "bad hair, calm, level headed, republican, older, suit, against Obamacare, experienced, soft spoken, nice, honest, fair, conservative, and will fight for north dakota" where "against Obamacare" was party, "Republican and Conservative" were party, and the rest were personal. 
Although these are only two brief examples, they highlight some important insights. First, person-based associations were predominant, with a multitude of participants only offering person-based responses (i.e., "Consise (sp), Nice, Well spoken, Professional, Confident, Structure, Background knowledge, Experienced, Smart, For the ppl, Caring” for Heitkamp and "Mean, Rude, Attacking, Controlling, Insulting, Quick on his feet, Disruptive, Annoying, Selfish, Conniving, and Interrupting” for Cramer).

Second, there is evidence of "brand match" (Koll \& von Wallpach, 2014) between the content of the debate and the associations in voters' minds. Although I was not able to do a quantitative content analysis of debate content and more precise content categories of brand associations, a qualitative overview can highlight brand matching in action, which is the link between the brand messaging and brand associations. For instance, "screwed up some campaign ad" and "apologetic" are examples of 1) an accusation Cramer made against Heitkamp and 2) a debate point offered up by Heitkamp. Additionally, "supports Obamacare" and "against Obamacare” are examples of both candidates positioning themselves on an issue and a voter recalling this positioning.

To better explore brand match, and to answer $R Q 3$, "What were the dominant attributes of candidates listed by respondents?" and $R Q 4$, "Was brand-matching evident in viewer brand associations?" computer assisted content analyses were conducted using the free content analytic software program AntConc. These computer-assisted content analyses were done for each candidate. In the tables below, results are presented which show the frequencies of dominant attributes of interest. The results are shown for associations made about each candidate for viewers from each party. In each table, select associations from the top 40 most frequent associations are reported. Words such as "the" 
or "of" were omitted. The number in parentheses represents the frequency of a word. A total of 5,154 were made by respondents.

Table 4.9: Missouri Brand Association Frequencies

\begin{tabular}{llll}
\multicolumn{2}{c}{ McCaskill } & & Hawley \\
\hline Democrats & Republicans & Democrats & Republicans \\
\hline She (36) & She (73) & His (31) & He (48) \\
Her (32) & Not (39) & Not (31) & Republican (41) \\
Democrat (21) & Her (29) & Republican (26) & Wants (36) \\
Party (19) & Democrat (27) & Family (24) & Family (33) \\
Honest (16) & Old (23) & For (21) & People (28) \\
Wants (16) & Supports (22) & Trump (21) & His (23) \\
Experienced (14) & Liberal (18) & Wants (18) & Trump 23) \\
Smart (14) & Years (15) & Young (18) & Wall (23) \\
Against (13) & Missouri (14) & People (17) & Man (22) \\
Wall (12) & Party (14) & Wall (15) & Supports (22) \\
Liberal (11) & People (14) & Man (13) & Young (21) \\
Missouri (11) & Politics (12) & Questions (13) & Missouri (17) \\
Old (11) & Wall (12) & Supports (13) & Change (12) \\
Politics (11) & Experienced (11) & Audience (10) & Claire (12) \\
Independent (11) & Says (10) & Personable (10) & Respectful (11) \\
Afraid (9) & Woman (10) & Against (9) & Attorney (10) \\
Strong (9) & Border (10) & Claire (9) & Conservative (10) \\
\hline
\end{tabular}

These results show several interesting components which were explored through the concordance lists in AntConc, which shows the responses where frequent words occurred. For instance, in Democratic responses, "afraid" was always used in responses stating that Claire McCaskill was "not" or "isn't" afraid, such as with one person having two associations that stated, "Not afraid to agree with President Trump" and "Not afraid to speak up for opposing view points." When stating that she is a Democrat, this was often a standalone association for both Democratic and Republican viewers, as was stating that she is "old."

The association for "party" revealed particularly interesting results, as part of Josh Hawley's debate strategy was to paint McCaskill as a "party-line liberal." Among both 
Democratic and Republican respondents, there was more nuance. Some examples from Democrats are "Party breaker," "wasn't afraid to go against party," "party line," "partyliner," and "crosses party lines." Among Republican respondents, examples are "supports her party," "crosses her party," "stays on party lines," and "not a clear party." In these associations we see people matching their associations about McCaskill to content from the debate, and we also see that both candidates had some success in branding McCaskill either for the party line or against it.

With Hawley, we see interesting results in the concordance list as well. Among the 33 Republican respondents who noted "family," 14 of these were the exact association "family man" with five responses of "family oriented." Hawley, who mentioned his wife and sons multiple times in the debate, was successful at branding himself as a family man to Republican viewers. He was successful with Democratic viewers as well, with seven individuals also stating "family man" as a standalone association, and four saying family-oriented. However, one person did remark, "plays the family man card" showing some judgment of his branding strategy. We also notice that Hawley is a challenger candidate, and challenger candidates make the elections about the incumbent senator (Fenno, 1996). We see this in that "Claire" shows up in his associations, with Republican responses like "critical of Claire" or "feels that Claire is not what Missouri needs" and Democratic responses like "cared more about Claire's point of view than his own" and "really did his research on Claire McCaskill." Additionally, we see he is tied to his party's incumbent president, with Trump being invoked more often for Hawley associations than for McCaskill associations, with a notable Republican response stating Hawley was "Riding the Trump wave" while 
Democrats responded that he was "Trump lite" as well as "scared to go against Trump publically (sp).” Trump was mentioned 23 times by Republicans in Hawley associations and 21 times by Democrats in Hawley associations but only three and six times respectively in McCaskill associations.

Next, I analyzed the brand associations from North Dakota viewers. These results are presented in Table 4.10 .

Table 4.10: North Dakota Brand Association Frequencies

Heitkamp

\begin{tabular}{llll}
\hline Democrats & Republicans & Democrats & Republicans \\
\hline She (69) & She (54) & He (52) & Trump (43) \\
Her (29) & Her (35) & Trump (28) & Republican (40) \\
More (22) & Democrat (33) & His (24) & He (30) \\
For (16) & Not (30) & Republican (21) & Not (27) \\
Democrat (15) & With (20) & Wants (17) & People (23) \\
Wants (13) & People (17) & Rude (16) & Supports (16) \\
Strong (12) & Strong (17) & Like (14) & Wants (15) \\
Well (12) & North (13) & Supports (12) & Conservative (14) \\
Issues (10) & Experienced (12) & Wall (11) & Honest (14) \\
Moderate (10) & Dakota (11) & Conservative (10) & Intelligent (14) \\
People (10) & Senator (10) & Disrespectful (7) & Strong (13) \\
Able (9) & Seems (9) & Sexual (7) & Dakota, North (12) \\
Dakota, North (8) & Intelligent (8) & Assault (6) & Supporter (12) \\
Caring (8) & Mistakes (8) & Talking (6) & Wall (12) \\
Cramer (8) & Opponent (8) & Aggressive (6) & Confident (11) \\
Passionate (7) & Passionate (8) & Believes (6) & Pro (11) \\
Seemed (7) & Woman (8) & Border (6) & Like (10) \\
\hline
\end{tabular}

For Heitkamp, some interesting responses are evident. Democrats made note of her gender, with seven responses simply being one word, "woman," but another being "woman of her word." Democrats also took note that Heitkamp had branded herself as a moderate, with responses such as “Moderate-provided instances in which she didn't side with Democrats." Additionally, Democrats took note of Heitkamp in relation to Cramer, with responses such as "Is more bipartisan than Cramer" and "was being attacked by 
Cramer.” To garner enough words with rich meaning, I went to the 50 most frequent words for Republican associations about Heitkamp. Republicans called her passionate, often as a standalone word association, but in another instance as "passionate about North Dakota." "Seems" was an interesting word as well, used by Republicans in contexts such as "Seems to be trained; she sounds rehearsed" as well as "seems more moderate." One interesting response showing attention to the pre-debate survey instrument stated, "If I were to vote in North Dakota, she would not have my vote!" Her opening apology in the debate also showed up in Republican responses such as "owns up to her mistakes" and "After watching the debate I think she is a person like everyone who makes mistakes but doesn't seem very trustworthy."

For Cramer, his personality came through with Republicans, such as responses about him being honest or intelligent. "Straight" was used 10 times but often to say he was straight-forward (6 times) or a straight shooter. This can be compared to Democratic associations about Cramer, where he was called rude, aggressive, and disrespectful. Associations about him being aggressive or disrespectful were always one word, as was rudeness for the most part other than an association "He's a little bit rude sometimes." With Cramer, compared to the other candidates, what is interesting is how Trump was the most common word, often for Republicans calling him a Trump supporter. This speaks to his debate branding strategy - he emphasized his support of Trump. This was evident with "supports" being frequent as well from Republicans noting he "supports Trump" or "Supports the wall." Cramer also branded himself as an ally of the incumbent president to Democratic viewers as well, with responses such as "he brought up Trump as much as possible," "very pro Trump," and "Classic Trump supporter." One Republican 
association noted that Cramer "supports women" as this related to a debate discussion on sexual violence. Democrats also took note of this, stating "needing more female cops has nothing to do with sexual assault" or "claims to stand with sexual assault victims but stands with Kavanaugh."

Summary. In the above section on political branding content analysis results, I have gone over several key tests and findings. First, debate viewers were more likely to offer in-group candidate brand associations than out-group candidate brand associations. They were more likely to offer positive in-group associations than positive out-group associations as well as to offer more positive in-group associations than negative outgroup associations. I found that in the overall content analysis, there were more positive brand associations than negative or neutral associations, and that although there was more of an emphasis on policy associations in Missouri relative to North Dakota, and more emphasis on party associations in North Dakota relative to Missouri, in both debates respondents were far more likely to offer person-based associations than policy or party. Finally, I examined qualitative results related to brand associations through a computerassisted content analysis of word frequencies. I found tentative support for brand matching. In the next section, I will examine the branding variables in relation to involvement. First, however I am concluding this section with Table 4.11, which has the brand associations and the favorability from a sample participant. In columns 2 and 5, the numbers 1, 2, and 3 stand for party, policy, and person respectively. In columns 3 and 6, the numbers 1, 2, and 3 stand for positive, negative, and neutral respectively. 
Table 4.11: Example Response of Associations

\begin{tabular}{|c|c|c|c|c|c|}
\hline $\begin{array}{l}\text { McCaskill } \\
\text { Associations }\end{array}$ & Element & Valence & $\begin{array}{l}\text { Hawley } \\
\text { Associations }\end{array}$ & Element & Valence \\
\hline Democrat & 1 & 3 & Republican & 1 & 1 \\
\hline Mizzou alumni & 3 & 1 & family man & 3 & 1 \\
\hline $\begin{array}{l}\text { for keeping } \\
\text { Obamacare }\end{array}$ & 2 & 3 & for medicaid & 2 & 1 \\
\hline $\begin{array}{l}\text { for boarder } \\
\text { control, to an } \\
\text { extent }\end{array}$ & 2 & 3 & $\begin{array}{l}\text { for social } \\
\text { security }\end{array}$ & 2 & 1 \\
\hline $\begin{array}{l}\text { for keeping } \\
\text { social security }\end{array}$ & 2 & 1 & $\begin{array}{l}\text { for pre-existing } \\
\text { conditions }\end{array}$ & 2 & 1 \\
\hline $\begin{array}{l}\text { for keeping } \\
\text { Medicaid }\end{array}$ & 2 & 1 & $\begin{array}{l}\text { for border } \\
\text { security }\end{array}$ & 2 & 3 \\
\hline $\begin{array}{l}\text { has been in } \\
\text { politics for a } \\
\text { long time }\end{array}$ & 3 & 2 & $\begin{array}{l}\text { data analysis for } \\
\text { racial/police } \\
\text { issues }\end{array}$ & 2 & 1 \\
\hline $\begin{array}{l}\text { grew up in a } \\
\text { farming family }\end{array}$ & 3 & 3 & $\begin{array}{l}\text { respectful to } \\
\text { people asking } \\
\text { questions }\end{array}$ & 3 & 1 \\
\hline $\begin{array}{l}\text { from rural } \\
\text { Missouri }\end{array}$ & 3 & 3 & $\begin{array}{l}\text { grew up in a } \\
\text { farming family }\end{array}$ & 3 & 3 \\
\hline $\begin{array}{l}\text { not as polite } \\
\text { with the people } \\
\text { who questioned } \\
\text { her }\end{array}$ & 3 & 2 & $\begin{array}{l}\text { does not want to } \\
\text { increase } \\
\text { minimum wage } \\
\text { (yet, at least) }\end{array}$ & 2 & 1 \\
\hline $\begin{array}{l}\text { was not as calm } \\
\text { as Hawley was } \\
\text { while } \\
\text { answering } \\
\text { questions }\end{array}$ & 3 & 2 & $\begin{array}{l}\text { believes it is } \\
\text { time for a change } \\
\text { in Missouri } \\
\text { politics }\end{array}$ & 3 & 1 \\
\hline
\end{tabular}

\section{Involvement: Branding and Persuasion}

To answer H11, "Greater involvement, whether through Personal Relevance or Nationalized Partisan Involvement, will lead to higher brand strength relative to viewers with lower involvement," and HIIa, "The presence of both Personal Relevance and Nationalized Partisan Involvement will lead to the highest brand strength," an ANOVA was conducted with the experimental conditions as factors and brand strength, the total number of associations made by responses, as the dependent variable. In the ANOVA, 
Levene's test of the equality of variances was significant, so I did a follow up Welch's test of the equality of means. The Welch's test verified the decision on $p(p=.018)$, justifying interpretation of the results. Results were significant, $F(3,269)=3.72, p=$ $.012, \eta^{2}=.04$, Power $=.804$, showing differences in brand strength based on condition. Specifically, respondents in Missouri National $(M=21.03, S D=8.27)$ produced more brand associations than respondents in North Dakota National $(M=18.22, S D=7.86, p=$ $.026)$ and North Dakota Informational $(M=17.13, S D=6.4, p=.001)$. Respondents in Missouri Informational $(M=19.09, S D=5.92)$ produced more responses than respondents in either North Dakota condition and fewer than those in Missouri National, though these differences were not statistically significant although they did trend in the hypothesized directions. North Dakota National did not significantly differ from North Dakota Informational, although it too trended in the hypothesized direction. Therefore, tentative support for $\mathrm{H} 11$ was found with more support for H11a, as Missouri National featured the highest brand strength. These results are visualized in Figure 4.2

Figure 4.2: Total Brand Strength

\section{Total Brand Strength}

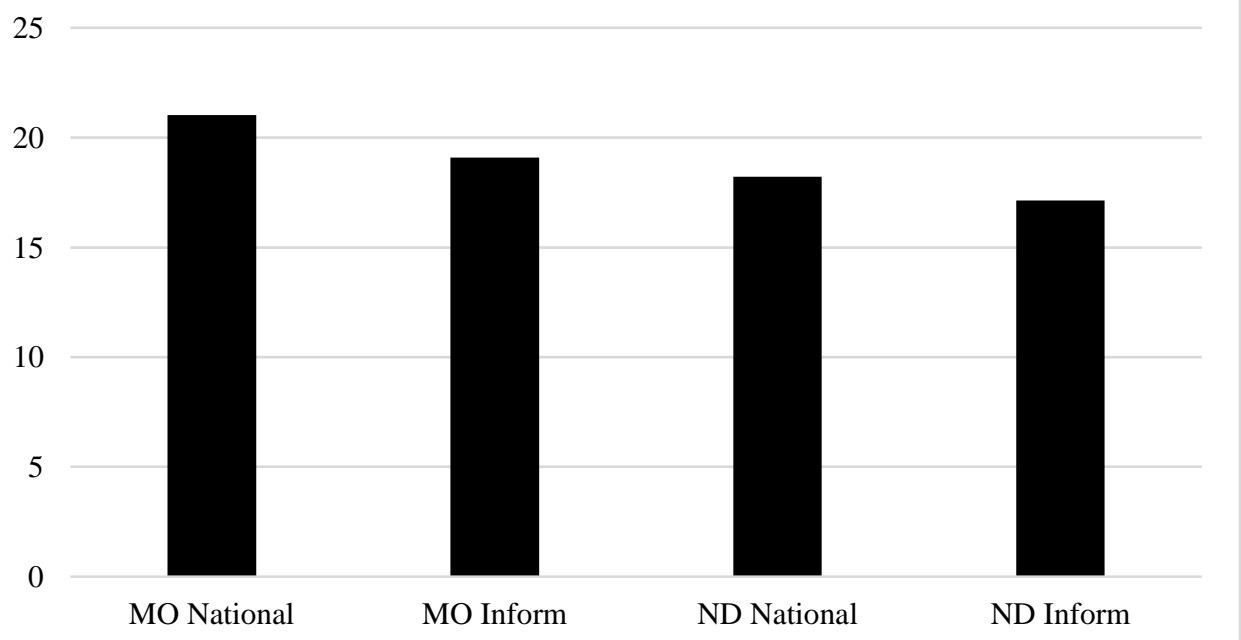


To assess the differences in brand strength based on in-party and out-party candidates, a MANOVA was conducted with condition as the factor, and Brand Strength for party candidates as the dependent variables. Results of the MANOVA showed main effects that approached conventional standards of statistical significance, $F(6,530)=$ 2.126, $p=.056, \eta^{2}=.023$, Pillai's Trace $=.046$, Power $=.75$. Between subjects effects were significant for and Out-Group Candidate Strength, $F(3,268)=4.09, p=.007, \eta^{2}=$ .044, Power $=.84$ but not In-Group Candidate Strength, $F(3,268)=2.53, p=.058, \eta^{2}=$ .03 , Power $=.62$. Levene's test was violated for out-group strength but a follow-up Welch's test was significant - validating the F-tests.

For in-group candidate brand strength, pairwise comparisons showed significant differences in in-group candidate brand strength between Missouri National and North Dakota Informational $(p=.009)$ while the difference between Missouri National and North Dakota National approached significance $(p=.056)$. For out-group candidate brand strength, there were significant differences between Missouri National and North Dakota National $(p=.025)$ and North Dakota Informational $(p=.001)$. Although differences between conditions relative to Missouri Informational were not significant, the differences between conditions trended in expected directions. The non-significant differences between Missouri Informational and North Dakota National also speaks to the nationalizing prompt serving as an equalizer. Moreover, for both in-group and out-group candidate brand strength, the condition with both personal relevance and nationalized involvement, Missouri National, had the highest brand strength. The means and standard deviations for in-group and out-group candidate brand strength by condition are available in Table 4.12 and visualized in Figure 4.3. 
Table 4.12: Candidate Brand Associations (total number of associations)

\begin{tabular}{lll}
\hline & In-Group Strength M(SD) & Out-Group Strength M(SD) \\
\hline MO National & $10.74(4.72)$ & $10.28(4.11)$ \\
MO Inform & $9.74(3.38)$ & $9.35(3.09)$ \\
ND National & $9.41(4.25)$ & $8.81(4.01)$ \\
ND Inform & $8.97(3.46)$ & $8.16(3.63)$ \\
\hline
\end{tabular}

Figure 4.3: Candidate Brand Strength by Condition

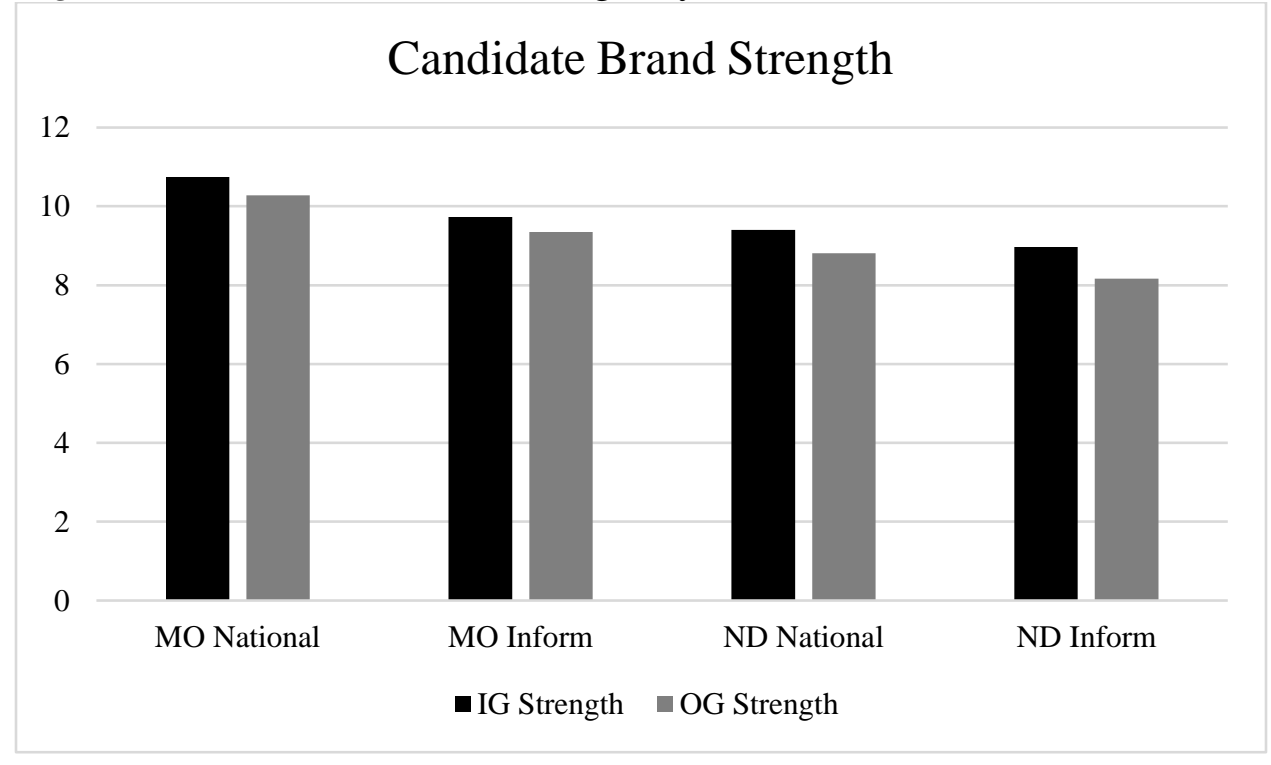

To answer H12, "Debate viewers with higher involvement, whether through

Personal Relevance or Nationalized Involvement, will have higher in-group candidate brand favorability and lower out-group candidate brand favorability relative to debate viewers with lower involvement," as well as H12a: “The presence of both Personal Relevance and Nationalized Partisan Involvement will lead to the highest in-group candidate brand favorability and the lowest out-group candidate brand favorability," a MANOVA was conducted with conditions as the factors and In-Group and Out-Group candidate brand favorability as the dependent variables. The MANOVA was not significant, $F(6,530)=1.08, p=.36, \eta^{2}=.012$, Pillai's Trace $=.025$, Power $=.44$, despite there being differences when examining the means, as shown in Table 4.13. 
Table 4.13: Candidate Brand Favorability by Condition

In-Group Favorability M(SD) Out-Group Favorability M(SD)

\begin{tabular}{lll}
\hline MO National & $5.80(5.31)$ & $-1.04(6.14)$ \\
MO Inform & $5.26(4.61)$ & $-1.62(4.85)$ \\
ND National & $4.61(5.21)$ & $-1.75(5.33)$ \\
ND Inform & $4.78(5.28)$ & $-0.07(5.60)$ \\
\hline
\end{tabular}

This variable was created based on Nielsen's (2016) political brand value variable where positive associations were +1 and negative associations were -1 , i.e., the total number of negative associations were subtracted from the total number of positive associations. To follow up the above analysis, I assessed overall brand positivity or brand negativity, which consisted of the total number of positive candidate associations or negative associations. These means and standard deviations are presented in Table 4.14. I then conducted a 4x4 MANOVA with condition as the factor and Positive In-Group Associations, Negative In-Group Associations, Positive Out-Group Associations, and Negative In-Group Associations as the dependent variables. However, this also did not reveal significant main effects, $F(12,792)=1.2, p=.28, \eta^{2}=.018$, Pillai's Trace $=.053$, Power $=.69$. Still, despite the non-significant results, the data trended in the expected directions, as visualized in Figure 4.4 which shows in-group positive associations and out-group negative associations by condition. Similar to brand strength, Missouri National, the condition with personal relevance and nationalized partisan involvement, had the highest in-group positivity and out-group negativity. 
Table 4.14: Candidate Brand Positivity and Negativity by Condition

\begin{tabular}{lllll}
\hline & $\begin{array}{l}\text { In-Group } \\
\text { Positive } \\
\text { M(SD) }\end{array}$ & $\begin{array}{l}\text { In-Group } \\
\text { Negative } \\
\text { M(SD) }\end{array}$ & $\begin{array}{l}\text { Out-Group } \\
\text { Positive } \\
\text { M(SD) }\end{array}$ & $\begin{array}{l}\text { Out-Group } \\
\text { Negative } \\
\text { M(SD) }\end{array}$ \\
\hline MO National & $7.32(4.51)$ & $1.53(1.8)$ & $3.76(3.54)$ & $4.8(3.57)$ \\
MO Inform & $6.66(3.78)$ & $1.4(1.62)$ & $2.9(2.49)$ & $4.51(3.16)$ \\
ND National & $6.11(4.35)$ & $1.51(1.56)$ & $2.68(2.69)$ & $4.42(3.81)$ \\
ND Inform & $6.12(3.92)$ & $1.34(2.28)$ & $3.41(3.48)$ & $3.49(3.1)$ \\
\hline
\end{tabular}

Figure 4.4: Positive and Negative Associations by Condition

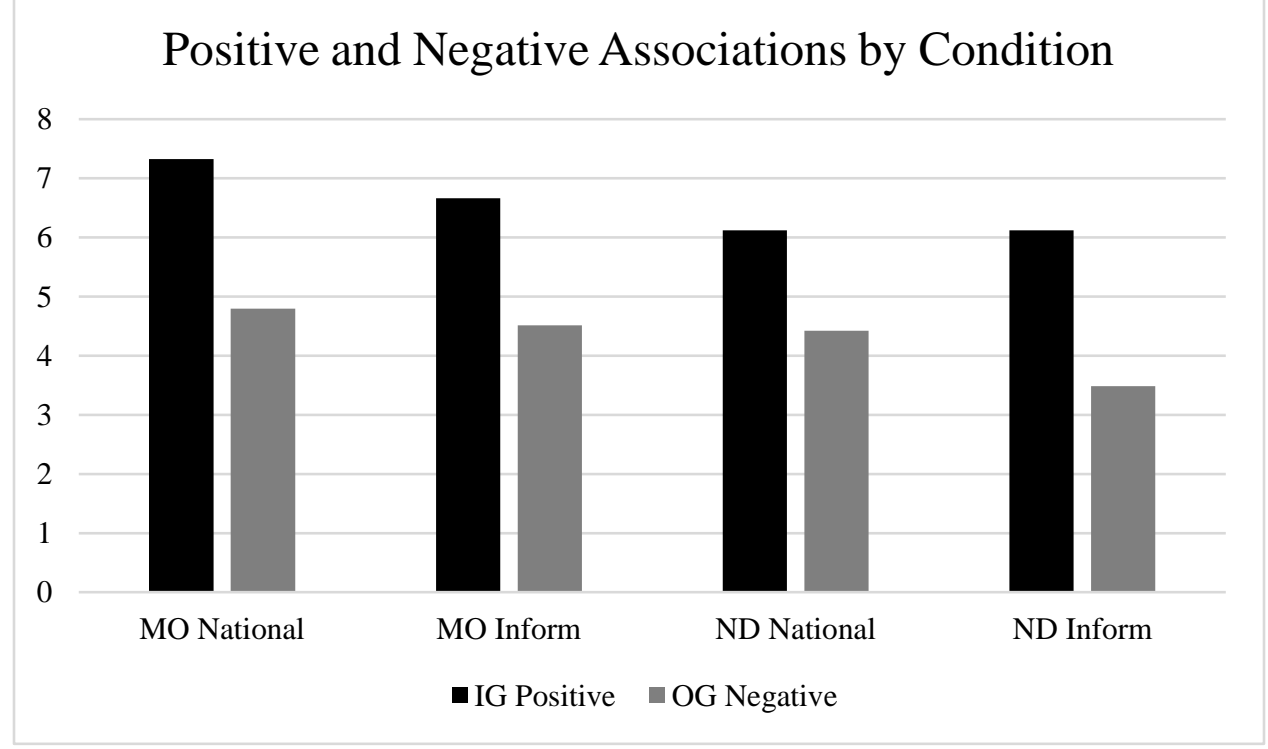

I therefore conducted post-host analyses to assess whether personal relevance and nationalized involvement, regardless of condition, could influence in-group favorable thoughts and out-group negative thoughts. To do this, I conducted two linear regressions, first accounting for gender, strength of partisanship, debate, and political interest before testing the influence of personal relevance and nationalized involvement as measured through the manipulation check variables. These results are highlighted in Table 4.15, and show that nationalized involvement, but not personal relevance, had a significant influence on the number of positive in-group brand associations, $F(6,262)=11.51, p<$ $.001, \mathrm{r}^{2}=.21, \Delta \mathrm{r}^{2}=.01$ and out-group negative associations, $F(6,262)=7.74, p<.001, \mathrm{r}^{2}$ $=.15, \Delta \mathrm{r}^{2}=.02$. The full regression tables are available in Appendix D. 
Table 4.15: Involvement and Evaluative Associations

\begin{tabular}{lll}
\hline & $\begin{array}{l}\text { In-Group Positive } \\
\text { Associations }\end{array}$ & $\begin{array}{l}\text { Out-Group Negative } \\
\text { Associations }\end{array}$ \\
\hline Being Female & $.14^{*}$ & .03 \\
Partisan Strength & $.29 * * *$ & $.17 * *$ \\
Viewing Missouri Debate & .04 & .03 \\
Pre-Debate Political Interest & -.09 & -.02 \\
Personal Relevance & .09 & .10 \\
Nationalized Involvement & $.17 *$ & $.23 * *$ \\
\hline Note: $*=p<.05, * * p<.01, * * *=p<.001$ &
\end{tabular}

As can be seen in Table 4.15, there are several interesting results for evaluative associations. First, being female was a significant predictor of in-group positive associations in debates where female candidates were present. Additionally, partisan strength was a significant predictor of producing evaluative associations. The stronger someone's sense of partisanship, the more likely they were to produce both positive ingroup associations and negative out-group associations. Finally, nationalized partisan involvement was a stronger predictor of the number of evaluative associations than political interest or personal relevance, showing the importance of nationalized partisan involvement in promoting attitudinal associations.

The final portion of my analysis in relation to involvement is to explore $R Q 5$, "Will different types of involvement make different brand element associations more salient?" Results of a 4x3 chi-square difference test were significant, $\chi^{2}(6)=54.45, p<$ .001 , indicating several interesting findings which are highlighted in Table 4.16. The nationalizing prompt did appear to promote more party-based associations, but only for North Dakota viewers. This could indicate that when viewers have low prior knowledge of a campaign and are provided the party identification of candidates as well as the national implications, then the party-brand will weigh heavily in memory. Of course, 
there were still a sizable portion of party-based associations in ND Inform, but again, this highlights that viewers of this debate did not have any prior information about the candidates or campaigns and therefore used party as a heuristic. Additionally, there were substantively more policy-based associations in both Missouri conditions compared to the North Dakota conditions, highlighting that when viewing a debate one is more familiar with (ability), and that is more personally relevant (motivation), viewers attune more to policy information. In every condition, however, person-based associations consisted of over $73 \%$ of total associations. These results largely reinforce the earlier content analytic results but allow for more nuance based on experimental design. Table 4.16 shows the totals and percentages for each content analytic category by condition.

Table 4.16: Political Brand Elements by Condition

\begin{tabular}{lllll}
\hline & MO National & MO Inform & ND National & ND Inform \\
\hline Party & $135(8.5 \%)$ & $157(12 \%)$ & $162(14.9 \%)$ & $158(13.5 \%)$ \\
Policy & $205(13 \%)$ & $176(13.4 \%)$ & $111(10.2 \%)$ & $87(7.4 \%)$ \\
Person & $1,216(76.9 \%)$ & $965(73.5 \%)$ & $802(73.6 \%)$ & $920(78.6 \%)$ \\
Other & $20(1.3 \%)$ & $11(0.8 \%)$ & $7(0.6 \%)$ & $3(0.3 \%)$ \\
Incomplete & $5(0.3 \%)$ & $4(0.3 \%)$ & $7(0.6 \%)$ & $3(0.3)$ \\
\hline
\end{tabular}

I also conducted a MANOVA where the total number of policy, party, or person brand element associations made by individuals were each dependent variables and the experimental condition was the independent variable. These results were similar to the content analysis totals by condition. Results of the MANOVA showed main effects, $F(9$, 795) $=4.12, p<.001, \eta^{2}=.05$, Pillai's Trace $=.13$, Power $=.99$. Between subjects effects were significant for Party Associations, $F(3,268)=2.73, p=.04, \eta^{2}=.03$, Power $=.66$, Policy Associations, $F(3,268)=3.16, p=.025, \eta^{2}=.035$, Power $=.73$, and approached conventional standards of statistical significance for Person Associations, $F(3,268)=2.57, p=.054, \eta^{2}=.028$, Power $=.63$. Policy associations violated Levene's 
test but passed Welch's test. When examining these results in the pairwise comparisons, North Dakota National had significantly higher party-based associations than Missouri National, North Dakota Informational had significantly lower policy-based associations than Missouri National and Missouri Informational, and Missouri National had significantly higher person-based associations than the two North Dakota conditions. These differences are highlighted in Table 4.17 and Figure 4.5. Nationalized involvement did not induce more party-based associations in Missouri but the partisan prime promoted more party-based associations in North Dakota National. The more personally relevant conditions in Missouri had significantly more recall of policy associations compared to the low involvement North Dakota condition. The condition with high personal relevance and high nationalized involvement produced the most person-based associations.

Table 4.17: Brand association means by condition

\begin{tabular}{|c|c|c|c|}
\hline & Party M(SD) & Policy M(SD) & Person M(SD) \\
\hline MO National & $1.82(1.77)$ & $2.77(3.70)$ & $16.43(8.24)$ \\
\hline MO Informational & $2.31(1.72)$ & $2.59(3.90)$ & $14.19(6.51)$ \\
\hline ND National & $2.75(1.97)$ & $1.8(2.52)$ & $13.59(7.43)$ \\
\hline ND Informational & $2.32(1.99)$ & $1.28(2.22)$ & $13.53(6.19)$ \\
\hline
\end{tabular}

Figure 4.5: Brand Elements by Condition

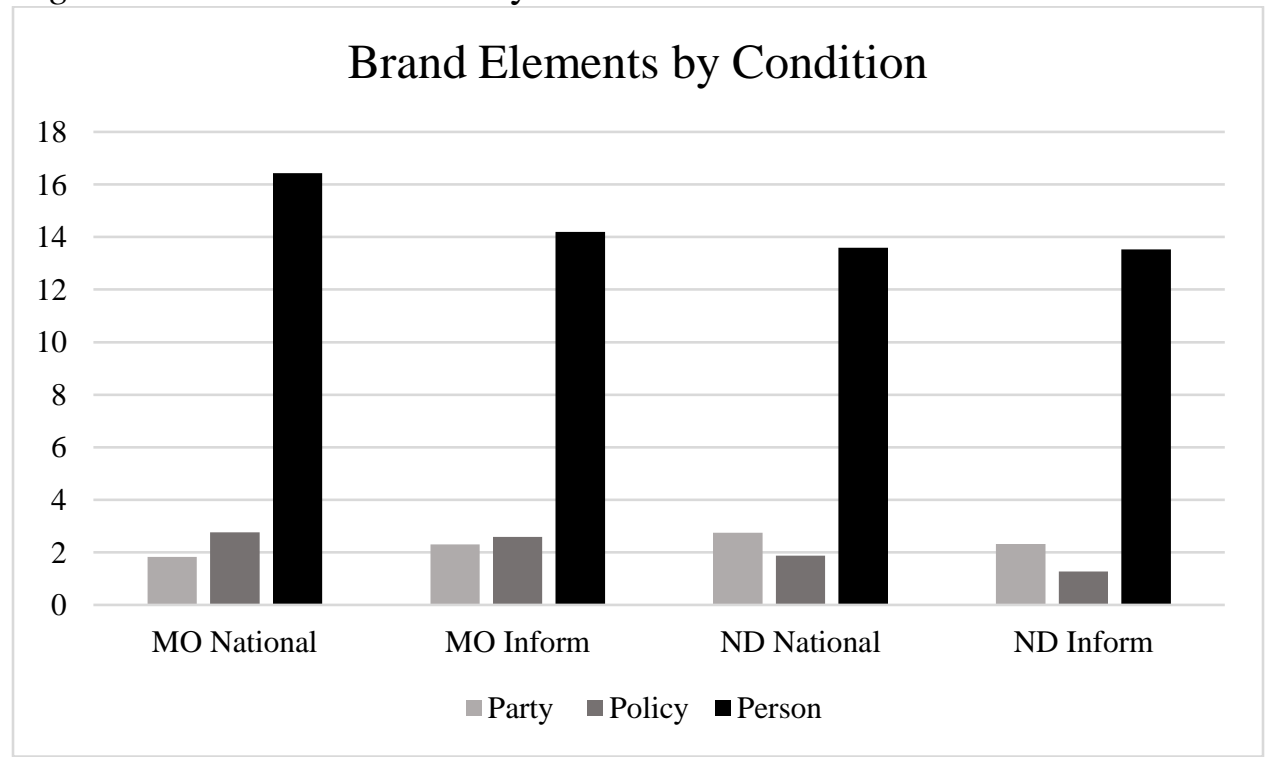


Results from the various tests discussed above reveal several key findings related to the effects of involvement on persuasion and brand associative memory. First, I found that the condition with the most expected involvement, Missouri National, which had high personal relevance and high nationalized involvement, was the condition in which participants had the most cognitive involvement in the form of the most brand associations (total brand strength). This condition also featured the most positive in-group candidate associations and the most negative out-group candidate associations. Second, I observed that brand favorability did not significantly differ by condition, although the results trended in the expected directions. Third, I found that the manipulation check variable for nationalized involvement was a significant predictor of more in-group candidate positive associations as well as out-group candidate negative associations. Finally, I observed differences in the types of brand elements emphasized in associative memory in the different conditions, with North Dakota National having the most partybased associations and the two personally relevant conditions in Missouri featuring the most policy-based associations. 


\section{Chapter V: Discussion}

This dissertation contributes to three primary areas: political branding and associative memory, persuasion and involvement, and televised debate effects. For each of these three areas, I will discuss my most important contributions. First, the primary methodology of my dissertation, brand associations, is a dynamic way to measure attribute memory from voters and a powerful predictor of attitudes toward candidates. Debate viewers offered more in-group associations than out-group associations, and more positive in-group associations than negative out-group associations. This points to a process I deem Debate Branding, where participating in a debate is more likely to boost a candidate's brand with supporters than harm the candidate's brand with detractors. Moreover, the valence of associations, i.e., being positive or negative, was subsequently shown to influence candidate evaluations. Associations overwhelmingly focused on personal-brand elements compared to policy- and party-based responses, and each brand element had a plurality of positivity in valence although party-based responses featured substantial neutral associations.

Second, my dissertation provides an important update to our understanding of the paths to cognitive involvement with persuasive messages. A core purpose of this dissertation was to emulate and extend the classic persuasion experiments related to personal relevance and elaboration (Petty \& Cacioppo, 1979; 1986). I did this through an experiment designed to manipulate personal relevance and prime nationalized involvement. My findings show continued support for personal relevance being a key factor in involvement. I also found tentative yet intriguing support for a new path to involvement in political messages: nationalized partisan involvement. When a campaign 
is personally relevant and the nationalized partisan stakes are made evident, viewers of a debate can attune more to the message which can lead to more associative recall.

Finally, my dissertation contributes to our understanding of televised debate effects, showing that subpresidential debates influence persuasive outcomes such as candidate evaluations, intention to vote for candidates, and intention to vote in elections, as well as various normative democratic attitudes such as political information efficacy, political cynicism, and elements of political interest. These three core areas of focus, political branding, persuasive involvement, and normative debate effects, contribute to persuasion, psychology, marketing, and political communication research. In this discussion chapter, I will detail how each of these areas were explored and how my findings contribute to theory and practice for each.

\section{Political Branding}

The first primary theoretical contribution of this study is in its utilization of political branding as a language and a tool to examine how televised debates influence voter memory and attitudes. Political marketing is a useful way to examine debate effects. The association task (Cwalina \& Falkowski, 2015) that I used in the post-debate survey prompted debate viewers to recall "what comes to mind when you think of Claire McCaskill?" Then, participants were asked to evaluate each of these associations for their favorability, i.e., positive, negative, or neutral. I then conducted a content analysis with coders to assess the political brand elements (Speed, Butler, \& Collins, 2015) within these associations and their focus on policy, party, and person.

I made several important observations through my analyses of brand associations. First, there were more positive in-group candidate brand associations than there were 
negative out-group associations, a phenomenon I have called Debate Branding, as debates are branding opportunities for candidates to increase their favorability among supporters. Second, the brand elements discussed by voters were overwhelmingly focused on personal-brand elements compared to party- and policy-based elements, highlighting the usefulness of viewing televised debates as political marketing events due to the centrality of candidate image. Third, the content of the brand associations related to the content of the debates, highlighting the importance of "brand matching" (Koll \& von Wallpach, 2014). Fourth, brand associations were predictors of attitudes, bolstering findings from prior research (Cwalina \& Falkowski, 2015) but in the context of televised debates. Finally, the level of involvement in a message influenced associations.

Debate Branding. The first key finding related to brand associations was the predominance of positive associations compared to negative or neutral associations. Debates increased brand equity for candidates, which is the number of associations, their favorability, and their content (Keller, 1993). As seen in Chapter IV, there were 1) overall more positive than negative associations in the full sample 2) more positive in-group candidate associations than negative out-group associations and 3) more positive associations than negative associations in each brand element category (Policy, Party, Person). Televised political debates are positive branding opportunities for candidates to market themselves to voters. This finding supports prior political communication research showing that debates have more upside than downside for candidates (Blais \& Perrella, 2008; Warner et al., 2018). In fact, debates often lead to more increases in ingroup candidate evaluations than decreases in out-group candidate evaluations (Warner et al., 2018). Similar findings were observed here, with positive changes for in-group 
evaluations having a greater effect size than negative changes for out-group candidate evaluations. Moreover, debate viewers generated more positive in-group brand associations than negative out-group associations, a process I have deemed Debate Branding. Competent candidates who participate in the marketing events of televised debates will strengthen their brand identity in the associative memory of supporters more than they will weaken it with detractors. Debate Branding could be a mechanism based on our tendencies to remember and accept things that affirm our prior attitudes (Lodge \& Taber, 2013) or our psychological preference for positive biases compared to negative biases (Garrett \& Stroud, 2014; Warner et al., 2018). Debate Branding could also be attitude reinforcement in action (Mullinix, 2015; Warner et al., 2018). The findings here are similar to a study of social-watching, where the candidate that was tweeted about the most in a presidential primary debate also experienced the most positive changes in candidate evaluations (McKinney, Houston, \& Hawthorne, 2014). In my study, participants produced more thoughts about their preferred candidate relative to the opposing candidate. Future studies will need to test if this positivity bias present in televised debates applies to other two-sided political information environments.

Political Brand Elements. Another key way in which my dissertation contributes to knowledge is in relation to the image-issue debate in political communication (e.g., Hacker, 2004a; McKinney et al., 2003; Parry-Giles, 2010). My use of the brand association task, and the subsequent coding of the associations for the brand elements of party, person, or policy, allowed me to examine what came to voters' minds when they thought of political candidates. My content analytic results showed an overwhelming majority of brand associations were about the "Person" compared to Policy and Party 
with over $75 \%$ of associations in both debates being about personal brand elements. Participants offered an average of about two policy associations, two party associations, and 15 person associations in this study. After viewing a debate full of policy arguments and positions on a number of topics ranging from healthcare to border security to tariffs, the viewers of these debates had much more to say about the personal brand elements of these candidates than they did about their policy positions. These findings are similar to a study by McKinney, Dudash, and Hodgkinson (2003), who conducted focus groups after presidential debates and found that $67 \%$ of comments pertained to candidate image while $33 \%$ pertained to issues (McKinney et al., 2003, p. 50). My study therefore found similar results in a non-presidential debate context.

The overwhelming number of person-based brand elements in my study bolsters research showing the importance of image-based evaluations of candidates (e.g., Warner \& Banwart, 2016), and that voters consider both image and issue when evaluating candidates in the campaign and in debates (Benoit, McKinney, \& Holbert, 2001; Hacker et al., 2000; McKinney et al., 2003). Participants in this study produced an average of 19 message-relevant brand associations toward combined candidates. Participants paid attention to the debate, retaining information on person, policy, and party-based brand elements. Person-based elements were simply present to a much higher extent than policy or party. Moreover, debates as a communication event are moments for viewers to assess the candidates as people. Although these debates did feature an hour of discussion of policies and current events, they also presented viewers the opportunity to assess the candidates on stage. In the brand associative memory of participants, the candidates as people weighed more heavily on their minds. 
However, when assessing policy associations, and the extent to which debates feature "candidate-controlled discourse" (Henson \& Benoit, 2009, p. 703) where candidates pursue their own agendas (Jackson-Beeck \& Meadow, 1979), these debates were successful instances of candidate issue branding as a plurality of policy associations were positive. Candidates who want to discuss policy will benefit from performing in debates, but as seen here, voters will also heavily evaluate their personal characteristics. The content analytic findings support a key argument and justification of the creation of this study: televised political debates are political marketing events that allow political candidates the opportunity to brand themselves to voters. In The Marketing of the President, Newman (1994) defined the purpose of political marketing: "The outcome of this process is the establishment of the candidate's image or the picture in voters' minds of who the candidate is and what he stands for. The candidate's image then becomes the strategic focus of his marketing strategy" (p. 87). Results from my content analysis affirm this view of politics as marketing because candidate image was so central to voter memory.

Brand Matching. Brand match is the extent to which content from a marketing message appears in the associative memory of consumers (Koll \& von Wallpach, 2014). In the current study, I observed considerable brand matching in my qualitative analysis of word frequencies. For instance, association responses such as "Has a Family; "2 Boys; Claims to represent Missourians' Claims to not be a 'party-line' politician; Wants to keep taxes low; Wants to build a wall; and Wants to get rid of Obamacare" are all responses from a participant that matched content emphasized by Josh Hawley in his debate. Although I was not able to do a quantitative content analysis of debate content or of more 
process content categories of the brand associations, the qualitative examples provided in Chapter IV show brand matching in action. There were other notable examples of brand matching. Kevin Cramer provides a particularly good example, as he worked rhetorically to align himself with President Trump, and the word "Trump" showed up frequently in the brand associations made toward him. However, this worked against him with Democratic viewers. Josh Hawley is another good example of candidate branding, as he reiterated throughout the debate that he is a father of two young boys. "Family" subsequently showed up as a frequent brand association. Claire McCaskill and Heidi Heitkamp were both successful in branding themselves as moderates, although Hawley's counter-branding of McCaskill as a "party-line liberal" did show up in associations. This highlights the clash of debates (Carlin, 1992) and their relevance as Battles for Branding.

Associations and Attitudes. The final finding to discuss in this section in relation to brand associations is in their ability to predict attitudes. I found that the evaluative nature of brand associations was a significant predictor of candidate evaluations. This is a primary contribution of my dissertation to the literature on political information processing. Cwalina and Falkowski (2015) found that as the number of positive associations for a European candidate went up, so did the support for that candidate. Similarly, I observed that positive or negative candidate brand associations were linked to higher or lower feelings toward candidates. Brand associations, and the self-evaluating of their favorability, are a powerful way in which to measure memory-based information processing toward political candidates. Positive in-group candidate brand associations were a strong predictor of higher in-group candidate evaluations. Negative in-group candidate brand associations were a strong predictor of lower in-group candidate 
evaluations. Positive out-group candidate brand associations were a strong predictor of higher out-group candidate evaluations. Negative out-group candidate brand associations were a strong predictor of lower out-group candidate evaluation. What's more, these evaluative associations were strong predictors of candidate evaluations even when accounting for the number of overall associations a participant made, showing that the positive or negative brand associations in a viewer's memory are linked to their overall evaluation of the political candidate. These findings are also important when considering the counter-branding we saw in the tables of brand word frequencies. Counter-branding and defining your opponent could lead to more negative associations which can subsequently lead to more negative attitudes. Positively branding yourself can lead to more positive associations and more positive attitudes. Televised debates are battles for branding and battles for the associations and attitudes voters will have about a candidate and their opponent.

Branding Discussion. Findings from my content analysis show that brand associations are a powerful way to measure voter cognition and the recall of political information from political messages. This study contributes to literature on memorybased candidate evaluations (Cwalina \& Falkowski, 2015; Kim \& Garrett, 2012; Lodge \& Taber, 2013; Nielsen, 2016). There are several ways to measure thoughts toward candidates, from dial-testing (Kim \& Garrett, 2012) to live-tweeting (Bramlett, McKinney, \& Warner, 2018; Houston, Hawthorne, Spialek, Greenwood, \& McKinney, 2013; Jennings, Coker, McKinney, \& Warner, 2017; McKinney, Houston, \& Hawthorne, 2014) to thought-listing (Cwalina, Falkowski, \& Newman, 2011; Hacker, 2000b; Kim \& Garrett, 2012). My study shows that examining voter memory through the lens of brand 
associative memory is an interesting and meaningful way in which to measure how people process and evaluate the information they receive from political debates.

Moreover, the brand association task is a measure of elaboration and cognitive involvement. Petty and Cacioppo (1986) note that "the thought-listing technique has proven to be an important supplemental tool in tracking the amount and type of cognitive activity involved in persuasion and resistance" (p 38) and my study is able to meet at the intersection of the fields of persuasion, branding, and political cognition. The fields use similar methodologies to measure similar processes. The utilization of the brand association task along with branding terminology and measures of brand strength and brand favorability allowed me to assess the second core component of my dissertation: persuasive involvement.

\section{Involvement}

The second theoretical contribution of my dissertation relates to involvement in persuasive messages. I was able to explore this through my use of brand associations as a proxy of elaboration. Specifically, I measured brand strength, which was the total number of thoughts offered by debate viewers, and brand favorability, which was their selfassessment of each association's evaluative nature.

In classic persuasion literature, there are various routes that lead to elaboration. The first is personal relevance, or outcome-involvement, which is the extent to which something can affect your personal life (Cho \& Boster, 2005; Johnson \& Eagly, 1989; 1990; Petty \& Cacioppo, 1979; 1986). Two others are impression-based involvement, which is caring about something based on what people will think of you, and valuesbased involvement, which is caring about an issue because it matters to your moral code 
(Cho \& Boster, 2005; Johnson \& Eagly, 1989; 1990). As I theorized earlier, these traditional explanations of involvement may not fully capture why people elaborate on political messages.

In political communication and competition, individuals are motivated by their partisan social identities (Greene, 1999; 2002; 2004; Mason, 2018). Competition between the political parties is driven in part by values, i.e., beliefs about climate change or abortion, and driven by outcomes, i.e., legislation impacting healthcare or roads, but it is also driven by a "partisan team-based mindset" (Mason, 2018, p. 43) where the competition between the two parties is important because of our rooting interests. Additionally, our rooting interests are guided by ties to the national political parties more than local or state parties (Hopkins, 2018), and today we have "elections dominated by national partisan identities" (Hopkins, 2018, p. 21). Therefore, I was intrigued by the prospect of examining this nationalization of political social identities in the context of persuasion. This led to my experimental design, where I first manipulated classical personal relevance, through whether an individual viewed either a Missouri debate (their presiding state) or a North Dakota debate. I then primed national partisan involvement, through my experimental prompt, to examine these nationalized partisan social identities.

Involvement and Branding. My core finding related to involvement is that the nationalization of politics matters the most when a race is personally relevant. In my study, the condition of high personal relevance and nationalized partisan involvement, which was Missouri National, had the most brand associations overall as well as the most toward both the in-party and out-party candidates. That is, participants who viewed the Missouri debate and were told of its national stakes had the most cognitive involvement 
as measured in the amount of brand association words in the post-debate survey. These differences were significant in comparison to both North Dakota conditions but not Missouri Informational, which itself did not have significant differences between the North Dakota conditions. The results did not fully support the theory of nationalized partisan involvement as the differences did not always achieve conventional levels of statistical significance. Still, the differences were as hypothesized, with Missouri National featuring the highest elaboration, Missouri Informational and North Dakota National resulting in roughly equivalent amounts of elaboration, and North Dakota Informational resulting in the least elaboration. These trends were evident when examining overall associations, in-group associations, and out-group associations. The findings here suggest that personal relevance still matters in relation to elaboration, but that in the context of political messages it can be bolstered by nationalizing the partisan stakes. When a campaign was personally relevant, and voters were notified of the national partisan stakes, they paid close attention to the message, recalled more campaign information from their associative memory, and advocated more for their team and against the other team.

Analysis of Manipulation Checks. Clear differences in the effect of the experimental design are also evident in the differences by condition based on the two manipulation check variables for personal relevance and nationalized involvement. The personal relevance variable was significantly higher for both Missouri conditions relative to the North Dakota conditions, highlighting the personal relevance of the Missouri debate for viewers of the debate living in Missouri. Additionally, personal relevance of the North Dakota debate was higher for the nationalized viewers relative to the 
Informational North Dakota viewers, indicating the ability of nationalization to make a debate personally relevant. Still, personal relevance was significantly lower for ND National viewers than for either Missouri condition. This was not the case with Nationalized Involvement. Here, the differences between the two Missouri conditions and ND National were not significant, while the nationalized involvement was significantly lower for ND Informational relative to the other three conditions. As measured through the manipulation check variable, nationalizing the North Dakota Senate race made it seem just as important to those viewers as the Missouri race was to Missouri viewers.

Involvement and Brand Favorability. Another core contribution of my dissertation relates to the interplay of involvement and brand favorability. First, the experimental conditions did prompt differences in the brand favorability toward candidates, although these differences were not significant, likely due to noise (error) in the estimation of these variables. Still, the differences trended in the involvement-based directions, with the Missouri conditions featuring an average of .89 more positive ingroup candidate associations and .74 more negative out-group associations than North Dakota, highlighting the ability for involvement to promote more polarized elaboration. In every condition, however, there were more positive in-group associations than negative out-group associations, and more overall in-group associations than out-group associations, providing further support to the concept of Debate Branding. Candidates were more likely to positively benefit than be penalized, and this was the case in every experimental condition. Although there were more negative out-group associations in the more involved conditions, there was still more positive in-group associations, showing support for Debate Branding even in high involvement conditions. When partisan social 
identities were activated, participants enjoyed rooting for their own candidate more than rooting against the other candidate.

I also conducted further analyses to assess the influence of the manipulation check variables of personal relevance and nationalized involvement on brand favorability. First, I found that nationalized involvement was a better predictor of both positive in-party associations and negative out-party associations than was the experimental condition of a participant. That is, one's feelings of the national importance of a race was a predictor of attitude-consistent evaluative associations towards candidates regardless of experimental condition. Second, I found that nationalized involvement, more than personal relevance, influenced the number of evaluative associations from participants (i.e. positive or negative brand associations toward a candidate). The results were strongest for out-group negative associations, a sign of negative partisanship (Iyengar et al., 2012; Mason, 2018), although nationalized involvement also generated more positive in-group associations as well. These results echo a study by Warner (2018), who found that the use of national partisan media promoted in-group increases and out-group decreases in candidate favorability during a mid-term Senate campaign (p. 13). In my study, feelings of national involvement did the same with candidate thoughts.

\section{Brand Elements and Involvement}

When examining brand elements by condition, I found that North Dakota National featured the most party-based associations, showing potential support for the effect of the nationalizing prime on viewer brand associations. Additionally, I found that the personally relevant conditions, Missouri National and Missouri Informational, featured the most policy associations, showing that personal relevance led to more issue- 
relevant thinking, providing support for prior research (Petty \& Cacioppo, 1986). The differences in which attributes weighed most heavily in voters' minds, along with the differences in brand strength based on experimental condition, highlights the continued importance of priming in political research (Lodge \& Taber, 2013).

\section{Normative Effects of Senate Debates}

The final primary contribution of my dissertation is in investigating whether down-ballot, subpresidential televised debates, in the form of U.S. Senate debates, would influence normative political attitudes in a similar or divergent manner as presidential debates have been shown to do. The academic literature on presidential debate effects is robust and expansive across decades (see McKinney \& Carlin, 2004), but the literature on subpresidential debates is lacking. This is regretful as there are vastly more subpresidential debates than presidential debates. Every four years, there are a dozen or so presidential primary debates for the non-incumbent party and three general election presidential debates. Contrast that to Senate debates. C-SPAN's video archive features 46 general election U.S. Senate debates from 2018, which is surely not exhaustive but only the debates which were archived by C-SPAN (C-SPAN, 2019).

It is unclear why there are so few studies related to subpresidential debates. It may be the case that presidential debates and presidential politics simply garners most of the attention, particularly in presidential election years. It could also be because subpresidential debates do not receive comparable levels of media coverage (Schroeder, 2008). In recent years, however, Senate debates are broadcast on cable news networks, and the social media environment allows for debates to be streamed online and for 
moments to go viral. Still, in relation to presidential debates they are less salient to voters (Fridkin \& Kenney, 2011).

These characteristics actually provide important theoretical reasons to examine non-presidential debates: as Chaffee (1978) famously posited, debates with lesser-known candidates are the debates which can matter the most. Therefore, a purpose of this study was to assess the influence Senate debates would have on several political attitudes: political learning, vote intentions and preference, candidate evaluations, political cynicism, political interest, and political information efficacy. In the following discussion, I will address important findings for each normative and persuasive attitude.

Political information efficacy. The first compelling normative attitude to discuss is political information efficacy (PIE), which is the confidence one has in their ability to talk about and engage in politics (Kaid et al., 2007). Shifts in PIE after viewing presidential debates makes sense as we live in a presidential-centric system. Viewing a presidential debate between the candidates who could become the leader of the country increases voters' confidence in their ability to discuss politics because, for the typical citizen, knowing about presidential politics is essentially knowing about politics. However, with Senate debates it could be different. There are 535 members of Congress and 100 Senators, to say nothing of the local elections and initiatives that populate the ballot. A single debate between two candidates vying for one single Senate seat may not be expected to lead to large shifts in PIE. However, in my analysis I found that PIE had the greatest shift from pre- to post-debate viewing of any of the normative attitudes. PIE featured a mean increase of 0.74 points and an effect size of $.69\left(d_{z}\right)$. This was a shift of almost a full point on a 1-7 scale, up to a mean of 3.97, which is just below the "neither 
agree nor disagree" response option. Moreover, the item, "If a friend asked me about the midterm elections, I feel I would have enough information to help my friend figure out who to vote for" had a mean shift of 1.18 points. The act of viewing a single debate, from one Senate race, made people more confident about their ability to discuss the midterm elections as a whole. This, perhaps more than any other normative attitude measured, highlights the power of televised political debates. Senate debates make people more confident in their ability to discuss politics.

Additionally, in McKinney and Warner's (2013) analysis, PIE's average increase was .17. In the primary debates they studied, PIE increased by an average of .42 (McKinney \& Warner, 2013, p. 249). This seems to indicate that Senate debates are more similar to presidential primary debates than general election presidential debates, which is an interesting comparison. Primaries are when people are first tuning into the campaign, and a debate can provide them with a wealth of information they did not yet have. Similarly, most people do not follow Senate campaigns as closely as the presidential general election, and viewing a Senate debate can provide them with enough information to make them more confident in their campaign knowledge.

A post-hoc analysis showed that PIE comparably increased in all four experimental conditions. The act of viewing a single debate, even when it is not personally relevant or seen as nationally important, still increased individual's confidence in their ability to talk about politics. People living in Missouri who viewed a North Dakota Senate debate, even without being informed of the national significance of the North Dakota election, experienced the same gains in PIE as people who viewed their instate debate. These findings have implications for educators around the country. Even if 
students find a debate boring or unimportant, they are still likely to come away from it more confident in their political knowledge.

Voting. The second normative attitude to discuss is voting intentions. It is wellestablished that presidential debates can shift candidate preferences (Benoit et al., 2003; Carlin \& McKinney, 1994; McKinney \& Carlin, 2004), and while in presidential elections many voters have a preference by the time of the debates (Schroeder, 2008), for undecided voters the debates can be the most important moment for voting decisions during the election (Carlin \& McKinney, 1994) and close Senate races are likely to feature a high amount of undecided voters (Kahn \& Kenney, 1999). When examining voting preference strength, my study featured an extremely high number of undecided voters prior to viewing a debate in part due to the experimental design. Participants did not know who the candidates were from North Dakota, and therefore could not determine who they were likely to vote for in the pre-debate questionnaire. Although one might assume that, absent prior knowledge, respondents would default to partisanship and select the candidate from their own party, they did not. Ninety-four percent of North Dakota viewers were undecided in the pre-debate survey. Even in the Missouri condition, approximately half (49.6\%) of the sample were undecided before viewing the debate, although the smaller amount of pre-debate undecided voters in Missouri does highlight the personal relevance of the campaign. Still, both debates featured decisive shifts in voting preference strength from pre- to post-debate.

Interestingly, post-debate voting preference strength had comparable means for both debates. Although there was a much higher amount of undecided viewers in North Dakota prior to the debate, by the end of the debate both North Dakota and Missouri 
viewers had similar vote intentions. This highlights a "catch-up effect" previously observed in debates (Warner, Bramlett, Hoeun, Manik, \& Bolton, 2018) as well as a potential plateau effect for vote intention decisions. In their study, Warner et al. (2018) found that viewers of early presidential primary debates had greater increases in normative attitudes than viewers of later primary debates, positing this was due to a "catch-up effect" where viewers who tune in to politics for the first time in an election season had more room for shifts in attitudes. Similarly, in my study, viewers of a debate where the candidates were unknown (North Dakota) had more catching up to do than viewers of the debate where the candidates were better known (Missouri). After viewing a debate, the average viewer's vote intention was between leaning toward and probably supporting a candidate. These results were similar when looking at in-group candidate voting likelihood, with the average respondent in both debates falling between being "somewhat likely" and "likely" to vote for their in-party candidate. The fact that the postdebate candidate voting preferences were comparable across the debates suggests two elements of persuasion as defined by Miller (2002): attitude formation in North Dakota, and attitude formation plus reinforcement in Missouri, with each leading to a plateau situated between "leaning" or "probably" voting for a candidate. Senate debates, like presidential debates, are important moments for voters to create voting preferences. Furthermore, because Senate campaigns are less salient than presidential campaigns (Fridkin \& Kenney, 2011), Senate debates can reach a more undecided audience and potentially exert larger effects compared to presidential debates.

An additional component of the debates' influence on voting intentions was on participants' likelihood of voting in the midterm elections. Viewers of both debates, 
Missouri, and North Dakota, reported a higher likelihood to vote in the midterm elections, showing that debate viewing can potentially increase turnout or turnout intention. This finding is fascinating particularly in the context of the North Dakota debate. Missouri voters who viewed a North Dakota debate between candidates they could not vote for were still more likely to vote in the midterm elections after viewing it. Further, a posthoc analysis found that viewers who received a nationalizing prime had higher shifts in likelihood to vote in the midterm elections than those who did not, potentially showing how nationalization can boost turnout.

Candidate evaluations. I wanted to explore whether Senate debates would lead to similar or divergent shifts in candidate evaluations compared to presidential debates (McKinney \& Warner, 2013). I did find shifts in candidate evaluations, and these results are presented in two ways. First, by in-group/out-group feelings, where feelings toward the Democratic candidate for Democratic voters and feelings toward the Republican candidate for Republican voters were merged. This was done based on a prior study (Warner et al., 2018). Second, by examining feelings toward each individual candidate by members of both parties.

When examining candidate feelings on an in-group/out-group basis, it can be seen that feelings toward the in-group candidate increased more, by a positive average of 15 degrees, than feelings toward the out-group candidate did, which decreased by an average of 3 degrees. The effect size was greater for in-group increase as well. These results point toward debates being moments that serve candidates in increasing their support from likeminded partisans. When looking at it by candidate and party, similar results are evident with a few caveats. Most notably, out-group candidate feelings decreased in 3 of the 4 
relevant categories (Democrats:Hawley, Democrats:Cramer, Republicans:Heitkamp). Republican viewers of the Missouri debate, however, saw an average increase of 5 degrees in feelings toward Claire McCaskill. These results are comparable to the metaanalysis by Warner et al. (2018) which found some instances of out-party candidate depolarization, as seen here with Republicans toward McCaskill, but more instances of out-party candidate polarization, as seen with the other three candidates. When considering why the debate depolarized Republican viewers toward McCaskill, there are some interesting possibilities. First, it could be the power of incumbency and familiarity. Second, from a political marketing perspective, she branded herself as a moderate and independent. Her rhetorical appeals and style may have appealed to out-party voters.

Another interesting result when considering candidate evaluations is the starting point for North Dakota viewers. For each case, the pre-debate feeling thermometer mean fell between 45 and 52 degrees. In the survey questionnaire, respondents were told that marking " 50 " indicated neutral or undecided feelings. The averages falling between 45 and 52 degrees indicates a high number of people placing their feelings in the range close to the neutral 50 degrees. After viewing the debate, however, feelings toward candidates shifted to comparable in-group/out-group feelings with the Missouri debate candidates. Similar to voting preferences, North Dakota viewers caught up with Missouri viewers from pre- to post-debate viewing. Post-debate candidate evaluations for in-group and outgroup candidates were similar in both debates.

Debate information acquisition. In presidential debates literature, it is wellestablished that voters learn from watching debates (Benoit \& Hanson, 2004; Benoit et al., 2003; Jamieson, 2015). Further, debates with lesser known candidates can generate 
more learning (Holbrook, 1999), and debates can inform about candidate characteristics in addition to issues (McKinney et al., 2003). Based on this literature, it was worth examining if Senate debates, with lesser known candidates, would also prompt learning. With lesser known candidates and lesser known issues there is more room to grow. In my analysis, I did find significant information acquisition even when accounting for demographic variables. Further, one's motivation, in the form of how much they elaborated during the debate, as well as their ability, in the form of how much pre-debate civics knowledge an individual had, were significant predictors of information acquisition from a debate. This supported prior research (Jennings et al., 2018) examining cognitive characteristics of individuals that can promote information acquisition from political debates. There were also no significant differences in the average number of correct post-debate quiz answers based on which debate was viewed.

Political cynicism and interest. Two other important normative attitudes are political cynicism and political interest. Presidential debates can decrease cynicism (Jamieson, 2015; McKinney \& Warner, 2013). In McKinney and Warner’s (2013) analysis of multiple presidential debate cycles, their study found an average decrease in cynicism of .15 points (p. 249). I found marginal shifts for both cynicism and interest. There was a decrease in cynicism of 0.10 points, with an effect size of .14 $\left(d_{z}\right)$. While this is not a sizable shift in cynicism based on the effect size, the slight decrease is still a positive shift when considering normative attitudes and is comparable to the McKinney and Warner (2013) analysis at the presidential level. Viewing a political debate between two candidates for Senate, even if not your own state's candidates, can make individuals feel better about the political process. Political interest had a similar shift in attitudes, 
with an increase of 0.10 points and an effect size of .12. However, in this case the increase only approached conventional levels of statistical significance $(p=.055)$, and part of this may be due to the measurement error discussed in Chapter III. When collapsing the 1-7 scale to a 1-5 scale, the overall increase in political interest was significant, which indicates that there was more movement between the end and middle points. Although the overall increase in interest on the 3-item scale was not significant, there was a significant shift in the second item, "I follow politics closely," which had a mean increase of .27 points. Political interest may be stable from before viewing a debate to afterwards, but one's feeling of how closely they follow politics can shift.

\section{Summary}

In this discussion section I outlined several core contributions of my dissertation to the literature. First, the use of political branding as a language and tool with which to assess voters' perceptions and attitudes toward candidates. Debates are political marketing events that allow for Debate Branding: a process through which participating in a debate allows candidates to positively brand themselves in the minds of supporters. Debates also allow candidates the opportunity to promote personal-brand elements, both for themselves and their opponents. The second core contribution of this dissertation is that brand favorability, i.e. positive in-group brand associations, is a significant predictor of candidate evaluations. This provides scholars with another effective strategy to measure voter memory processes in relation to attitudes. Third, involvement in a political message can be prompted through nationalized partisan involvement, an updated way of viewing involvement which contributes to our understanding of political communication in the contemporary partisan environment. Building upon classic elaboration likelihood 
literature, I found that involvement is highest, in the form of total brand associations made toward candidates, when a campaign is not only personally relevant but also nationally important to a voter. My third core contribution is related to the second in that nationalized involvement, in the form of the variable (not the conditions) was a significant predictor of not only more positive in-group candidate brand associations but also more negative out-group brand associations. This has implications for polarization as well as media promotion for states featuring high-stakes Senate races (Warner, 2018). The fifth and final core finding of my dissertation is in relation to the normative effects of debates. In this study I observed that watching a Senate debate can substantively increase political information efficacy while also prompting information acquisition, highlighting the importance of debates in their ability to not only provide political information to voters but also improve voters' sense of self-confidence in their political knowledge. Watching these debates also prompted shifts in voting intentions and candidate evaluations, with marginal shifts in political cynicism and political interest. The findings presented in this study highlight contributions to political debates, persuasion, and branding. In the next section, I will discuss practical implications.

\section{Connecting Theory to Praxis}

In this section I will offer brief thoughts on the practical implications of this study. First, Senate debates, like presidential debates, promote positive changes in normative democratic attitudes. Parents and civics teachers around the country should be eager to promote televised debates when they are on the air. This is particularly true with subpresidential debates. Presidential debates are already covered on every major network. Educators, media professionals, and parents should make efforts to promote 
subpresidential debates to inform voters. Television programming planners should look to host and broadcast televised debates during election season. Second, candidates in competitive races should be eager to participate in debates, even if they are not presidential candidates. Results from this study indicate that there are more positive benefits for candidates than downsides. While the prompt of nationalization did increase more negative associations toward the out-party candidate, it also prompted more positive associations toward the in-party candidate, and there were more positive in-party associations than negative out-party associations. Additionally, in the overall study there were 1) more total associations toward in-group candidates than out-group candidates and 2) more positive associations toward in-group candidates than negative associations toward out-group candidates. Participating in a debate will help competent candidates more with their party than it will hurt them with the other party.

This study has practical implications for social scientists. The current study contributes to the methodological literature on branding (e.g., Aaker, 1996; Cwalina \& Falkowski, 2015; Keller, 1993; \& Nielsen, 2016) in the political context as well as elaboration and involvement in persuasive messages (Cho \& Boster, 2005; Johnson \& Eagly, 1989; 1990; Petty \& Cacioppo, 1986). Brand associative memory is a fascinating way to measure how consumers or voters recall information, and it allows for participants to offer their own thoughts in a more free-flowing manner. It also captures the memory processing of voters, providing a useful tool for measuring the link between recall and attitudes. This study, by examining brand associative memory, brings several areas of social science into conversation with one another - showing that the disciplines of 
political communication, consumer marketing, and traditional persuasion have overlap and that all disciplines should work to communicate more with one another.

Finally, this study has electoral implications and contributes to understanding our nationalized political environment. If a civic organization, campaign, or television company wants voters to care about a campaign in their state, it is important to let people know of the nationalized partisan stakes. The next time that a state features a high-profile Senate campaign, such as Maine, Colorado, or Alabama in 2020, organizations and campaigns should emphasize to voters how important the race is to the entire country. This can promote more engagement (as shown in the brand strength for Missouri National), closer attention to policy information (as evidenced in the number of policy associations in Missouri), and more awareness of the importance of the campaign. It could also be a double-edged sword, however, by promoting more polarization via higher out-group candidate negativity. Moreover, the act of priming nationalization, as was done in the current study, is no substitute for the underlying electoral nationalizing trends (Hopkins, 2018). Nationalized voting is in part about straight-ticket voting for local, state, and national offices based on nationalized perceptions of the parties (Hopkins, 2018). As shown in my study, nationalizing the stakes of a campaign will reinforce partisan involvement but if a candidate presides in a state where their partisans are outnumbered by the other party, nationalization could backfire. In fact, an outcome of the 2018 elections as a whole was that "the red states became redder" and the "blue states became bluer" (Grossmann \& Hopkins, 2018, p. 570) and this was evident in the outcomes of the two Senate campaigns featured in this study. Incumbents Heidi Heitkamp and Claire McCaskill both lost to their GOP opponents, as "all four of the Senate seats Republicans 
won in 2018 were in states Donald Trump had carried in 2016" (Carson \& Hitefield, 2018, p. 545). Nationalization is an important strategic tool for campaigns in states where electoral headwinds favor them, and my study presents one way in which to promote nationalized partisan stakes.

Although Republicans did increase their majority by two seats, the nationalizing prompt in my study held true. If Heitkamp, McCaskill, and one other incumbent Democrat such as Bill Nelson or Joe Donnelly had all won, the Senate would have been 50-50 instead of 53-47. These high-stakes Senate campaigns were crucial in deciding the majority in the Senate. Moreover, the results of the two campaigns were close particularly in comparison to 2016. Trump won North Dakota by 35.7 points in 2016 but Heitkamp only lost by 10.8 (Coleman, 2018). Trump won Missouri by 18.5 points in 2016 but McCaskill only lost by 6 points in 2018 (Coleman, 2018). These election results, when compared to the presidential campaign, highlight the inherent differences in Senate campaigns to presidential campaigns, the importance of incumbency, and the importance of Senate campaign communication.

\section{Limitations and future directions}

There are several limitations to discuss before assessing future directions. First, statistical power was a concern with some of the noisier tests of the effects of involvement on brand strength and favorability. Furthermore, it would have added to the generalizability of results if this study could have been conducted simultaneously in North Dakota to mirror the design of this dissertation. In other words, I would have liked to have had another sample featuring North Dakota college students viewing the North Dakota debate and the Missouri debate. Third, this study did not examine the differences 
in personal relevance and nationalized involvement for a Senate vs. gubernatorial debate - it is not clear that Senate debates should be expected to behave similarly to other subpresidential electoral contexts. Fourth, the use of a convenience sample influences generalizability. Although Benoit et al. (2003) did observe that there were no differences in effects based on college student vs. adult samples, there are other features of convenience samples that could limit the generalizability of my findings, such as lower political interest or partisan strength among college students relative to the adult population. Further, there was incentive for participants to view the debate, as they were participating for extra credit.

An additional limitation is that I was not able to assess the decay of debate effects. I made efforts to conduct a longitudinal study, but only 26 participants completed a follow-up survey when I sent it out three weeks after Election Day 2018. In future studies, with more funding, I will assess longitudinal effects of debate viewing. Another limitation is that every debate could not be shown live, and in future studies I will work to show each debate live when possible. Moreover, when considering the debates themselves, one limitation is in their presentation and style. The Missouri debate had elements of town hall and panelist formats, with questions from journalists as well as citizens. The North Dakota debate only featured questions from journalist panelists. Additionally, production quality differed, with the Missouri debate being produced by PBS and the North Dakota debate being on a local television network. The North Dakota campaign originally had a debate scheduled that would be moderated by PBS' Judy Woodruff, just as Missouri's was, but it was canceled due to the Brett Kavanaugh confirmation vote (Dura, 2018). Still, the two debates did feature similar candidate 
characteristics, such as an incumbent female Democratic senator and an office-holding male GOP challenger.

Future research should also pair content analysis that systematically codes the debate content and brand associations for more specific categories. This would allow for a robust analysis of brand match (Koll \& von Wallpach, 2014). Although I was not able to do this, I was able to conduct a thorough content analysis of broad brand element categories which yielded some intriguing findings. Future research should also apply the design of this study to political advertisements and other political stimuli to assess the effects of personal relevance and nationalized involvement in contexts beyond debates.

There are many additional future directions for the research program established in this dissertation. First, I will continue to make use of the brand association task in other contexts such as presidential debates, political comedy, political advertising, and consumer advertising. It is an effective way to measure memory-based recall of brand attributes whether that be a political candidate, nonprofit organization, or consumer product. I have also established a research program focused on subpresidential campaigns. I will continue to examine how political communication phenomena at the non-presidential level inform, persuade, and engage voters. Additionally, this study highlights the importance of clearly defined and manageable code books for human content analysis. My code book was simple, with one variable and three mutually exclusive clear categories (party, policy, person). Due to this, I was able to achieve exceptional reliability from my coders in both debate samples. The content analysis would have been more difficult if I had had the coders determine the favorability of responses, but I was able to have participants self-report favorability. Future scholars 
conducting content analyses should similarly think of the most efficient way in which to answer their research questions. Finally, this research project allows me to be in a position to opine on debates in subsequent election cycles as a scholar and pundit. I will also seek to analyze subpresidential debates in subsequent election cycles in the name of replicability. While there were intriguing findings in the present study, future studies are needed in different election cycles, with different presidents and national political climates to assess the generalizability of claims about the effects of subpresidential debates. Additionally, I intend to further analyze national involvement in the nationalized political environment.

\section{Conclusion}

Televised debates are optimal political branding opportunities for campaigns and candidates to brand themselves in the minds of voters. Televised debates offer more opportunities for positive branding than negative branding, a phenomenon I have called Debate Branding, although there are certainly opportunities for counter-branding of the opponent as well. In the debates studied here, there were more in-group positive thoughts than out-group negative thoughts, showing the positive branding power of televised Senate debates. Candidates should not be afraid to participate in debates as they can improve their personal, policy, and party brand associations in the minds of voters. Televised debates are sources of information that improve the political information efficacy of voters. The act of watching a single debate makes individuals more confident in their ability to discuss the entire election season. Televised debates inform voters about political issues and persuade voters on candidate preferences and evaluations. 
Brand associative memory is a novel way to measure what voters remember about political candidates, how they evaluate those attributes, and how the recollection of these attributes can influence attitudes toward candidates. Political debates provide voters with a lot of information that they retain and recall in associative memory, at least in the short term. The use of human coding for brand elements allows for insights into the types of associations that are made. In the current study, it was shown that after viewing a televised political debate, voters were far more likely to conjure person-based associations over party- or policy-based associations, emphasizing the notion of televised political debates as political marketing events. Scholars should continue to examine political cognitive processes in relation to political communication events. Associative memory is a useful lens through which to examine how individual voters process information, making it an appropriate method for researchers as well as campaigns to use to better understand voters. Newman (1994) posited that "successful political campaigns today have the same consumer focus as successful businesses. This means that the political campaign begins and ends with the voter in mind" (p. 137).

Finally, involvement in a persuasive message can be assessed in a number of ways, and in this study I introduced nationalized partisan involvement. As politics increasingly becomes nationalized (Hopkins, 2018), campaigns and TV networks can increase interest in Senate, congressional, and gubernatorial campaigns by reiterating their national implications. The 2020 election cycle is already on the horizon and once again the attention is focused on presidential politics. As this dissertation showed, however, we should pay more attention to subpresidential debates for their political marketing power, normative influences, and persuasive potential. 


\section{References}

2018 Senate. (2018, June 28). Retrieved from

http://www.centerforpolitics.org/crystalball/2018-senate/

Aaker, D. A. (1996). Building strong brands. London: Simon \& Schuster UK Ltd.

Abramowitz, A. I. (1978). The impact of a presidential debate on voter rationality. American Journal of Political Science, 22, 680-690.

Abramowitz, A. I., \& Segal, J. A. (1992). Senate elections. Ann Arbor: University of Michigan Press.

Airne, D., \& Benoit, W. L. (2005). 2004 Illinois U.S. Senate debates: Keyes versus Obama. American Behavioral Scientist, 49(2), 343-352. doi:10.1177/0002764205279721

Almond, G. A., \& Verba, S. (1963). The civic culture: Political attitudes and democracy in five nations. Princeton, NJ: Princeton University Press.

Anderson, J. R. (1983). A spreading activation theory of memory. Journal of Verbal Learning and Verbal Behavior, 22(3), 261-295.

Associated Press. (2012, October 23). Mourdock talks rape, pregnancy, and God's plan. Retrieved from https://www.politico.com/story/2012/10/mourdock-rapepregnancy-and-gods-plan-082795

Auer, J. J. (1962). The counterfeit debates. In S. Kraus (Ed.), The great debates: Carter vs. Ford, 1976 (pp.142-150). Bloomington: Indiana University Press.

Auer, J. J. (1981). Great myths about the great debates. Speaker and Gavel, 18, 14-21.

Benoit, W. L. (2014). Political election debates: Informing voters about policy and character. Lanham, MD: Lexington Books. 
Benoit, W. L., \& Hansen, G. J. (2004). Presidential debate watching, issue knowledge, character evaluation and vote choice. Human Communication Research, 30, 124144.

Benoit, W. L., Hansen, G. J., \& Verser, R. M. (2003). A meta-analysis of the effects of viewing U.S. presidential debates. Communication Monographs, 70(4), 335-350. http://doi.org/10.1080/0363775032000179133

Benoit, W. L., McKinney, M. S., \& Holbert, R. L. (2001). Beyond learning and persona: extending the scope of presidential debate effects. Communication Monographs, 68, 259-273.

Bennett, W. L., \& Iyengar, S. (2008). A new era of minimal effects? The changing foundations of political communication. Journal of Communication, 58, 707-731. doi:10.1111/j.1460-2466.2008.00410.x

Bennett, W. K., \& Pfetsch, B. (2018). Rethinking political communication in a time of disrupted public spheres. Journal of Communication, 68, 243-253. doi:10.1093/joc/jqx017

Berenson, T. (2016, October 28). Illinois sen. Mark Kirk mocks rival's Asian heritage in debate. Retrieved from http://time.com/4548902/illinois-mark-kirk-tammyduckworth-racial/

Bhattacharya, B. C., \& Sen, S. (2003). Consumer-company identification: A framework for understanding consumers' relationships with companies. Journal of Marketing, 67, 76-88. 
Blais, A., \& Perrella, A. M. L. (2008). Systemic effects of televised candidates' debates. The International Journal of Press/Politics, 13(4), 451-464. doi: $10.1177 / 1940161208323548$

Bloom, M. H. (1973). Public relations and political campaigns: A crisis in democracy. New York: Thomas Y. Crowell Company.

Bramlett, J. C., McKinney, M. S., \& Warner, B. R. (2018). Processing the political: Presidential primary debate "live-tweeting" as information processing. In B. R. Warner, D. G. Bystrom, M. S. McKinney, \& M. C. Banwart (Eds.), An unprecedented election: Media, communication, and the electorate in the 2016 presidential campaign (pp. 169-188). Santa Barbara, CA: Praeger.

Brasher, H. (2003). Capitalizing on contention: Issue agendas in U.S. Senate campaigns. Political Communication, 20, 453-471. doi:10.1080/10584600390244194

Briz, A., Fisher, T., Jin, B., McClure, J., \& Mihalik, L. (2019, April 24). Election results 2018. Politico. Retrieved from https://www.politico.com/election-results/2018/

Cacciatore, M. A., Scheufele, D. A., Iyengar, S. (2016). The end of framing as we know it ... And the future of media effects. Mass Communication and Society, 19(1), 723. doi:10.1080/15205436.2015.1068811

Cacioppo, J. T., von Himmel, W., \& Ernst, J. M. (1997). Mapping cognitive structures and processes through verbal content: The thought-listing technique. Journal of Consulting and Clinical Psychology, 65(6), 928-940.

Cameron, G. T., Cropp, F., \& Reber, B. H. (2001). Getting past platitudes: Factors limiting accommodation in public relations. Journal of Communication Management, 5(3), 242-261. 
Campbell, J. E. (2018). Forecasting the 2018 U.S. midterm elections. American Political Science Association, PS: Special Issue. doi: 10.1017/s1049096518001592

Campbell, A., Converse, P. E., Miller, W., \& Stokes, D. L. (1960). The American voter. New York: Wiley.

Campbell, A., Gurin, G., \& Miller, W. E. (1954). The voter decides. Evanston, IL: Row Peterson.

Campbell, J. E., \& Sumners, J. A. (1990). Presidential coattails in Senate elections. The American Political Science Review, 84(2), 513-524.

Carlin, D. P. (1989). A defense of the "debate" in presidential debates. Argumentation and Advocacy, 25, 208-213.

Carlin, D. P. (1992). Presidential debates as focal points for campaign arguments. Political Communication, 9, 251-265.

Carlin, D. P., \& McKinney, M. S. (Eds) (1994). The 1992 presidential debates in focus. Westport, CT: Praeger.

Carson, J. L., \& Hitefield, A. A. (2018). Donald Trump, nationalization, and the 2018 midterm elections. The Forum 2018, 16(4), 531-549. Doi:10.1515/for-2018-0035

Chadwick, A. (2013). The hybrid media system: Politics and power. New York: Oxford University Press.

Chaffee, S. H. (1978). Presidential debates: Are they helpful to voters? Communication Monographs, 45(4), 330-346. http://dx.doi.org/10.1080/03637757809375978

Coleman, J. M. (2018, November 15). 2018 Senate: How the "Trump ten" races compares to 2016. Sabato's Crystal Ball. Retrieved from 
http://crystalball.centerforpolitics.org/crystalball/articles/2018-senate-races-howthe-trump-ten-compared-to-the-president/

Collins, A. M., \& Loftus, E. F. (1975). A spreading-activation theory of semantic processing. Psychological Review, 82, 407-428.

Cwalina, W., \& Falkowski, A. (2015). Political branding: Political candidates positioning based on inter-object associative affinity index. Journal of Political Marketing, 14(1-2), doi:10.1080/15377857.2014.990842

Cwalina, W., Falkowski, A., \& Newman, B. I. (2011). Political marketing: Theoretical and strategic foundations. Armonk, NY: M.E. Sharpe.

Dalager, J. K. (1996). Voters, issues, and elections: Are the candidates' messages getting through? The Journal of Politics, 58(2), 486-515.

DeAndrea, D. C., \& Holbert, R. L. (2017). Increasing clarity where it is needed most: articulating and evaluating theoretical contributions. Annals of the International Communication Association, 41, 168-180. doi:10.1080/23808985.2017.1304163

Delli Carpini, M. X., \& Keeter, S. (1996). What Americans know about politics and why it matters. New Haven, CT: Yale University Press.

Delli Carpini, M. X., Keeter, S., \& Webb, S. (1993, May). Effects of 'the people's presidential debate' on undecided voters in the Richmond area. Paper presented at the annual meeting of the American Association for Public Opinion Research, St. Charles, Illinois.

Dennis, J., Chaffee, S., \& Choe, S. (1979). Impact upon partisan: Image and issue voting. In S. Kraus (Ed.), The great debates: Carter vs. Ford, 1976 (pp. 314-330). Bloomington: Indiana University Press. 
Downs, A. (1957). An economic theory of democracy. New York: Harper \& Row.

Drew, D., \& Weaver, D. (1999). Voter learning in the 1996 presidential election: Did the media matter? Journalism \& Mass Communication Quarterly 75(2): 292-301.

Drew, D., \& Weaver, D. (2006). Voter learning in the 2004 presidential election: Did the media matter? Journalism and Mass Communication Quarterly, 83(1), 25-42.

Druckman, J. N. (2003). The power of television images: The first Kennedy-Nixon debate revisited. The Journal of Politics, 65(2), 559-571.

Druckman, J. N. (2004). Priming the vote: Campaign effects in a U.S. Senate election. Political Psychology, 25(4), 577-594.

Duquette, C., Mixon, F. G., \& Cebula, R. J. (2017). Candidate quality and U.S. Senate elections. Applied Economics Letters, 24(3), 193-197.

Doi:10.1080/13504851.2016.1176107

Dura, J. (2018, October 5). First Cramer-Heitkamp debate canceled, but Prairie Public's offer stands. Bismarck Tribune. Retrieved from https://bismarcktribune.com/news/election/first-cramer-heitkamp-debatecanceled-but-prairie-public-s-offer/article_c62fe46d-539b-5324-87ceOab756bbb949.html

Fenno, R. F. (1996). Senators on the campaign trail. Norman: University of Oklahoma Press.

French, A., and G. Smith. (2010). Measuring political brand equity: A consumer oriented approach. European Journal of Marketing, 44(3-4), 460-477.

Fridkin, K. L, \& Kenney, P. J. (2011). The role of candidate traits in campaigns. The Journal of Politics, 73(1), 61-73. doi:10.1017/S0022381610000861 
Garrett, R. K., \& Stroud, N. J. (2014). Partisan paths to exposure diversity: Differences in pro and counterattitudinal news consumption. Journal of Communication, 64, 680-701. doi:10.1111/jcom.12105

Geer, J. (1988). The effects of presidential debates on the electoral preferences for candidates. American Politics Quarterly, 16, 486-501.

Greenberg, D. (2009). Torchlight parades for the television age: The presidential debates as political ritual. Daedalus, 138(2), 6-19.

Greenberg, D. (2016). Republic of spin: An inside history of the American presidency. New York: W. W. Norton \& Company.

Greene, S. (1999). Understanding party identification: A social identity approach. Political Psychology, 20, 393-403.

Greene, S. (2002). The social-psychological measurement of partisanship. Political Behavior, 24, 171-97.

Greene, S. (2004). Social identity theory and party identification. Social Science Quarterly, 85(1), 136-153.

Grossmann, M., \& Hopkins, D. A. (2018). From Fox News to viral views: The influence of ideological media in the 2018 elections. The Forum 2018, 16(4), 551-571. doi:10.1515/for-2018-0037

Guzmán, F., Paswan, A. K., Van Steenburg, E. (2015). Self-referencing and political candidate brands: A congruency perspective. Journal of Political Marketing, 14(1-2), doi:10.1080/15377857.2014.990837 
Hacker, K. L. (2004a). The continued importance of the candidate image construct. In K. L. Hacker (Ed.) Presidential candidate images (pp. 1-19). Lanham, MD: Rowman \& Littlefield.

Hacker, K. L. (2004b). A dual-processing perspective of candidate image formation. In K. L. Hacker (Ed.) Presidential candidate images (pp. 105-132). Lanham, MD: Rowman \& Littlefield.

Hacker, K., L., Zakahi, W. R., Giles, M. J., \& McQuitty, S. (2000). Components of candidate images: Statistical analysis of the issue-persona dichotomy in the presidential campaign of 1996. Communication Monographs, 67(3), 227-238.

Hageman, J. (2018, July 5). Senate candidates Heitkamp, Cramer lock down two more October debates. Grand Forks Herald. Retrieved from http://www.grandforksherald.com/news/government-and-politics/4469082-senatecandidates-heitkamp-cramer-lock-down-two-moreoctober\#.W0BGuaGccIY.twitter

Hayes, A. F., \& Krippendorff, K. (2007). Answering the call for a standard reliability measure for coding data. Communication Methods and Measures, 1, 77-89.

He, H., Li, Y., \& Harris, L. (2012). Social identity perspective on brand loyalty. Journal of Business Research, 65, 648-657. doi:10.1016/j.jbusres.2011.03.007

Hendry, E. R. (2018, October 18). Watch live: Claire McCaskill, Josh Hawley face off in Missouri Senate debate. PBS. Retrieved from https://www.pbs.org/newshour/politics/watch-live-claire-mccaskill-josh-hawleyface-off-in-missouri-senate-debate 
Henson, J. R., \& Benoit, W. L. (2009). Functional federalism in political campaign debates. Publius: The Journal of Federalism, 39(4), 696-706. doi:10.1093/publius/pjp018

Hibbing, J. R., \& Alford, J. R. (1981). The electoral impact of economic conditions: Who is held responsible? American Journal of Political Science, 25(3), 423-429.

Hibbing, J. R., \& Brandes, S. L. (1983). State population and the electoral success of U.S. senators. American Journal of Political Science, 27(4), 808-819.

Hill, S. J. (2017). Changing votes or changing voters? How candidates and election context swing voters and mobilize the base. Electoral Studies, 48, 131-148. http://dx.doi.org/10.1016/j.electstud.2017.06.001

Holbert, R. L. (2005). Debate viewing as mediator and partisan reinforcement in the relationship between news use and vote choice. Journal of Communication, 55, 85-102.

Holbert, R. L., Garrett, R. K., \& Gleason, L. S. (2010). A new era of minimal effects? A response to Bennett and Iyengar. Journal of Communication, 60, 15-34.

Holbrook, T. M. (1996). Do campaigns matter? Thousand Oaks, CA: Sage.

Holbrook, T. M. (1999). Political learning from presidential debates. Political Behavior, 21(1), 67-89.

Hopkins, D. (2018). The increasingly United States: How and why American political behavior nationalized. University of Chicago Press: Chicago, IL.

Houston, J. B., Hawthorne, J., Spialek, M. L., Greenwood, M., \& McKinney, M. S. (2013). Tweeting during presidential debates: Effect on candidate evaluations and debate attitudes. Argumentation and Advocacy, 49, 301-311. 
Iyengar, S., \& Kinder, D. R. (1987). News that matters: Television and American opinion. Chicago, IL: University of Chicago Press.

Iyengar, S., Sood, G., \& Lelkes, Y. (2012). Affect, not ideology: A social identity perspective on polarization. Public Opinion Quarterly, 76, 405-431. doi:10.1093/poq/nfs038

Jackson-Beeck, M., \& Meadow, R. (1979). The triple agenda of presidential debates. Public Opinion Quarterly, 43, 173-180.

Jacobson, G. C., \& Wolfinger, R. E. (1989). Information and voting in California Senate elections. Legislative Studies Quarterly, 14(4), 509-529.

Jamieson, K. H. (2015). The discipline's debate contributions: Then, now, and next. Quarterly Journal of Speech, 101, 85-97.

Jamieson, K. H., \& Adasiewicz, C. (2000). What can voters learn from election debates? In S. Coleman (Ed.), Televised election debates: International perspectives (pp. 25-42). New York: St. Martin's Press.

Jamieson, K. H., \& Birdsell, D. S. (1988). Presidential debates: The challenge of creating an informed electorate. New York: Oxford University Press.

Jarman, J. W. (2016). Motivated reasoning and viewer's reactions to the first 2012 presidential debate. Speaker \& Gavel, 53, 83-101.

Jennings, F. J., Coker, C. R., McKinney, M. S., \& Warner, B. R. (2017). Tweeting presidential primary debates: Debate processing through motivated Twitter instruction. American Behavioral Scientist, 61(4), 455-474. doi: $10.1177 / 0002764217704867$ 
Jennings, F. J., Warner, B. R., McKinney, M. S., Kearney, C. C., Funk, M. E., \& Bramlett, J. C. (2018, November). Learning from presidential debates: Who learns the most and why? Paper presentation at the National Communication Association annual conference, Salt Lake City, UT.

Johnson, B. T, \& Eagly, A. H. (1989). Effects of involvement on persuasion: A metaanalysis. Psychological Bulletin, 106, 290-314.

Johnson, B. T., \& Eagly, A. H. (1990). Involvement and persuasion: Types, traditions, and the evidence. Psychological Bulletin, 107, 375-384.

Kahn, K. F., Kenney, P. J. (1999). The spectacle of U.S. Senate campaigns. Princeton, NJ: Princeton University Press.

Kaid, L. L., McKinney, M. S., \& Tedesco, J. C. (2000). Civic dialogue in the presidential campaign: Candidate, media, and public voices. Cresskill, NJ: Hampton Press.

Kaid, L. L., McKinney, S. M., \& Tedesco, J. C. (2007). Introduction: Political information efficacy and young voters. American Behavioral Scientist, 50, 10931111.

Katz, E., \& Feldman, J. J. (1962). The debates in the light of research: A survey of surveys. In S. Kraus (Ed.), The great debates: Kennedy vs. Nixon, 1960 (pp. 173223). Bloomington, Indiana University Press.

Keller, K. L. (1993). Conceptualizing, measuring, managing customer-based brand equity. Journal of Marketing, 57(1), 1-22.

Kenski, K., Hardy, B. W., \& Jamieson, K. H. (2010). The Obama victory: How media, money, and message shaped the 2008 election. New York: Oxford University Press. 
Kim, Y. M., \& Garrett, K. (2012). Online and memory based: Revisiting the relationship between candidate evaluation processing models. Political Behavior, 34, 345-368.

Kiousis, S., \& Shields, A. (2008). Intercandidate agenda-setting in presidential elections: Issue and attribute agendas in the 2004 campaign. Public Relations Review, 34, 325-330.

Koch, J. W. (2000). Candidate status, presidential approval, and voting for U.S. senator. Electoral Studies, 19, 479-492.

Koll, O., \& von Wallpach, S. (2014). Intended brand associations: Do they really drive consumer response? Journal of Business Research, 67(7), 1501-1507.

Konisky, D. M., \& Richardson Jr., L. E. (2012). Penalizing the party: Health care reform issue voting in the 2010 election. American Politics Research, 40(5), 903-926. doi:10.1177/1532673X11434141

Kotler, P. (1975). Overview of political candidate marketing. Advances in Consumer Research, 2, 761-770.

Krasno, J. S. (1994). Challengers, competition, and reelection. New Haven: Yale University Press.

Kraus, S., \& Smith, R. (1962). Images and issues. In S. Kraus (Ed.), The great debates: Background, perspective, effects (pp. 289-312). Bloomington: Indiana University Press.

Kreiss, D. (2016). Prototype politics: Technology-intensive campaigning and the data of democracy. New York, USA: Oxford University Press.

Lanoue, D. J., \& Schrott, P. R. (1991). The joint press conference: the history, impact, and prospects of American presidential debates. New York: Greenwood. 
Latest polls. Retrieved from https://www.realclearpolitics.com/epolls/latest_polls/

Lodge, M., \& Taber, C. S. (2013). The rationalizing voter. New York, NY: Cambridge University Press.

Lord, C. G., Ross, L., \& Lepper, M. R. (1979). Biased assimilation and attitude polarization: The effect of prior theories on subsequent considered evidence. Journal of Personal and Social Psychology, 37, 2098-2109. doi: 10.1037/00223514.37.11.2098

Louden, A. (2005). Research non-Presidential Debates: A moment in time. Contemporary Argumentation \& Debate, 26, 41-50

Mason, L. (2018). Uncivil agreement. University of Chicago Press: Chicago, IL. McGinnis, J. (1969). The selling of the president. New York: Simon \& Shuster.

McKinney, M. S. (2005). Let the people speak: The public's agenda and presidential town hall debates. American Behavioral Scientist, 49, 198-212.

McKinney, M. S., \& Carlin, D. B. (2004). Political campaign debates. In L. L. Kaid (Ed.), Handbook of political communication research (pp. 203-234). Mahwah, NJ: Lawrence Erlbaum Publishers.

McKinney, M. S., \& Chattopadhyay, S. (2007). Political engagement through debates: Young citizens' reactions to the 2004 presidential debates. American Behavioral Scientist, 50, 1169-1182.

McKinney, M. S., Dudash, E. A., \& Hodgkinson, G. (2003). Viewer reactions to the 2000 presidential debates: Learning issues and image information. In L. L Kaid, J. C. Tedesco, D. G. Bystrom, \& M. S. McKinney (Eds.), The millennium election: 
Communication in the 2000 campaign (pp. 43-58) . New York: Rowman \& Littlefield.

McKinney, M. S., Houston, J. B., \& Hawthorne, J. (2014). Social watching a 2012 Republican presidential primary debate. American Behavioral Scientist, 58, 556573.

McKinney, M. S., Rill, L. A., \& Gully, D. (2011). Political engagement through presidential debates: Attitudes of political engagement throughout the 2008 election. In M. S. McKinney \& M. C. Banwart (Eds), Communication in the 2008 U.S. election: Digital natives elect a president (pp. 121-142). New York: Peter Lang Publishing.

McKinney, M. S., Rill, L. A., \& Watson, R. G. (2011). Who framed Sarah Palin? Viewer reactions to the 2008 vice presidential debate. American Behavioral Scientist, 55, 212-231. doi:10.1177/0002764210392158

McKinney, M. S., \& Warner, B. R. (2013). Do presidential debates matter? Examining a decade of campaign debate effects. Argumentation \& Advocacy, 49(4), 238-258.

Milewicz, C. M., \& Milewicz, M. C. (2014). The branding of candidates and parties: The U.S. news media and the legitimization of a new political term. Journal of Political Marketing, 13(4), 233-263. doi:10.1080/15377857.2014.958364

Miller, A. H. (1990). Public judgments of Senate and House candidates. Legislative Studies Quarterly, 15(4), 525-542.

Miller, G. R. (2002). On being persuaded: Some basic distinctions. In J. P. Dillard \& M. Pfau (Eds.), The persuasion handbook: Developments in theory and practice (pp. 3-16). Thousand Oaks, CA: Sage. 
Missouri Senate debate. (2018, October 18). C-SPAN. Retrieved from https://www.cspan.org/video/?453606-1/missouri-senate-debate

Most expensive races. (2019, March 6). Open Secrets. Retrieved from https://www.opensecrets.org/overview/topraces.php

Mühlbacher, H., Raies, K., Grohs, R., \& Koll, O. (2016). Drivers of brand strength: Configural paths to strong cognitive brand equity. Journal of Business Research, 69, 2774-2780.

Mullinix, K. J. (2015). Presidential debates, partisan motivations, and political interest. Presidential Studies Quarterly, 45, 270-288.

Munro, G. D., Ditto, P. H., Lockhart, L. K., Fagerlin, A., Gready, M., \& Peterson, E. (2002). Biased assimilation of sociopolitical arguments: Evaluating the 1996 U.S. presidential debate. Basic \& Applied Social Psychology, 24, 15-26.

New books in political science. (n.d.). Retrieved from https://itunes.apple.com/us/podcast/new-books-in-politicalscience/id425414426? $\mathrm{mt}=2$

Newman, B. I. (1994). The marketing of the president: Political marketing as campaign strategy. Thousand Oaks, CA: Sage Publications.

Nielsen, S. W. (2016). Mapping political brands: An art and a science of the mind. Journal of Political Marketing, 15(1), 70-95. doi:10.1080/15377857.2014.959682

Nielsen, S. W. (2017). On political brands: A systematic review of the literature. Journal of Political Marketing, 16(2), 118-146. doi:10.1080/15377857.2014.959694

Nielsen, S. W., and M. V. Larsen. (2014). Party brands and voting. Electoral Studies, 33, $153-65$. 
Nimmo, D. (1975). Images and voters' decision-making processes. Advances in Consumer Research, 2, 771-782.

Nimmo, D. D., \& Savage, R. L. (1976). Candidates and their images: Concepts, methods, and findings. Pacific Palisades, CA: Goodyear.

North Dakota Senate debate. (2018, October 18). C-SPAN. Retrieved from https://www.c-span.org/video/?453416-1/north-dakota-senate-debate

Park, H. S., Levine, T. R., Westerman, C. Y. K., Orfgen, T., \& Foregger, S. (2007). The effects of argument quality and involvement type on attitude formation and attitude change: A test of dual-process and social judgment predictions. Human Communication Research, 33, 81-102.

Parry-Giles, T. (2010). Resisting a "treacherous piety": Issues, images, and public deliberation in presidential campaigns. Rhetoric \& Public Affairs, 13, 37-64. doi:10.1353/rap.0.0138

Petrocik, J. R. (1996). Issue ownership in presidential elections, with a 1980 case study. American Journal of Political Science, 40, 825-850.

Petty, R. E., \& Cacioppo, J. T. (1979). Issue involvement can increase or decrease persuasion by enhancing message-relevant cognitive responses. Journal of Personality and Social Psychology, 37, 1915-1926.

Petty, R. E., \& Cacioppo, J. T. (1986). Communication and persuasion: Central and peripheral routes to attitude change. New York: Springer-Verlag.

Petty, R. E., Cacioppo, J. T., \& Goldman, R. (1981). Personal involvement as a determinant of argument-based persuasion. Journal of Personality and Social Psychology, 41, 847-855. 
Pfau, M. (1987). The influence of intraparty political debates on candidate preference. Communication Research, 14, 687-697.

Pfau, M. (2002). The subtle nature of presidential debate influence. The Journal of the American Forensic Association: Argumentation and Advocacy, 38, 251-261.

Pfau, M., Houston, J. B., \& Semmler S. (2007). Mediating the vote: The changing media landscape in presidential campaigns. Lanham, MD: Rowan \& Littlefield.

Reed, A. (2002). Social identity as a useful perspective for self-concept-based consumer research. Psychology and Marketing, 19(3), 235-266.

Reynolds, R. A. (1997). A validation test of a message elaboration measure. Communication Research Reports, 14(3), 269-278. doi:10.1080/08824099709388670

Robertson, T. (2005). A Perfect Storm: A case study analysis of the defeat of Tom Daschle by John Thune in the 2004 South Dakota senate race. American Behavioral Scientist, 49, 326-342.

Romaniuk, J., \& Nenycz-Thiel, M. (2013). Behavioral brand loyalty and consumer brand associations. Journal of Business Research, 66(1), 67-72.

Sabato, L., \& Kondik, K. (2018, November 7). How'd we do? Longstanding picks of a Democratic House, significant Democratic gubernatorial gains, and GOP Senate pan out. Sabato's Crystal Ball. Retrieved from http://crystalball.centerforpolitics.org/crystalball/articles/howd-we-do/

Scacco, J. M., \& Coe, K. (2017). Acting “presidential:” The modern campaign meets the ubiquitous presidency. In R. E. Denton Jr. (Ed.), Political campaign 
communication: Theory, method and practice (pp. 303-326). New York, NY: Lexington Books.

Scammell, M. (2014). Consumer democracy. Cambridge: Cambridge University Press.

Schrott, P. R., \& Lanoue, D. J. (2013). The power and limitations of televised presidential debates: Assessing the real impact of candidate performance on public opinion and vote choice. Electoral Studies, 32, 684-692. doi:

10.1016/j.electstud.2013.03.006

Schroeder, A. (2008). Presidential debates: Forty years of high risk TV. ( $2^{\text {nd }}$ ed). New York: Columbia University Press.

Seiter, J. S., Weger Jr., H., Kinzer, H. J., \& Jensen, A. S. (2009). Impression management in televised debates: The effect of background nonverbal behavior on audience perceptions of debaters' likeability. Communication Research Reports, 26(1), 111.

Senate debate videos. (n.d.). C-SPAN. Retrieved from https://www.cspan.org $/$ search $/$ sdate $=2018-01-01 \&$ edate $=2019-01-$ $01 \&$ searchtype $=$ Videos\&sort $=$ Most + Recent + Event $\&$ text $=0 \&$ tagid $\% 5 B \% 5 \mathrm{D}=298$ $\&$ formatid $\% 5 \mathrm{~B} \% 5 \mathrm{D}=18$

Senate election polls. (n.d.). Retrieved from https://www.realclearpolitics.com/epolls/latest_polls/senate/

Shama, A. (1976). The marketing of political candidates. Journal of the Academy of Marketing Science, 4(4), 764-777. 
Simons, H., \& Leibowitz, K. (1979). Shifts in candidate images. In S. Kraus (Ed.), The great debates: Carter vs. Ford, 1976 (pp. 398-304). Bloomington: Indiana University Press.

Speed, R., P. Butler, and N. Collins. (2015). Human branding in political marketing: Applying contemporary branding thought to political parties and their leaders. Journal of Political Marketing, 14(1-2), 129-151. doi:10.1080/15377857.2014.990833

Stewart III, C. (1989). A sequential model of U.S. Senate elections. Legislative Studies Quarterly, 14(4), 567-601.

Stewart, P. A. (2011). The influence of self- and other-deprecatory humor on presidential candidate evaluation during the 2008 U.S. election. Social Science Information, 50(2), 201-222. doi:10.1177/0539018410396616

Stroud, N. J., Stephens, M., \& Pye, D. (2011). The influence of debate viewing context on political cynicism and strategic interpretations. American Behavioral Scientist. 55, 270-283.

Tajfel, H. (1982). Social psychology of intergroup relations. Annual Review of Psychology, 33, 1-39.

Tannenbaum, P., Greenberg, B., \& Silverman, F. (1962). Candidate images. In S. Kraus (Ed.), The great debates: Background, perspective, effects (pp. 271-288).

Bloomington: Indiana University Press.

Van Meter, J. R. (2008). Tippecanoe and Tyler Too: Famous slogans and catchphrases in American history. Chicago: The University of Chicago Press. 
Van Osselaer, S. M. J., \& Janiszewski, C. (2001). Two ways of learning brand associations. Journal of Consumer Research, 28(2), 202-223.

Verba, S., Schlozman, K. L., \& Brady, H. E. (1995). Voices and equality: Civic voluntarism in American politics. Cambridge, MA: Harvard University Press.

Wald, K., \& Lupfer, M. (1978). The presidential debate as a civics lesson. Public Opinion Quarterly, 42, 342-353.

Warner, B. R. (2018). Modeling partisan media effects in the 2014 U.S. midterm elections. Journalism \& Mass Communication Quarterly, 95(3), 647-669. doi:10.1177/1077699017712991

Warner, B. R., \& Banwart, M. C. (2016). A multifactor approach to candidate image. Communication Studies, 67(3), 258-279. doi:10.1080/10510974.2016.1156005

Warner, B. R., Bramlett, J. C., Hoeun, S., Manik, D. I., \& Bolton, J. P. (2018). Presidential primary debates compared: Timing of debate and size of candidate field as moderators of debate effects. Argumentation and Advocacy. doi:10.1080/00028533.2018.1446868

Warner, B. R., Carlin, D. B., Winfrey, K., Schnoebelen, J., \& Trosanovski, M. (2011). Will the "Real" candidates for president and vice president please stand up? 2008 pre- and post-debate viewer perceptions of candidate image. American Behavioral Scientist, 53(3), 232-252. doi:10.1177/0002764210392160

Warner, B. R., Turner McGowen, S., \& Hawthorne, J. (2012). Limbaugh's social media nightmare: Facebook and Twitter as spaces for political action. Journal of Radio and Audio Media, 19(2), 257-275. doi: 10.1080/19376529.2012.722479 
Warner, B. R., McKinney, M. S., Jennings, F. J., Bramlett, J. C., \& Funk, M. E. (2018, May). Reconsidering partisanship as a constraint on the persuasive effects of debates: The case of U.S. presidential and vice presidential debates (2004-2016). Paper presented at the $68^{\text {th }}$ annual International Communication Association conference, Prague, Czech Republic.

Winneg, K., \& Jamieson, K. H. (2017). Learning from the 2016 U.S. general election presidential debates. American Behavioral Scientist, 61(4), 362-378. doi: $10.1177 / 0002764217702770$

Yawn, M., Ellsworth, K., Beatty, B., \& Kahn, K. F. (1998). How a presidential primary debate changed attitudes of audience members. Political Behavior, 20(2), 155181.

Zakahi, W. R. (2004). Presidential debates and candidate image formation: 1992, 1996, 2000. (pp. 151-175). In K. Hacker (Ed.), Presidential candidate images. New York: Rowman \& Littlefield.

Zhu, J., Milavsky, J. R., \& Biswas, R. (1994). Do televised debates affect image perception more than issue knowledge? A study of the first 1992 presidential debate. Human Communication Research, 20, 302-333. 


\section{Appendix A: Candidate Brand Elements Code Book}

The purpose of this study is to content analyze open-ended responses provided by undergraduate students watching a 2018 U.S. Senate debate.

\section{Participants were asked, "What comes to mind when you think of Claire McCaskill/Josh Hawley/Heidi Heitkamp /Kevin Cramer?"}

The goal of the current study is to examine if responses are more focused on Policy, Person, or Party.

\section{Instructions:}

You will be presented with an Excel sheet full of data. The first column of the Excel sheet has the number of the code in the complete sample. The second column has participant ID number. The third column has the number of the association relevant to the participant. The fourth column has the text of the association. The fifth column is where you will enter a numerical code for if the association is about Policy, Person, or Party. The sixth comment is where you can enter notes on your coding thought process.

\section{You should code a brand association for the DOMINANT element present in the response.}

Party: An association should be coded as a party-brand element if it discusses the party which the candidate is a member of or the ideology of the candidate and/or candidate's party. For instance, if an association says, "He is a Republican," this response would be coded as Party. A response such as "He is in Trump's party" or "She supports Obama" would also be coded for Party. References to liberalism, conservatism, bipartisanship, "party line," or being moderate, independent, left-wing, or right wing would also fall under party. References to party slogans, such as "MAGA" would also be coded as party. References to well-known party individuals, such as Donald Trump, Barack Obama, Chuck Schumer, Mitch McConnell, Nancy Pelosi, or Paul Ryan would be indicative of a party-based association. Essentially, when the person makes this response, are they thinking about the parties? Anti-party sentiments are also party-dominant associations.

Policy: An association should be coded as a policy-brand element if it discusses policies such as taxes, the economy, healthcare, crime, immigration, foreign policy etc. For instance, if an association says, "He supports tax cuts" or "She is against tariffs" then it would be coded for Policy. Anti-policy (e.g., "she's against the wall") are also partybased associations. Essentially, is this response thinking about what the candidate supports or would do related to a policy?

In the Missouri debate, some of the policies discussed were: the federal deficit and debt; Social Security and Medicare, Obamacare, healthcare, and pre-existing conditions; tax cuts; U.S. relations with Saudi Arabia, Jamal Khashoggi; foreign policy; military spending and veterans; the Iran deal; mass shootings and school safety; tariffs, farming, and the trade war with China; NAFTA, racial tensions and law enforcement, climate 
change, Right to Work and unions, the minimum wage, the border wall and immigration, and judges.

In the North Dakota debate, some of the issues discussed were healthcare, Obamacare, and pre-existing conditions; tariffs, farming, and trade deals; protecting schools; the Mueller investigation and interference in elections; freedom of the press; Jamal Khashoggi; the Brett Kavanaugh confirmation; post office privatization, voter registration in North Dakota; oil, coal, and climate change; sexual violence against women; sanctuary cities, the caravan, ICE, and the border wall; Medicare and Social Security; banks, and Native American issues.

Person: An association should be coded as a person-brand element if it discusses the candidate as a person or is related to them as a person. For instance, if an association says, "He had glasses," "He's a Dad," "He's young," "She's well-spoken," "She is currently senator," or "She's experienced" then it would be coded for Person. Personbased associations can deal with candidates' current job and role, their qualifications, their experience, their appearance, their gender, their debate behavior, their temperament, and other personal traits. Other personal elements include leadership, competence, intelligence, personality, etc. An association could also be person-based if what comes to mind when a respondent thinks of a candidate is broader elements related to their jobs/roles, i.e., if a response says something like "The Senate," "Politics," or "Washington D.C." Responses that state "Missouri" or "North Dakota" with no other content would also be considered a personal brand element.

Other: An association can be coded as Other if the response is clearly not a thought relevant to the candidate or relevant to the study. For instance, people may respond "Please give me my extra credit" or "The debate was boring." These are coded as 0.

Incomplete: An association can be coded as incomplete if it is clear that the person did not finish their statement and there is not a completed thought in the response. This will only occur occasionally, and will only occur on individuals' last response about a candidate. In the study, people were given 2.5 minutes to write their responses, and the screen automatically advanced after 2.5 minutes. This caused some final responses to stop mid-thought or mid-word. In some instances, you may be able to clearly understand what the response said, such as if it says "He's a Republica" but the final letter was cut off, or "She has been in Washington a long time and," where a full thought was completed, but a second thought was not (i.e., what would have come after "and"). These responses can be coded normally for brand elements. Other times, a word will be cut off before you can tell what it was, such as "De" or "Po" which could be Democrat, Debated Well, Politics, or Police, etc, or a response may be cut off mid-thought, such as "He is for." These would be clearly incomplete.

If a response is Incomplete, code it with an "X." I will review them and remove them from the analysis. Reminder: these will only occur on someone's last response about a candidate. 
Upon reviewing an association, please code it for the appropriate category:

$$
\begin{aligned}
& 1=\text { Party } \\
& 2=\text { Policy } \\
& 3=\text { Person } \\
& 0=\text { Other } \\
& X=\text { Incomplete }
\end{aligned}
$$




\section{Appendix B: Civics Knowledge Questions}

1. What political office does Jeff Sessions now hold?

Answer: Attorney General (19.7\% correct)

2. What political office does Mike Pence now hold?

Answer: Vice President (63.9\% correct)

3. What political office does John Roberts now hold?

Answer: Chief Justice of the Supreme Court (10.8\% correct)

4. What political office does Paul Ryan now hold?

Answer: Speaker of the House (39.4\% correct)

5. Do you know how many times a person can be elected President of the United States under current laws?

Answer: Two full terms (92.2\% correct)

6. For how many years is a United States Senator elected? That is, how many years are there in one full term of office for a U.S. Senator?

Answer: Six years $(27.9 \%$ correct)

7. On which of the following does the U.S. Federal Government currently spend the least (foreign aid, Medicare, national defense, or Social Security)?

Answer: Foreign aid (35.3\% correct) 


\section{Appendix C: Debate Knowledge Questions}

\section{North Dakota Post-Debate Quiz}

1. During the debate, what crop did Heidi Heitkamp call one of the most important for North Dakota? (open-ended)

Answer: Soybeans (77.2\% correct)

2. During the debate, what was the topic of the advertisement that Kevin Cramer called "dishonest"? (open-ended)

Answer: Raising his own salary (70.9\% correct)

Multiple Choice Key: 1 = Heitkamp 2 = Cramer 3 = Both 4 = Neither 5 = Don't Know

3. During the debate, which candidate proposed federal funding for school resource officers to help school safety?

Answer: Heitkamp (74\% correct)

4. During the debate, which candidate said they support protections for pre-existing conditions? Answer: Both $(33.9 \%$ correct)

5. During the debate, which candidate said the Mueller investigation should "wrap up"? Answer: Cramer ( $70.1 \%$ correct)

6. During the debate, which candidate said they support privatizing the Post Office? Answer: Neither (32.3\% correct)

7. During the debate, which candidate said that "the future has to be with people who are moderate"?

Answer: Heitkamp (60.6\% correct)

8. During the debate, which candidate said that "identity politics has got to stop"? Answer: Cramer (55.9\% correct) 


\section{Missouri Post-Debate Quiz}

1. During the debate, what Trump policy did Josh Hawley say Claire McCaskill called “embarrassing"? (open-ended)

Answer: The Wall (76.1\% correct)

2. During the debate, what country did Claire McCaskill say she would support sanctions on? (open-ended)

Answer: Saudi Arabia (45.8\% correct)

Multiple Choice Key: 1 = Hawley $2=$ McCaskill $3=$ Both $4=$ Neither 5 = Don't Know

3. During the debate, which candidate said that tariffs hurt Missouri bean farmers?

Answer: McCaskill (67.6\% correct)

4. During the debate, which candidate said they support protections for pre-existing conditions? Answer: Both (43\% correct)

5. During the debate, which candidate said that they would support banning bump stocks?

Answer: McCaskill (55.6\% correct)

6. During the debate, which candidate said they opposed renegotiating NAFTA?

Answer: Neither (22.5\% correct)

7. During the debate, which candidate said that we have had a foreign policy of "weakness and appeasement"?

Answer: Hawley (57\% correct)

8. During the debate, which candidate said that China started the trade war?

Answer: Hawley (72.5\% correct) 


\section{Appendix D: Full Regression Tables}

Influence of In-Group Positive Associations on In-Group Candidate Evaluations

\begin{tabular}{llllll}
\hline & B & SE & $\boldsymbol{\beta}$ & $\mathbf{t}$ & P \\
\hline Pre-Debate IG FT & .28 & .05 & .25 & 5.56 & $<.001$ \\
Being Female & .41 & 1.67 & .01 & .25 & .80 \\
Partisan Strength & 2.47 & .99 & .12 & 2.49 & .01 \\
Viewing MO & 2.77 & 1.60 & .08 & 1.74 & .08 \\
IG Strength & -1.81 & .32 & -.41 & -.567 & $<.001$ \\
IG Positive & 3.55 & .32 & .83 & 10.98 & $<.001$ \\
Associations & & & & & \\
\hline
\end{tabular}

Influence of In-Group Negative Associations on In-Group Candidate Evaluations

\begin{tabular}{llllll}
\hline & B & SE & $\boldsymbol{\beta}$ & $\mathbf{t}$ & P \\
\hline Pre-Debate IG FT & .28 & .05 & .24 & 5.08 & $<.001$ \\
Being Female & 1.33 & 1.78 & .04 & .75 & .46 \\
Partisan Strength & 3.13 & 1.06 & .15 & 2.96 & .003 \\
Viewing MO & 2.87 & 1.71 & .08 & 1.68 & .09 \\
IG Strength & 1.28 & .22 & .29 & 5.73 & $<.001$ \\
IG Negative Associations & -4.14 & .48 & -.42 & -8.58 & $<.001$ \\
\hline
\end{tabular}

Influence of Out-Group Positive Associations on Out-Group Candidate Evaluations

\begin{tabular}{llllll}
\hline & $\mathbf{B}$ & SE & $\boldsymbol{\beta}$ & $\mathbf{t}$ & $\mathbf{P}$ \\
\hline Pre-Debate OG & .42 & .07 & .32 & 6.52 & $<.001$ \\
FT & & & & & \\
Being Female & 2.14 & 2.18 & .05 & .98 & .33 \\
Partisan Strength & -6.72 & 1.27 & -.26 & -5.28 & $<.001$ \\
Viewing MO & 5.89 & 2.15 & .13 & 2.75 & .006 \\
OG Strength & -1.23 & .32 & -.21 & -3.86 & $<.001$ \\
OG Positive & 3.38 & .38 & .47 & 8.80 & $<.001$ \\
Associations & & & & & \\
\hline
\end{tabular}

Influence of Out-Group Negative Associations on Out-Group Candidate Evaluations

\begin{tabular}{llllll}
\hline & $\mathbf{B}$ & SE & $\boldsymbol{\beta}$ & $\mathbf{t}$ & $\mathbf{p}$ \\
\hline Pre-Debate OG & .40 & .06 & .30 & 6.27 & $<.001$ \\
FT & & & & & \\
Being Female & 2.23 & 2.13 & .05 & 1.05 & .30 \\
Partisan & -6.51 & 1.25 & -.25 & -5.23 & $<.001$ \\
Strength & & & & & \\
Viewing MO & 5.17 & 2.10 & .12 & 2.47 & .01 \\
OG Strength & 1.62 & .31 & .27 & 5.19 & $<.001$ \\
OG Negative & -3.38 & .35 & -.52 & -9.67 & $<.001$ \\
Associations & & & & & \\
\hline
\end{tabular}


Influence of Involvement on In-Group Positive Associations

\begin{tabular}{llllll}
\hline & $\mathbf{B}$ & SE & $\boldsymbol{\beta}$ & $\mathbf{T}$ & $\mathbf{p}$ \\
\hline Being & 1.23 & .50 & .14 & 2.48 & .01 \\
$\begin{array}{l}\text { Female } \\
\text { Partisan }\end{array}$ & 1.40 & .28 & .29 & 4.94 & $<.001$ \\
$\begin{array}{l}\text { Strength } \\
\text { Viewing MO }\end{array}$ & .36 & .5 & .04 & .71 & .48 \\
$\begin{array}{l}\text { Pre-Debate } \\
\text { Political }\end{array}$ & -.23 & .17 & -.09 & -1.37 & .17 \\
$\begin{array}{l}\text { Interest } \\
\begin{array}{l}\text { Personal } \\
\text { Relevance }\end{array}\end{array}$ & .23 & .24 & .09 & .96 & .34 \\
$\begin{array}{l}\text { Nationalized } \\
\text { Involvement }\end{array}$ & .58 & .28 & .17 & 2.08 & .04 \\
\hline
\end{tabular}

Influence of Involvement on Out-Group Negative Associations

\begin{tabular}{llllll}
\hline & $\mathbf{B}$ & $\mathbf{S E}$ & $\boldsymbol{\beta}$ & $\mathbf{t}$ & $\mathbf{p}$ \\
\hline Being & .23 & .42 & .03 & .54 & .59 \\
$\begin{array}{l}\text { Female } \\
\text { Partisan }\end{array}$ & .66 & .24 & .17 & 2.72 & .007 \\
$\begin{array}{l}\text { Strength } \\
\text { Viewing MO }\end{array}$ & .19 & .42 & .03 & .45 & .65 \\
$\begin{array}{l}\text { Pre-Debate } \\
\text { Political }\end{array}$ & -.05 & .14 & -.02 & -.36 & .72 \\
$\begin{array}{l}\text { Interest } \\
\text { Personal }\end{array}$ & .21 & .21 & .10 & 1.04 & .30 \\
$\begin{array}{l}\text { Relevance } \\
\text { Nationalized }\end{array}$ & .63 & .24 & .23 & 2.65 & .009 \\
Involvement & & & & & \\
\hline
\end{tabular}


VITA

Josh C. Bramlett was born in Cincinnati, Ohio in 1988 to Ron and Cheryl

Bramlett. His family moved home to Arkansas, where his parents grew up, in 1991 when his dad was hired at the University of Central Arkansas. Josh grew up in Conway, Arkansas, attending Conway Public Schools and graduating from Conway Senior High School in 2006 and the University of Central Arkansas in 2010. At UCA, he earned a B.A. in Political Science and was a member of the Honors College. In 2010, Josh worked on congressional campaigns in Arkansas and Missouri. From 2011 to 2013, Josh was a social media manager for the Arkansas Times newspaper in Little Rock, Arkansas. From 2013 to 2014, he attended Arkansas State University, where he earned an M.S. in mass communications. In August 2015 he began the doctoral program in the Department of Communication at the University of Missouri and on May 7, 2019 he successfully defended this dissertation. 